Catherine Coquidé

C. Vermeulen

\title{
Évolution d'une zone d'habitat rural du ler s. av. J.-C. au Ille s. ap. J.-C. : Chassieu-Genas L'Épine (Rhône)
}

In: Revue archéologique de Narbonnaise, Tome 32, 1999. pp. 197-244.

Citer ce document / Cite this document :

Coquidé Catherine, Vermeulen C. Évolution d'une zone d'habitat rural du ler s. av. J.-C. au Ille s. ap. J.-C. : Chassieu-Genas L'Épine (Rhône). In: Revue archéologique de Narbonnaise, Tome 32, 1999. pp. 197-244.

doi : $10.3406 /$ ran.1999.1526

http://www.persee.fr/web/revues/home/prescript/article/ran_0557-7705_1999_num_32_1_1526 


\section{Abstract}

Excavations carried out before the improvement of the roads east of Lyons yielded quite a few ancient deposits at the northern outskirts of the Narbonnaise; Chassieu L'Epine is one of them. This site spreading more than four hectares allowed the study of a settlement dating back from the first century B. C. to the third century A.D. The cleaning brought to the fore a large site whose ancient occupations are not in-keeping with rural world schemes: the huge space observed cannot be compared either to a villa or to a secondary urban area. The first century B. C. could fit with a «native farm» scheme. But beginning with the Augustean age, two settlements at least are placed side by side; they include light material, kilns, boardings and enclosures; two metal workshops are added to the set. While during the second third of the first century A.D. the occupation of the site suddenly declined a few isolated signs bear witness that it lasted until the third century.

\section{Résumé}

Les campagnes de fouilles, menées en amont du réaménagement routier est lyonnais, ont révélé un certain nombre de gisements antiques aux confins nord de la Narbonnaise ; Chassieu « L'Épine » est l'une d'entre elles. Ouvert sur plus de 4 hectares, ce site a permis l'étude d'un habitat du ler s. av. J.-C. au IIle s. ap. Le décapage a mis au jour un vaste site dont les occupations antiques ne correspondent pas aux schémas habituels du monde rural : le vaste espace observé n'est comparable ni à une villa, ni à une agglomération secondaire. Le ler s. av. J.-C. pourrait pourtant s'inscrire dans un schéma de type «ferme indigène». En revanche, à partir de l'époque augustéenne, on observe la juxtaposition d'au moins deux habitats, formés d'édifices construits en matériaux légers, de fours, de palissades, d'enclos ; deux ateliers métallurgiques se greffent à l'ensemble. Alors que le second tiers du Ler s. de notre ère marque le brusque déclin de cette occupation, quelques traces isolées témoignent d'une persistance de l'occupation jusqu'au Ille s. 


\section{ÉVOLUTION D’UNE ZONE D'HABITAT RURAL \\ DU I ${ }^{\text {er }}$ S. AV. J.-C. AU III S. AP. J.-C. : CHASSIEU-GENAS « L'ÉPINE » (RHÔNE)}

\section{COQUIDÉ* et C. VERMEULEN*}

Résumé - Les campagnes de fouilles, menées en amont du réaménagement routier est lyonnais, ont révélé un certain nombre de gisements antiques aux confins nord de la Narbonnaise; Chassieu "L'Épine " est l'une d'entre elles. Ouvert sur plus de 4 hectares, ce site a permis l'étude d'un habitat du Irer s. av. J.-C. au III s. ap. Le décapage a mis au jour un vaste site dont les occupations antiques ne correspondent pas aux schémas habituels du monde rural: le vaste espace observé n'est comparable ni à une villa, ni à une agglomération secondaire. Le Irr s. av. J.-C. pourrait pourtant sinscrire dans un schéma de type "ferme indigène". En revanche, à partir de l'époque augustéenne, on observe la juxtaposition d'au moins deux habitats, formés d'édifices construits en matériaux légers, de fours, de palissades, d'enclos; deux ateliers métallurgiques se greffent à l'ensemble. Alors que le second tiers du $I^{e r}$ s. de notre ère marque le brusque déclin de cette occupation, quelques traces isolées témoignent d'une persistance de l'occupation jusqu'au III's.

Abstract - Excavations carried out before the improvement of the roads east of Lyons yielded quite a few ancient deposits at the northern outskirts of the Narbonnaise; Chassieu L'Épine is one of them. This site spreading more than four hectares allowed the study of a settlement dating back from the first century B.C. to the third century A.D. The cleaning brought to the fore a large site whose ancient occupations are not in-keeping with rural world schemes: the huge space observed cannot be compared either to a villa or to a secondary urban area. The first century B.C. could fit with a "native farm" scheme. But beginning with the Augustean age, two settlements at least are placed side by side; they include light material, kilns, boardings and enclosures; two metal workshops are added to the set. While during the second third of the first century A.D. the occupation of the site suddenly declined a few isolated signs bear witness that it lasted until the third century.

Avec la collaboration de : J. Argant (ARPA-palynologie/carpologie/zoologie), C. Chaussé (AFAN-géomorphologie), G. Chouquer (CNRS-hypothèses de cadastrations sur le Velin), N. Dieudonné-Glad (Université de Poitiers-métallurgic), MM. Dormoy er Orcel (Archéolabs-anthracologie), D. Frascone (AFAN-numismatie), P. Jacquet (AFAN-céramiques protohistoriques), J.-L. Joly (AFAN-Site de "Sous Trillet"), W. Widlak (AFANcéramiques du Haut-Empire)' ${ }^{1}$.

*AFAN Rhône Alpes, 12 rue Maggiorini, 69500 Bron.

(1) La prise en charge du dossier "rocade est "a été réalisée par M. R. Royet, conservateur du patrimoine au SRA de Rhòne Alpes. Les premières relectures de l'article ont été d'abord effectuées par M. R. Royet, sans qui ce projet n'aurait jamais pu être mené à bien, puis patiemment revues par M. A. Ferdière.

\section{INTRODUCTION}

\section{ChASSIEU/GenAS L'ÉPINE : LE CADRE DU PROJET}

La Rocade Est est un maillon routier de $15 \mathrm{~km}$ essentiel dans la restructuration du réseau routier lyonnais. Ce tracé se situe sur la courone orientale de l'agglomération, à $12 \mathrm{~km}$ de la confluence du Rhône et de la Saône. Il traverse un relief modelé par les derniers glaciers, caractérisé par

suite (1) Les dessins de céramiques et mises au net sont de Mme $\mathrm{M}$. $\mathrm{N}$. Baudrand, le traitement informatique, le montage et le rendu graphique de la documentation sont de Mme C. Vermeulen (AFAN). 
une plaine fluvio-glaciaire monotone ponctuée de buttes morainiques au relief marqué.

\section{HISTORIQUE DES RECHERCHES}

La variété des implantations humaines de l'Est lyonnais, longtemps occultée par la proximité de la capitale des Gaules, a peu à peu été mise en lumière. La butte morainique concernée par l'emprise du projet, et en bordure de laquelle se situe le site de "L'Épine ", avait déjà fait l'objet de plusieurs observations archéologiques (fig. 1). Dès le siècle dernier, des travaux avaient permis d'enregistrer de nombreuses découvertes : pointes de flèches néolithiques à Genas-Azieu, nombreux témoins antiques à Décines et Genas. Plus récemment, des associations locales ont mené des recherches sur le terrain contribuant à enrichir la carte archéologique. Des prospections pédestres et des surveillances de travaux ont confirmé la densité des sites, notamment antiques, autour des reliefs : au pied de la butte morainique, deux villae ont d'ailleurs été partiellement mises au jour à Meyzieu " La Dent " et Genas " La Grande Seiglière " (Monnier 1990). Des sondages ont également permis de repérer les murs d'autres bâtiments ("Le Rambion " et "Peyssilieu ").

Dès 1988, une phase de prospection pédestre organisée sur l'ensemble du tracé de la rocade avait permis de définir une série de secteurs archéologiquement sensibles. Le document issu de cette première approche faisait également le bilan des connaissances, rassemblant les données historiques et archéologiques. Le programme des recherches s'est trouvé considérablement élargi lorsque furent pris en compte les phénomènes de colluvionnement autour des reliefs. Ainsi, à l'issue des campagnes d'évaluation de 1991, " la totalité des terrains de la butte morainique où se trouve le site de "L'Épine " a finalement été sondée. Quatre sites ont ainsi été mis au jour sur l'emprise des reliefs : du nord au sud, un habitat et une nécropole antique à DécinesMeyzieu "Trillet "(Frascone, Staniaszek 1992), des systèmes parcellaires et des radiers sur Chassieu "Sous Trillet " (Joly, Dawson 1992), "Chassieu-Genas "L'Épine " (Coquidé, Sandoz. 1992), enfin des occupations protohistoriques à Genas "Sous Genas " (Vital, Taras, Thiériot 1992).

\section{« L'ÉPINE » : PROBLÉMATIQUES ET RÉSULTATS}

Après décapage a pu être avancée une fourchette de datation relativement cohérente s'étalant principalement du $I^{\mathrm{er}} s$. av. au $\mathrm{I}^{\mathrm{er}}$ s. ap. J.-C., au cours de laquelle se sont succédé deux

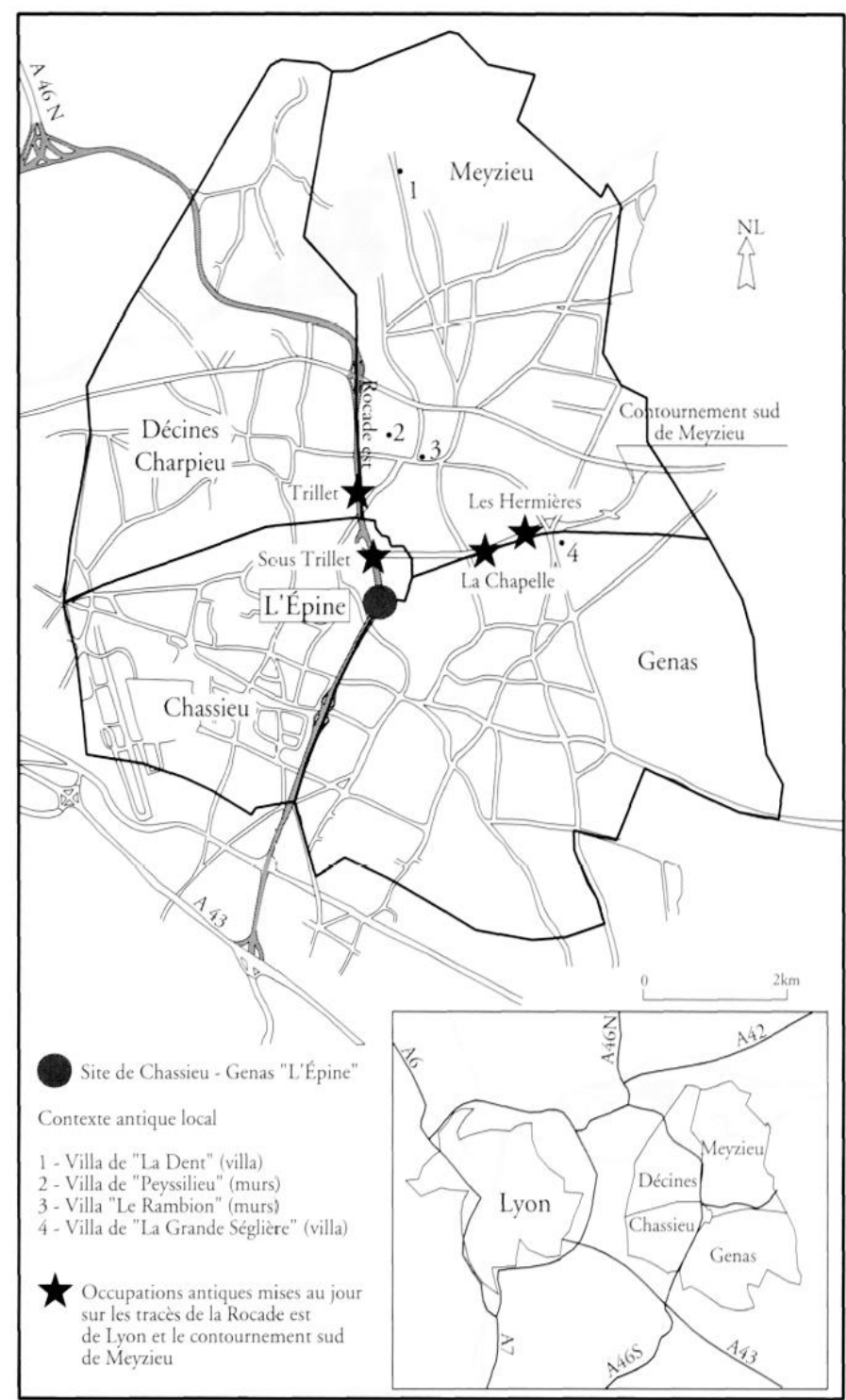

Fig. 1. Localisation et environnement antique du site de ChassieuGenas "L'Épine " sur le tracé de la rocade est de Lyon.

établissements d'ampleurs différentes; un gisement de fasciès protohistorique, matérialisé par des édifices sur supports plantés et des fosses, semblait conservé sur une zone assez restreinte; l'occupation gallo-romaine connaissait un accroissement rapide, mais éphémère, qui ne paraissait pas dépasser le $\mathrm{I}^{\mathrm{er}} \mathrm{s}$. de notre ère; des structures semi-enterrées, des trous de poteaux, des foyers, des systèmes de fossés et de palissades indiquaient alors des structures légères et une activité tournée vers le travail du fer. Les occupations hallstattiennes et d'époques médiévales/modernes qui ont été sporadiquement enregistrées ne seront pas reprises dans cet article.

Abstraction faite des traces d'activité métallurgique, dont l'importance sur le site restait discutable, le gisement de "L'Épine " méritait une étude attentive. La nature du site, 
caractérisée par une trame assez lâche de vestiges sur plus de 4 hectares, restait mal déterminée. S'agissait-il de la zone d'activité d'une importante villa non détectée ou d'une bourgade? Dans un cas comme dans l'autre, on ne disposait pas de point de comparaison de cette ampleur dans le Velin.

Cette implantation se situe en effet en dehors des grandes catégories d'habitats ruraux communément admis pour l'Antiquité. Sa définition, ainsi que celle de certaines structures, a posé de nombreux problèmes de terminologie, que cet article ne pourra résoudre à lui seul. Sa finalité est d'abord de présenter les données environnementales et chronologiques, suivies d'éléments de synthèse visant à intégrer le site dans un cadre régional.

\section{LE SITE ET SON ENVIRONNEMENT}

Cette première partie insère le site dans son cadre géomorphologique local avant d'aborder le problème de l'emprise humaine sur le paysage par le biais des différents réseaux de fossés qui s'étendent bien au delà des zones d'habitat.

La superposition de réseaux d'orientations divergentes et le recoupement de certains fossés illustrent l'évolution du sytème parcellaire alors que leur imbrication justifie une prise en compte globale de leur évolution. A partir de ces données, plusieurs hypothèses concernant leurs fonctions ont été avancées : gestion de l'eau, limites agraires de portée locale ou cadastration d'intérêt régional.

\section{LE CADRE GÉOMORPHOLOGIQUE (FIG. 2)}

L'Est lyonnais se caractérise par une série de collines radiales, au cœur mollassique et à couverture morainique, surplombant une plaine fluvio-glaciaire monotone $\mathrm{e}^{2}$. Ce revêtement, mis en place durant les crues glaciaires du Riss, a été par la suite remanié par les mouvements du glacier würmien, dont les avancées ont accentué le creusement des couloirs fluvio-glaciaires. Lors de périodes de réchauffement, des placages de loess ont colmaté les dépressions et atténué certains versants. L'ensemble du relief morainique qui nous intéresse ici adopte un plan allongé, d'orientation nord-oucst/sud-est, qui atteint $260 \mathrm{~m}$ par endroits; la plaine s'étend en contrebas de 209 à $212 \mathrm{~m}$ d'altitude.

(2) Les observations géomorphologiques citées dans ce paragraphe ont été effectuées par Mme C. Chaussé (AFAN) dans un rapport remis au SRA Rhône Alpes (Chaussé 1992). Ce rapport, faisant ćtat de quelques remarques concernant l'hydromorphie de certaines coupes, est également mentionné plus loin.
Le site de L'Épine s'adosse sur le flanc occidental d'une colline culminant à $250 \mathrm{~m}$; ce secteur occupe le sommet de l'un des versants sud de la butte, rythmé par une série de ruptures de pente vers la plaine, empatée par des formations limoneuses remaniées. Au nord, les vestiges s'étalent sur les replats du relief, de 232 à $235 \mathrm{~m}$ d'altitude. Plus au sud, sur la section la plus inclinée du versant, la densité des vestiges décroit nettement $(223 \mathrm{~m})$.

La dilatation de la couverture limoneuse varie du nord au sud; mince en sommet de versant (nord), elle s'épaissit progressivement jusqu'en bas de pente (sud). Les niveaux archéologiques apparaissent soit sous le labour, soit sous un léger colmatage de limons colluviés, notamment le long de la déclivité (Mandier 1988). La présence d'un niveau de sol d'occupation antique vers le chemin communal de Brigneux, au centre des décapages, ou plus au sud, avant l'amorce du versant, témoigne de changements modérés dans la topographie sur les deux tiers nord de l'habitat. On peut néanmoins remarquer que le colmatage sableux de certains fossés et l'épaisseur de la couverture limoneuse (au sud) illustrent le démantèlement du substrat morainique à l'extérieur des zones bâties. Ce phénomène indique un milieu relativement ouvert.

\section{LES SYSTÈMES DE FOSSÉS (FIG. 3)}

Trois ensembles de fossés se distinguent; les deux principaux se situent aux extrémités nord et sud de la zone explorée, le troisième est matérialisé par de longs tracés rectilignes orientés nord-sud, entre les deux pôles d'occuparion antique.

Les indices de datation sont ténus et reposent sur quelques données chronologiques associées à l'analyse spatiale des vestiges. Les comblements marquant le colmatage de certains fossés ont livré des tegulae ou tessons de céramiques, indiquant une mise en place lors de la période antique. De même, une analyse $14 \mathrm{C}$ effectuée à partir de dépôts charbonneux dans le comblement d'abandon de l'un des fossés du site mitoyen de "Sous Trillet " 3 confirme l'existence de ces réseaux dès les premiers siècles de notre ère.

On remarque également l'implantation des fossés nord et sud en marge de l'occupation, malgré quelques empiètements sur les zones de contact. La similitude des orienta-

(3) A "Sous Trillet ", la datation au carbone 14 du foyer 41 situé dans le comblement supérieur de l'un des fossés livre un indice d'abandon entre 130 et 530 ap. J.-C. (Joly, Dawson 1992). 


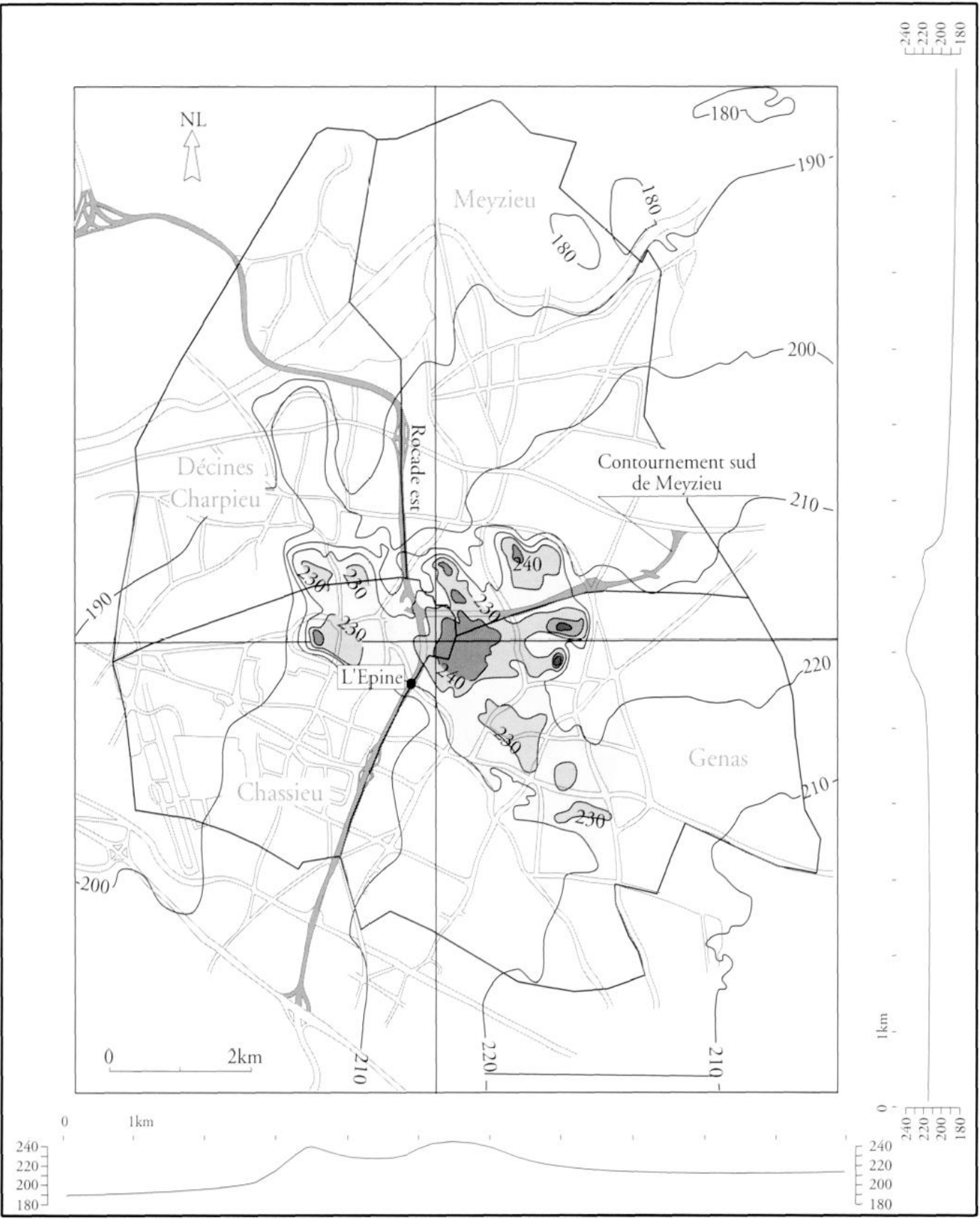

Fig. 2. Plan topographique de la butte morainique de Chassieu, Genas, Meyzieu et Décines. tions avec les axes des vestiges d'habitat doit également être signalée. Au centre de l'emprise, c'est l'imbrication même des structures avec les autres vestiges qui témoignent de leur contemporanéité.

\section{Deux systèmes d'orientations différentes au nord}

Deux ensembles de fossés coexistent au nord; le montage des plans de masse des deux sites mitoyens de "LÉpine " et de "Sous Trillet " révèlent l'extension de ces réseaux vers l'intérieur de la butte morainique sur au moins $500 \mathrm{~m}$. Leurs comblements limono-sableux pauvres en inclusions et la rareté des charbons de bois ou des morceaux de terre cuite semblent indiquer le relatif éloignement des habitats. Ces fossés revêtent des réalités différentes. Le décapage linéaire limite probablement l'interprétation mais certains semblent délimiter des enclos (104 et 105) ou de larges divisions de l'espace rural ( 15 et 14 ou 6 juillet et 8 ). Les surfaces encloses sont difficilement appréciables. Celle qui est délimitée par les fossés 7 et 8 présente au moins $110 \mathrm{~m}$ sur $60 \mathrm{~m}$ de côté. D'autres fossés montrent un tracé linéaire dont les aboutissements nous échappent.

Les éléments du premier groupe, ou leur perpendiculaire, sont orientés autour des $17^{\circ}$ Est (par exemple, les fossés 104,12 et 5, 36/37 ainsi que le chemin de Brigneux). 
Néanmoins, il faut remarquer quelques divergences entre 104 et 5 par exemple où d'autres fossés $(264,1)$ s'infléchissent progressivement vers l'est. Le second groupe adopte une orientation très proche du nord-sud ( 15 ou 6 juillet) ou de sa perpendiculaire ( 14 ou 8 ) bien que de légères inclinaisons soient parfois observées (14).

L'un des points les plus remarquables est l'imbrication de ces deux réseaux, concrétisées par des intersections : sur "L'Épine " entre les fossés 15 et 14, sur lequel se connectent 104 et 105 , ou à "Sous Trillet " entre 6 juillet et 36/37. Si les connexions sont restées illisibles à "L'Épine ", à "Sous Trillet " l'orientation nord-sud paraît être postérieure aux inclinaisons orientales.

Sur "L'Épine ", certaines largeurs de fossés varient de 0,7 à $1 \mathrm{~m}$, leur profil est très évasé; de fait, après érosion, les profondeurs sont peu marquées, de 0,15 à $0,30 \mathrm{~m}$. Certaines dimensions sont beaucoup plus importantes: jusqu'à $5 \mathrm{~m}$ de large pour une profondeur de 0,30 à $0,70 \mathrm{~m}$ seulement (portion sud du fossé 14); cette disproportion dénote sans doute des reprises de tracés que le peu de contraste des coupes n'a pu restituer. Quelques exceptions existent, les fossés 1 et 15 présentent des profils plus marqués : respectivement larg. 1,50 à $1,60 \mathrm{~m}$, prof. de $0,50 \mathrm{~m}$ et $1,6 \mathrm{~m}$, prof. $1,1 \mathrm{~m}$. S'agit-il alors de point d'ancrage des réseaux dans le paysage? A "Sous Trillet ", les modules des fossés $8,24,36,44$ sont également plus importants, les largeurs dépassant fréquemment $2 \mathrm{~m}$.

Des foyers peu rubéfiés de plan circulaire et de diamètres divers (diam. : 1,50 à $0,60 \mathrm{~m}$, prof. : 0,10 à $0,70 \mathrm{~m}$ ) sont le plus souvent installés aux abords, voire parfois à l'intérieur, des fossés; le foyer 13 semble isolé. Seule l'analyse $14 \mathrm{C}$ tentée sur un prélèvement charbonneux issu du foyer 41 fournit un indice de datation (130/530 ap. J.-C., voir $\$$ précédent).

\section{Les enclos sud}

Au sud de la zone dégagée, seuls deux enclos ont été rattachés à la période antique. Leur orientation, globalement nord-sud, est calquée sur l'habitat mitoyen, mais certaines incurvations des côtés se rapprochent des $17^{\circ}$ Est observés précédemment (857).

Un matériel antique a été mis au jour dans les comblements des fossés : (337 : des fragments de céramique commune sombre à pâte grossière. 832 : des fragments de céramique commune sombre à pâte grossière, dont un bord éversé et un bord de jatte à lèvre saillante et décor digité; de la céramique commune claire, dont deux bords en bandeau. 857 : un fragment de bord, à lèvre éversée avec gorge interne).

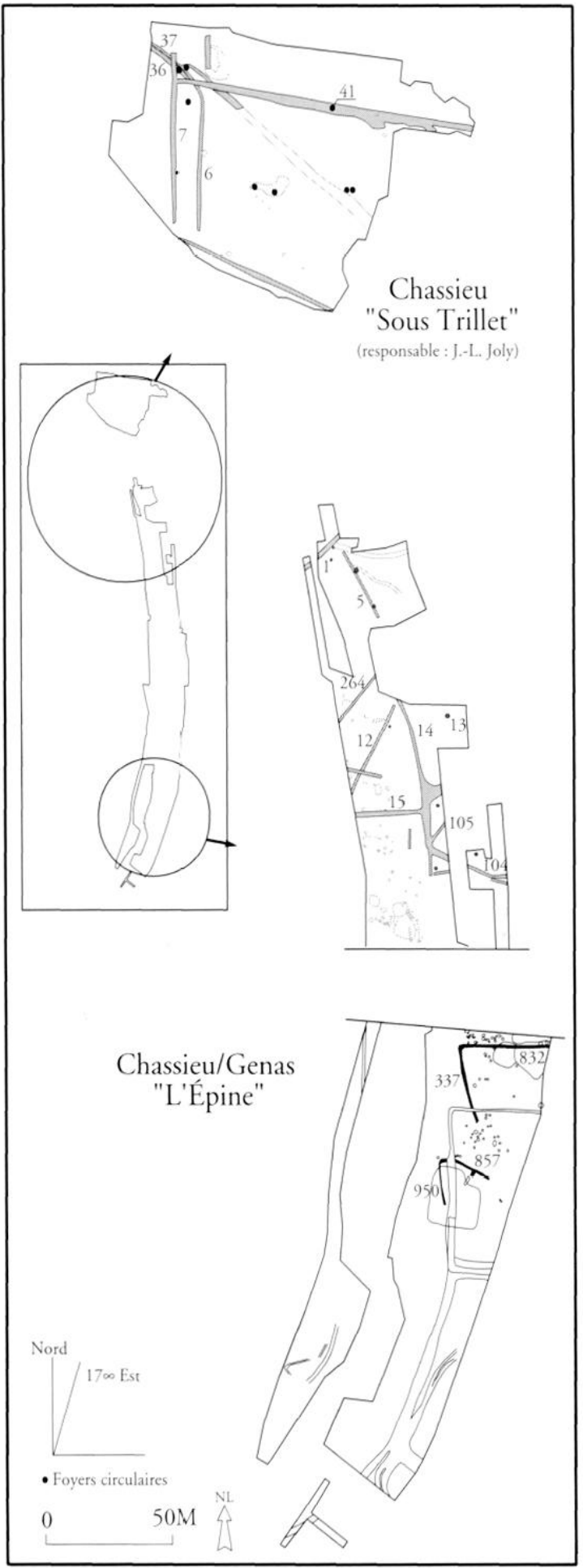

Fig. 3. Les réseaux de fossés situés au nord et au sud du site.

Faible densité et tracés légèrement curvilignes indiquent içi une occupation des sols différente de celle observée sur la partie nord et probablement induite par la contrainte topographique que représente la pente menant à la plaine fluvio-glaciaire. Ces enclos, délimités sur deux côtés, s'ouvrent vers le sud. Les fossés 337/832 (larg. : 
$0,60 \mathrm{~m}$ à $0,45 \mathrm{~m}$, prof. : $0,30 \mathrm{~m}$ et $0,75 \mathrm{~m}$ ) offrent des comblements homogènes de limon brun gris et de galets. Le fossé 857 (larg. : $1 \mathrm{~m}$ à $0,20 \mathrm{~m}$ ) est arasé vers l'est, tandis que la portion nord-sud (950) est recoupée par des ensembles probablement médiévaux. Enfin, deux fossés datés des périodes historiques ont été mis au jour sur le site de " sous Genas ", situé au sud dc "L'Épine " (Vital, Taras, Thiériot 1992). On y retrouve les deux orientations mentionnées par ailleurs (nord-sud et $17^{\circ} \mathrm{E}$ ).

\section{Les doubles tracés centraux (fig. 4)}

Entre ces deux secteurs, deux longs fossés nord-sud (194 et 81) ont été découverts sur $125 \mathrm{~m}$ de long (larg. : 0,50 à
$0,80 \mathrm{~m}$, prof. : 0,20 à $0,35 \mathrm{~m}$ ). Ils s'insèrent entre les deux pôles antiques exposés en seconde partie. Le matériel recueilli dans les comblements de 194 (scories au nord) et sa butée contre contre un édifice du $\mathrm{I}^{\text {er }}$ s. ap. J.-C. (208) confirment sa contemporanéité avec l'habitat. Le fossé 81 , malgré le parallélisme avec 194, reste de datation indéterminée.

Leurs comblements sont variés, limoneux avec du charbon de bois sur l'extrémité nord, alors que des traces de dépôts en milieu humide sont remarquées sur les sections centrales; ces dernières sont éloignées de l'habitat et pour cette raison sans doute plus stériles. Les profils, irréguliers, montrent des traces de curage.

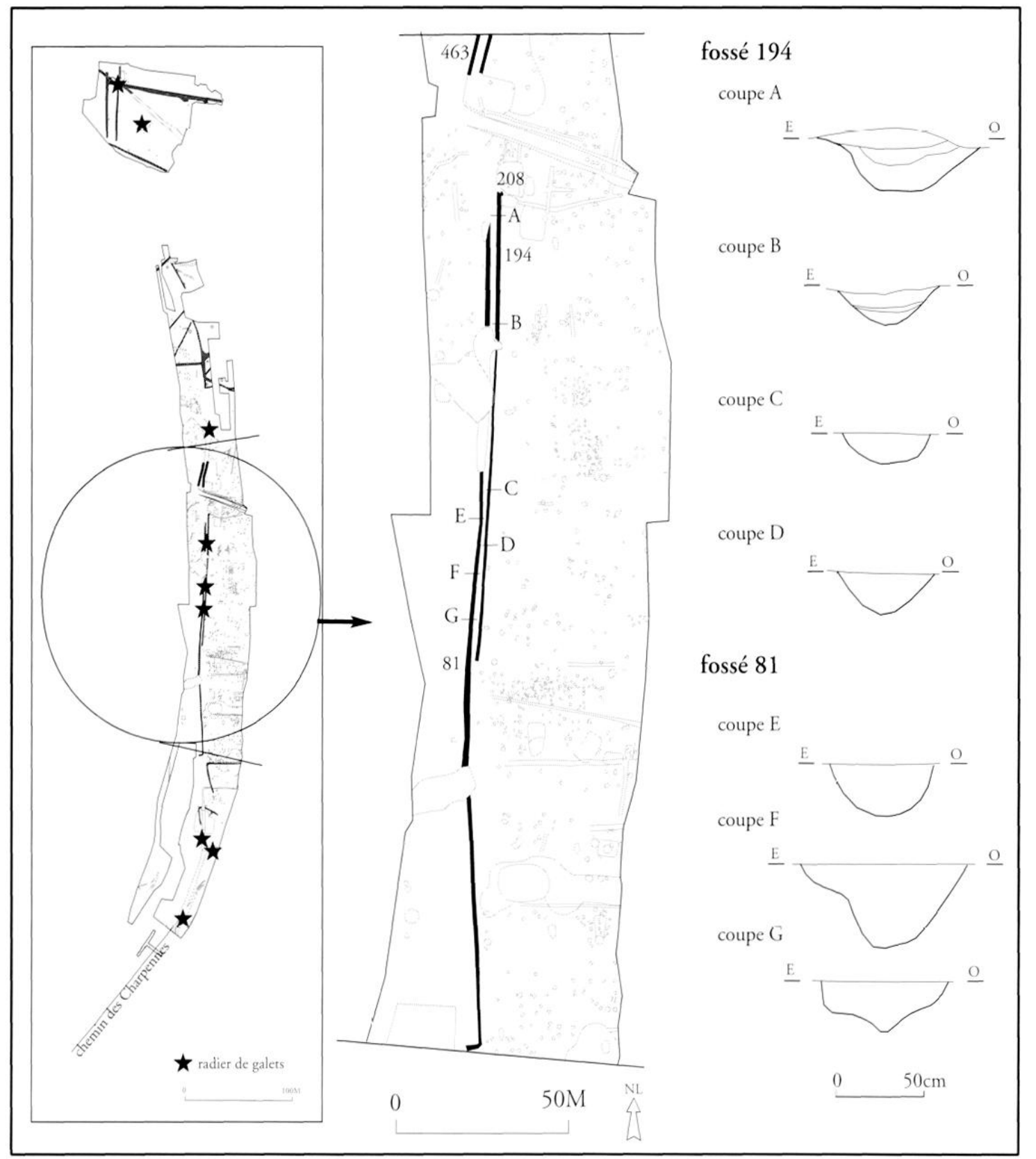

Fig. 4. Les doubles tracés centraux. 
Deux autres fossés, également parallèles, se prolongent vers le nord (463). Ceux-ci ont été colmatés par un épandage de tuiles, de galets, des fragments de céramiques antiques ainsi que par quelques éléments en fer; ce niveau plan est reconnu sur $50 \mathrm{~m}$ de long et $3 \mathrm{~m}$ de large (non illustré).

On y note des fragments de céramiques à pâte grossière, dont une panse à décor côtelé, quelques tessons de commune claire et d'amphores (dont Dr. 1), un fragment de sigillée (Drag. 18/31). On observe également, pour le matériel en fer: un crochet, une poignée, une tige torsadée et un couteau.

L'hypothèse d'une voie a été émise afin d'expliquer le parallélisme de ces structures sur une aussi longue section. Certains épandages de matériel ou les radiers de galets qui les recouvrent, sembleraient étayer cette lecture. Notons que des radiers similaires ont été découverts au nord à "Sous Trillet " et qu'un matériel médiéval y a été recueilli en surface. Au sud de "L'Épine ", ces niveaux de galets se poursuivent d'ailleurs dans des fossés postérieurs à la période antique. Ainsi, si la " chaussée " est probablement médiévale, elle reprend des tracés en partie mis en place lors de l'expansion de l'occupation antique. Ces limites ont partiellement survécu jusquà nos jours, sous forme de divisions parcellaires; l'extrémité sud est en revanche restée une desserte rurale jusquau $\mathrm{XIX}^{\mathrm{e}}$ s. (chemin des Charpennes).

\section{GESTION DE L'EAU ET LiMITES PARCELlaires}

Quel(s) rôle(s) attribuer à ces fossés à partir des données disponibles? Gestion de l'élément vital que représente l'eau, limites agraires liées aux habitats, normalisation ou cadastration des espaces ruraux...?

\section{Une gestion de l'eau (fig. 5 et 6 )}

Différentes structures assurent la gestion de l'eau : fossés et ravines, mares, puits. Ces structures, aussi variées qu'adaptées au terrain et au relief, sont ainsi en usage dès les premiers temps de l'occupation du Haut-Empire, alors que leurs périodes d'abandon n'ont pu être appréhendées.

- Les fossés : l'examen des matériaux sédimentaires (sables à structures entrecroisées) du fond des fossés 1 et 15, dont les largeurs dépassent d'ailleurs celles des tracés voisins, a permis de souligner la présence d'un écoulement concentré (Chaussé 1992). Par ailleurs, au nord, des ravines aux tracés irréguliers s'écoulaient dans le sens de la pente. L'intérêt de ces observations vient surtout des liens qui se sont créés entre ces deux types de structures. On

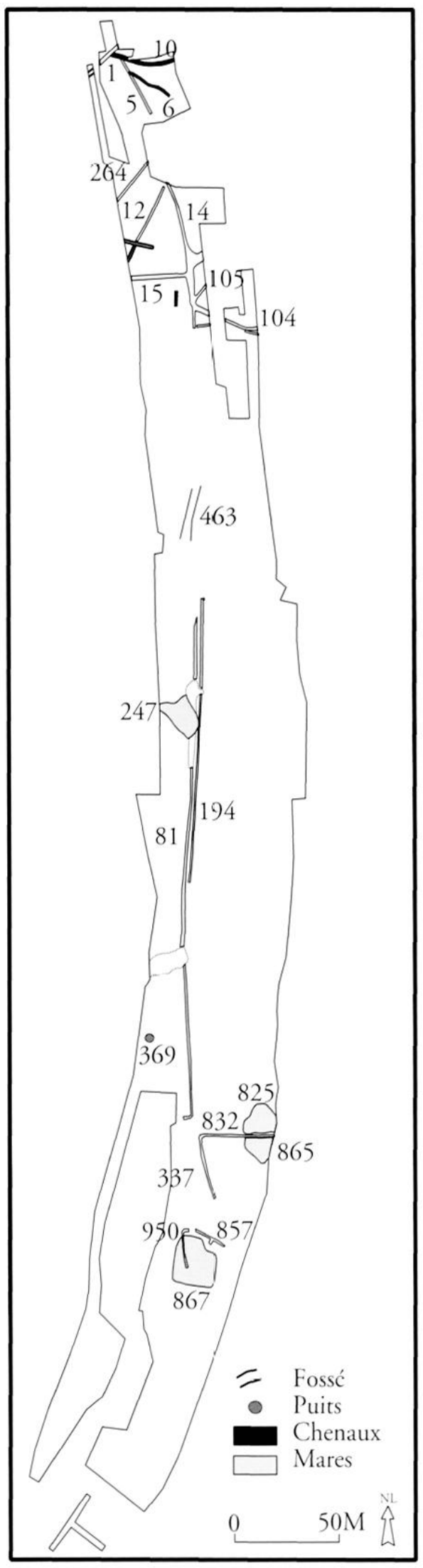

Fig. 5. La gestion de l'eau (plan général). 


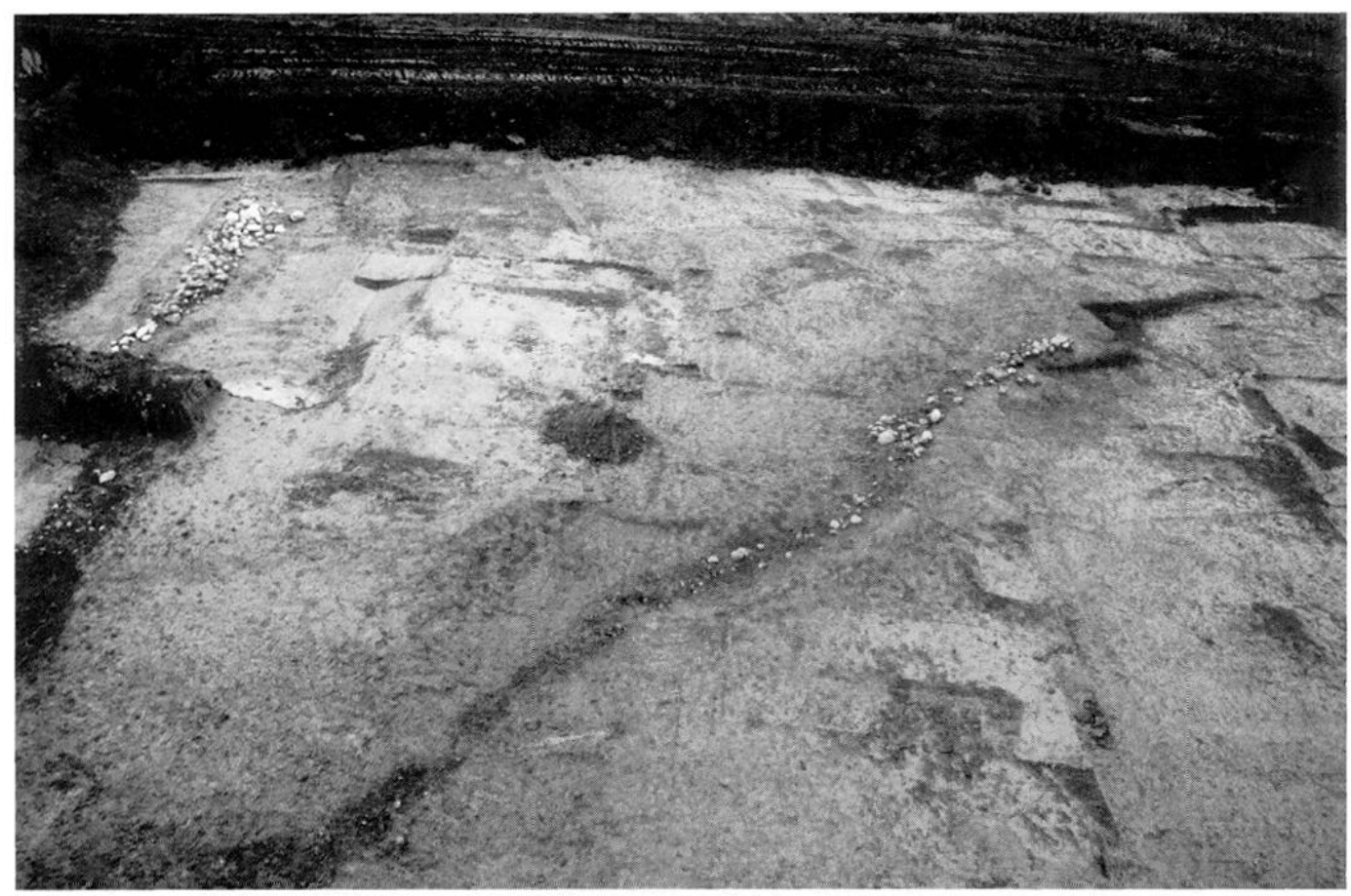

Fig. 6. Illustration

des chenaux ou ravines.

note en effet que la ravine, ou chenal, 10 est recoupée par le fossé 1 , indiquant ainsi le captage d'un écoulement naturel par ce fossé. Le même phénomène est noté entre la ravine 6 et le fossé 5 sur ce même secteur, ainsi que sur le site mitoyen de "Sous Trillet ", où coexistent aussi ravines et réseaux de fossés (Joly, Dawson 1992) ${ }^{4}$.

On remarque également que les sables triés constituant la base des comblements de la structure 6 , illustration d'un écoulement concentré superficiel et ravinant, ainsi que les accumulations de galets calibrés rencontrées sur les parties supérieures (le limon encaissant en est dépourvu), évoquent peut-être une tentative de canalisation (Chaussé 1992) (fig. 6).

- Les mares (fig. 7) : les limons argileux couvrant le substrat morainique sont relativement imperméables; l'eau est ainsi piégée dans les irrégularités du sol : deux larges excavations semblent avoir renforcé ce phénomène de rétention d'eau (247, au sud-ouest du chemin de Brigneux, et 867 , plus au sud). Une troisième mare, implantée sur la moraine perméable, profite d'un aménagement de fond (825).

La large excavation 247 (long. nord-sud : $17 \mathrm{~m}$, long. est-ouest : $18 \mathrm{~m}$, prof. max. $1,80 \mathrm{~m}$ ) présente un profil

(4) Ce rapport de fouille, dont sont tirées plusicurs données parcellaires et indications chronologiques, a été urilisé dans sa globalité et ne donne pas lieu à des mentions de pagination précisc. S'agissant en revanche d'une équipe de fouille indépendante de celle du site de "L'Épine ", nous avons tenu à en cirer la référence aussi souvent que nécessaire. marqué. Un creusement moins profond la borde à l'est, les deux se confondant au décapage. Sa situation, à quelque distance de l'occupation, en un lieu recueillant les ruissellements, permet d'y voir un bassin de rétention appréciable; les colorations bleutées des matériaux de base témoignent en effet de la stagnation de l'eau dans un milieu essentiellement réducteur.

Le niveau de fond de la dépression a révélé quelques scories et fragments de tuiles.

A l'opposé, sur la pente sud, un autre creusement, à l'origine peut-être naturel ( 867 : prof. : $1,50 \mathrm{~m}, 21 \mathrm{~m}$ de côtés), mais recreusé et élargi, est comblé par des sables lités. Ce colmatage sableux présente des traits d'oxydo-réduction (coloration rouille à grise) qui soulignent un milieu noyé avec battance du niveau d'eau (Chaussé 1992).

Le seul élément céramique recueilli est un vase tronconique côtelé entier et daté de la période augustéenne.

Un autre type de mare se situe le long de l'emprise est, sur le substrat morainique perméable $(825:$ larg. $12 \mathrm{~m}$, prof. $0,50 \mathrm{~m}$ ). Le fond de la structure est alors tapissé de petits galets et de quelques petits morceaux de tuiles régulièrement déposés sur l'encaissant morainique. Mitoyenne au sud, une autre dépression (865), moins profonde (prof. $0,25 \mathrm{~m}$ pour $13 \mathrm{~m}$ de côtés), présente un comblement analogue, sans quaucune trace de radier n'y soit visible.

- Un puits, 369, est situé à l'ouest; la coupe effectuée à la pelle mécanique n'a pas permis d'en atteindre le fond. 


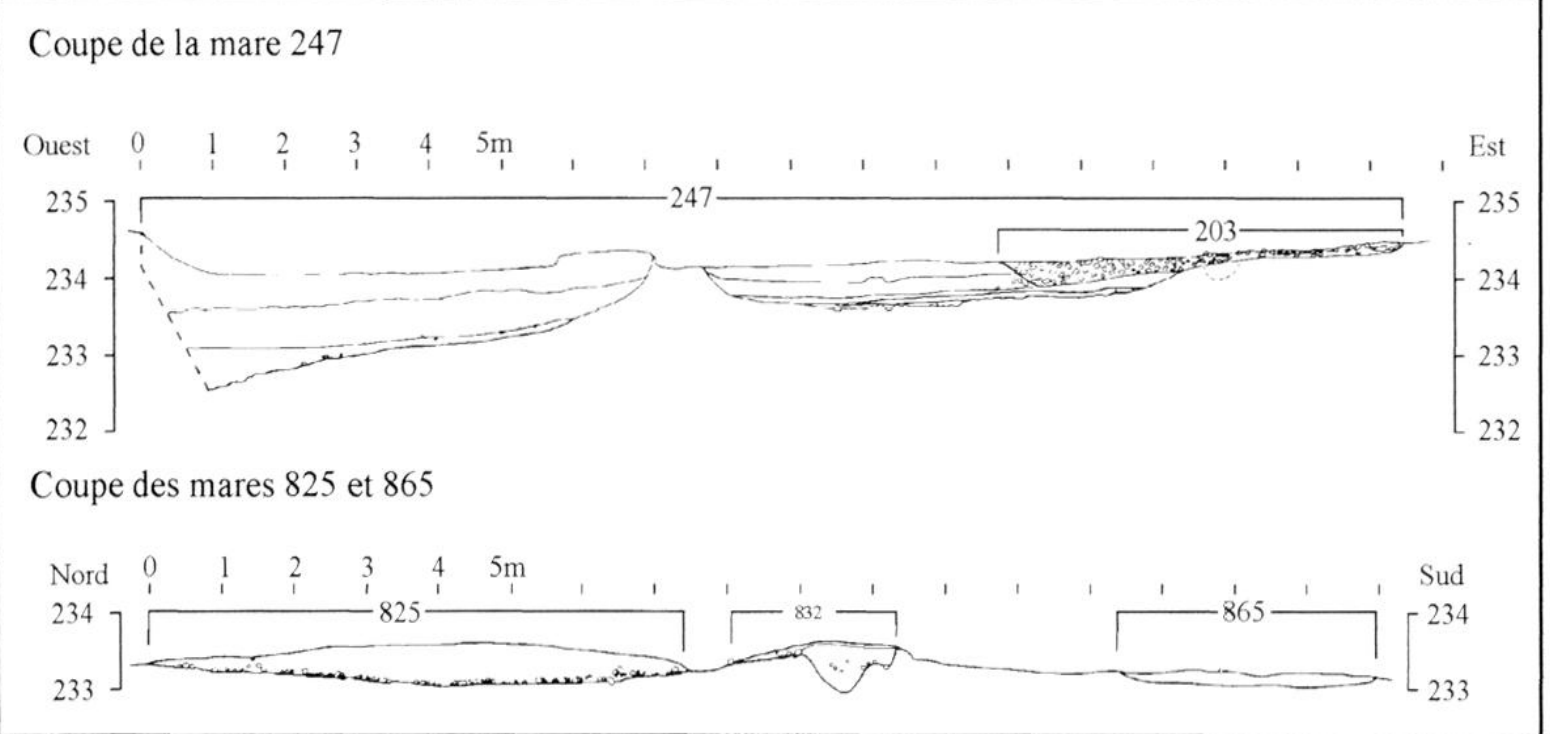

Fig. 7. Coupes des mares 247 et 825 .

L'ampleur de l'ouverture de surface $(4 \mathrm{~m})$ rappelle celle provoquée par un cône d'effondrement ou par la récupération des matériaux de construction de l'ouverture. En coupe, différents lits de moraine issus du sol encaissant alternent avec des coulées limoneuses, puis sont scellés par des limons bruns à bruns foncés. Le diamètre du creusement, en fond de sondage, atteint $2 \mathrm{~m}$. Si l'existence d'un chemisage semble probable dans ce substrat morainique, aucune trace n'en a été relevée.

Le matériel céramique issu du remblai supérieur date l'abandon final à partir des premières décennies du ler $s$. de notre ère (un fond d'assiette, imitation de sigillée estampillée d'une rosette, quelques fragments d'amphores dont une Dr. 20).

La présence de telles structures en sommet de buttes peut sembler curieuse au vue de la profondeur à atteindre (des nappes perchées existent et facilitent parfois le captage). Pourtant, la présence de puits profonds est encore attestée au début du siècle, sur le Mont Saint-Paul au centre de l'actuelle commune de Chassieu, où ils atteignent parfois $60 \mathrm{~m}$ (Chassieu en Velin, 1990, p. 27).

\section{Des témoins agraires}

Peu d'indices permettent de lier les fossés aux pratiques agraires $^{5}$. Les analyses zoologiques et polliniques n'ont donné que très peu de résultats concernant l'environnement animal et végétal. En effet, les échantillons positifs sont restés relativement pauvres et n'ont permis qu'un nombre restreint d'identifications. Ainsi, la rareté des restes

(5) Carpologie, palynologie et zoologic : Arpa, Bron (69) (Argant 1992)Anthracologie : Archéolabs, St Bonnet de Chavagne (38) (Dormoy, Orcel 1992). floristiques n'apporte aucune indication sur les éventuels types de culture. L'étude anthracologique en revanche, met en évidence la coexistence d'un espace défriché souligné de haies et des sous-bois issus de chênaies proches.

- La faune : L'extrême rareté des restes osseux recueillis sur le site ne fournit que des observations anecdotiques: deux bovidés de grande taille et un cheval de taille petite à moyenne ( 3 ossements sur 4 hectares)... La conservation presque exclusive des éléments de dentition plaide en faveur d'une disparition de bon nombre de restes.

- Les pollens : Les échantillons sont presque stériles ${ }^{6}$. II s'agit de sédiment provenant du fond du fossé 15 , situé à l'extrême nord du site, d'un enclos, d'un foyer près de l'habitat au nord et de la mare 247 . On note des traces de bruyères, de fougères, de bouleau, de noisetier (espèces rencontrés dans les landes et les lisières de bois) ou d'aulnes, signalant la présence de lieux humides. Le pollen de bruyère, qui se disperse très mal, confirme la proximité de ces zones défrichées; ce végétal était parfois utilisé comme combustible, ou servait à la confection de toiture ou de litière pour les animaux. Une analyse concernant des macro-restes végétaux a également été effectuée sur un ensemble de graines recueillies lors du tamisage du sol de l'édifice 455 : les 140 graines de chenopodes indiquent la présence de cultures sarclées, de chemins ou de décombres.

- Les charbons : Les 44 prélèvements de charbon de bois sont issus du comblement de foyers, de fours et de deux aires dédiées au travail du fer. Identifié dans 38 ensembles, le chêne domine largement. Le hêtre et le châtaignier n'ont été observés que dans 6 prélévements. La présence des autres espèces est anecdotique et indique la combustion de pomoideae (pommier, poirier, cognassier, sorbier, néflier...), d'orme et de sapin.

(6) Sur les 4 échantillons étudiés, 3 lames révèlent uniquement 1 à 3 grains de pollen. 


\section{L'HYPOTHÈSE DES CADASTRES ANTIQUES}

L'hypothèse d'une cadastration antique de l'Est lyonnais a donné lieu à plusieurs publications ces dernières décennies. L'ancien schéma comportant deux orientations dominantes, l'une proche de $0^{\circ}$ (d'influence viennoise), l'autre de $23^{\circ} 30^{\prime}$ Est (d'influence lyonnaise), a longtemps servi de base aux études sur une éventuelle présence de centuriations autour de Lyon (Chouquer, Favory 1980).

Ces résultats ont été affinés par de récentes études portant autant sur la photo-interprétation et ses différents filtrages, que sur le résultat des fouilles archéologiques. Les observations concernant les orientations dominantes se sont trouvé complétées par une recherche des périodicités dans les occurences linéaires d'une orientation donnée, et leurs correspondances avec les multiples de l'actus romain. Les résultats préliminaires ont mis en valeur trois possibilités de centuriations concernant la région qui nous intéresse, le Velin (Velin A : $23^{\circ} \mathrm{W}$, Velin B : $7^{\circ} \mathrm{W}$, Velin $\mathrm{C}$ : $3^{\circ} .30^{\prime} \mathrm{E}$ ) (Chouquer 1995).

\section{Les orientations}

Chassieu "L'Épine " comporterait deux orientations : un axe plus ou moins nord-sud, proche de l'orientation dite viennoise et Velin C, et un autre d'environ $17 / 20^{\circ}$ Est, appuyé de nos jours sur la portion du chemin de Brigneux recoupée par l'emprise.

En élargissant notre point de vue aux réseaux mis au jour sur les sites de l'Est lyonnais, on constate un grand nombre de fossés datés du $\mathrm{I}^{\mathrm{er}} \mathrm{s}$. de notre ère. Leurs orientations s'avèrent fort diverses, des sites proches pouvant néanmoins révéler des axes similaires, comme à Lima et Grange Rouge au nord, alors que d'autres schémas d'implantation président ailleurs. Une orientation proche de l'axe nord-sud semble pourtant dominer sur plusieurs sites, à Chassieu "Le Trillet " (Frascone, Staniazsek 1992), et vers le sud, à Saint-Priest "Ilford "(Joly, Bédart 1995), à Marennes "Le Pillon " (Martin, Blaizot 1994)...

Il faut néanmoins nuancer ces observations. Pour certains sites, le relief pourrait naturellement servir de support à une trame homogène, sans aucune adhésion à un schéma imposé; des occupations humaines successives, depuis l'Age du Bronze jusqu'à nos jours, avec de longs hiatus chronologiques, reflètent en effet des choix identiques dans l'établissement des axes d'implantation, comme à Beynost "Les Grandes Croix " (Motte, Vicherd 1992) ou Meyzieu
"Les Hermières " (Jacquer 1995) ou "La Chapelle " (Coquidé, Vermeulen 1995), ces deux derniers situés à tout juste $2 \mathrm{~km}$ à l'est de "L'Épine ".

Pour " L'Épine ", le réseau orienté à l'Est trouve une similitude avec la direction adoptée par la butte morainique à cet endroit. En revanche, le réseau nord-sud ne trouve aucun parallèle topogaphique.

\section{Les périodicités}

Les décapages mettent en lumière de nombreuses limites qui ne sont plus visibles dans les parcellaires actuels, ni repérables à l'examen des photos aériennes. Beaucoup de données ne deviennent accessibles que grâce aux études de terrain. Malgré tout, l'abondance, la superposition, la difficile dissociation chronologique limitent la lisibilité des occurrences. Le parcellaire nord permet d'observer le départ de plusieurs enclos, ainsi que quelques limires qui semblent linéaires, mais le décapage parait insuffisant pour dégager une éventuelle logique d'implantation.

De plus, la lecture de ces mesures supporte quelques imprécisions dues à des niveaux d'arasement variés et des courtes distances linéaires (soit des emprises de 50 à $70 \mathrm{~m}$ ). Les variations d'axe, et les distances inter-axes, pour un même fossé ou pour un réseau, peuvent alors être conséquentes. L'implantation originelle demandait-elle d'ailleurs une extrême rigueur métrique à un niveau local?

\section{Centuriations ou réseaux locaux?}

L'étendue des tracés en dehors des habitats confirme l'étendue de l'emprise de l'homme sur le paysage pendant que la juxtaposition et l'imbrication d'orientations divergentes démontrent une évolution qui ne fait jamais table rase du passé. Dans le secteur nord, le cadastre napoléonien (fig. 8) révèle d'ailleurs le curieux aspect dentelé de certaines limites parcellaires: la superposition de ces plans du XIX ${ }^{\mathfrak{e}}$ s. aux réseaux de fossés antiques donne une concordance entre les limites contemporaines et la juxtaposition des deux orientations étudiées plus haut.

L'habitat se développe-t-il dans un cadre cadastré contraignant (la centuriation) ou prolonge-t-il son propre développement par l'établissement de réseaux de fossés indépendants? On peut envisager la coexistence des deux systèmes : le développement d'une occupation selon des règles qui lui sont propres, mais dont les limites restent soumises au schéma directeur d'une centuriation. 
A Chassieu "L'Épine ", et à titre d'hypothèse, la comparaison des études globales conduites à l'échelle du Velin (Chouquer 1995) et des orientations mises au jour à la fouille pourraient permettre de conclure à la mixité de ces interprétations. Les fossés semblent centralisés par et autour de l'habitat, phénomène déjà observé par ailleurs (Bayard 1996, p. 177; Chouquer, Favory 1991, p. 193) et probablement appuyé sur des lignes topographiques. Pourtant, l'intégration de ces réseaux à un environnement beaucoup plus large paraît plausible, puisque l'une des trois centuriations avancées, à titre d'hypothèse, par Gérard Chouquer pour l'Est lyonnais se retrouverait ici (Velin C ou orientation proche du nord-sud) (Chouquer 1995).

\section{L'ÉTABLISSEMENT DU ${ }^{\text {er }}$ S. AV. NOTRE ÈRE}

Le $\mathrm{I}^{\mathrm{er}}$ s. av. J.-C. voit les prémices d'une occupation permanente du site. Trois secteurs bien distincrs révèlent des

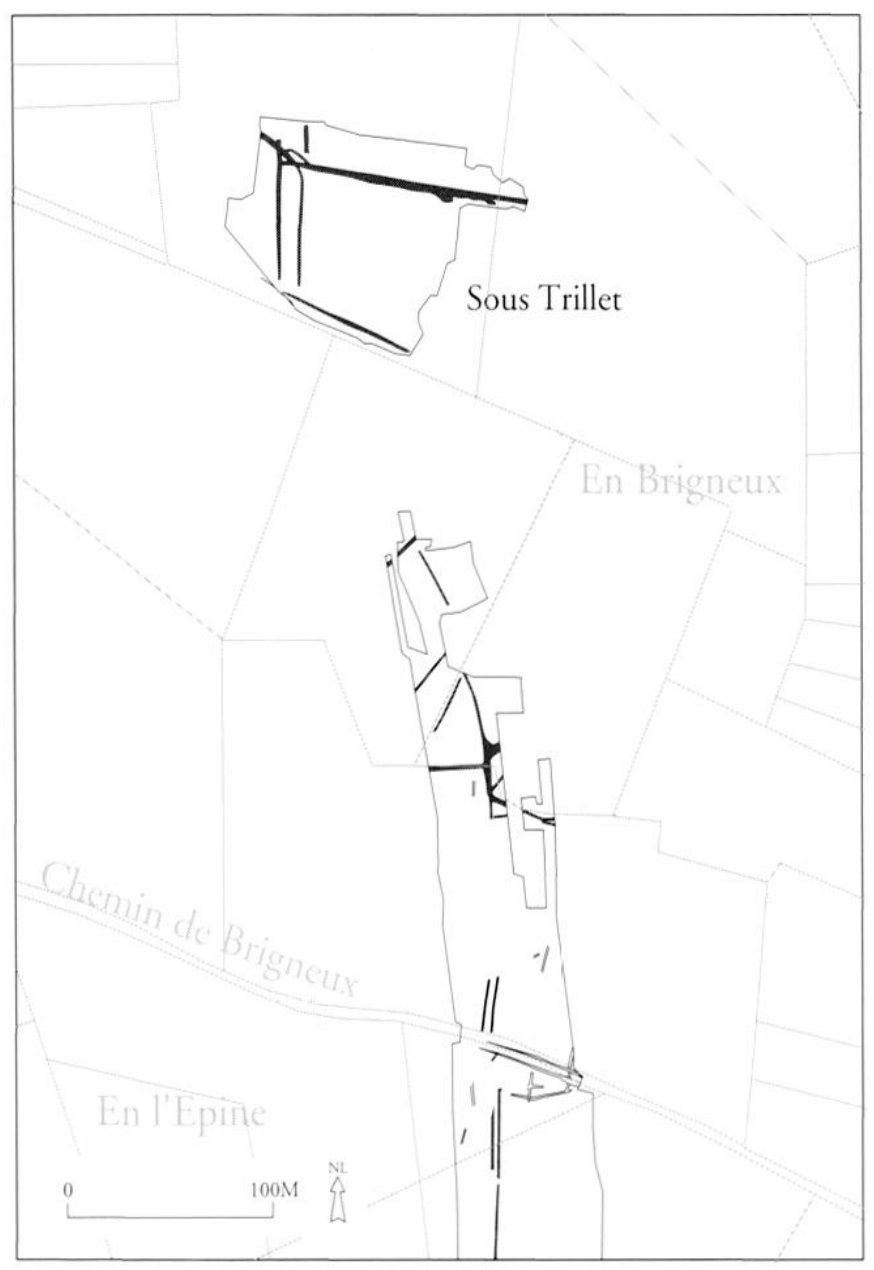

Fig. 8. Site de "L'Épine" : report de l'occupation gallo-romaine sur le cadastre napoléonien. vestiges antérieurs au $\mathrm{I}^{\mathrm{er}} \mathrm{s}$. de notre ère. Des greniers surélevés, parfois complétés d'avant-corps ou de palissade, ainsi que quelques structures annexes : silos, fosses, aires empierrées ont été mis au jour au centre de la zone étudiée (fig. 9). Au nord, de petits enclos circulaires, très perturbés par des fosses postérieures, restent énigmatiques; l'hypothèse funéraire n'est pas à rejeter bien qu'aucun indice ne vienne l'étayer. Au sud, de nombreux poteaux occupent un espace restreint sans qu'il soit possible d'en dégager de plan. Enfin, d'autres structures paraissent isolées : au sudouest du chemin de Brigneux, la fosse 121 a permis de recueillir deux vases. Un vase ovoïde à profil très doux de teinte rouge orangée inhabituel à La Tène $(-80 /-50$ ?) se réfere plutôt à une tradition hallstattienne alors qu'une jatte à épaulement en céramique fine est présente de La Tène ancienne à La Tène finale (Jacquet 1992). De nombreux autres creusements, sans matériel, l'environnent et participent peut-être au même contexte.

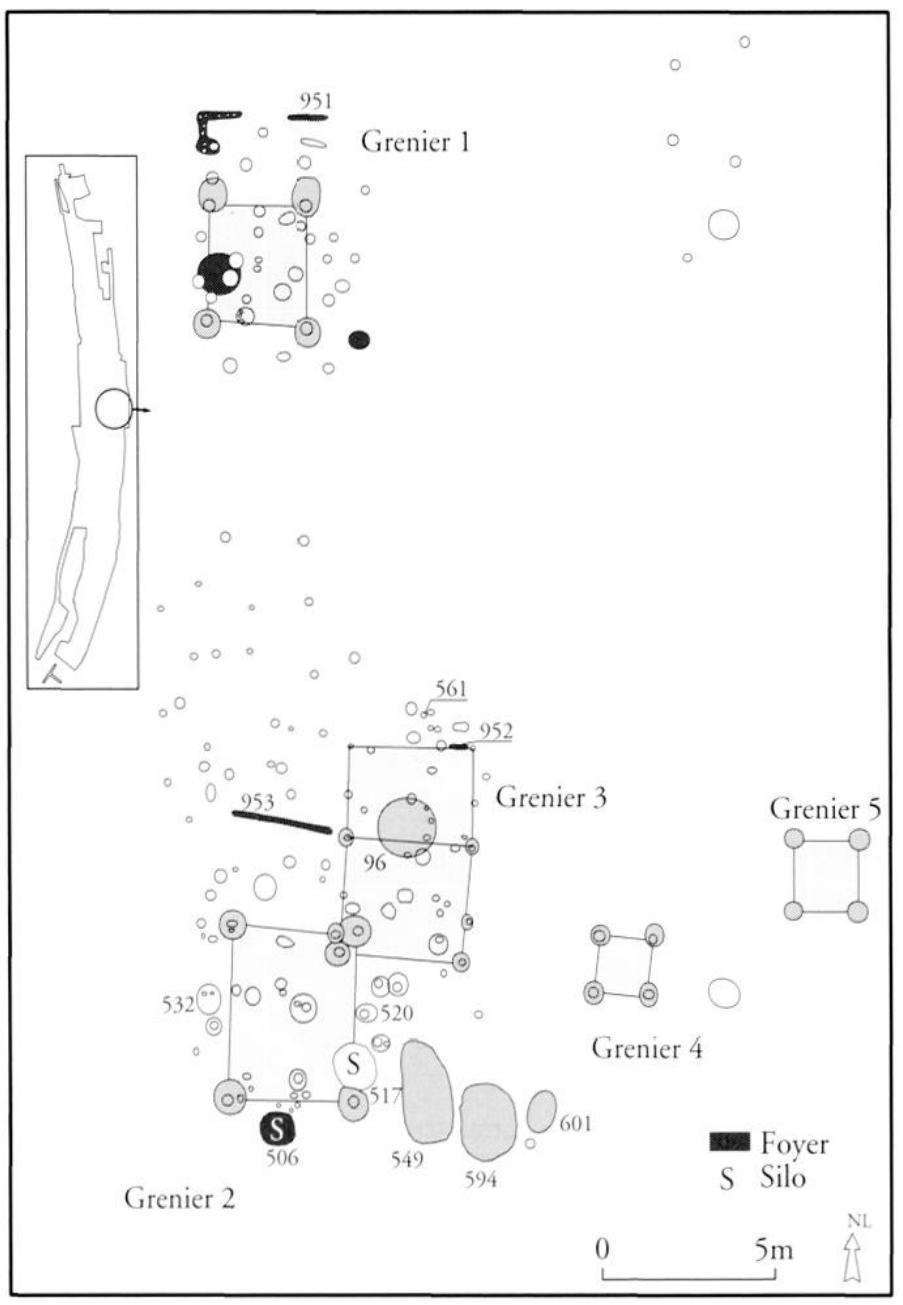

Fig. 9. Laire de stockage : les greniers, les silos et les petites zones empierrées. 
En revanche, le décapage n'a pas révélé de systèmes fossoyés pouvant faire office d'enclos de grande envergure. Les ensembles décrits évoquent plutôt la périphérie d'un ou de plusieurs habitat(s) ouvert(s), aux zones d'activités clairement définies, établis sans contrainte spatiale apparente ${ }^{7}$.

Seuls les greniers ont livré un matériel céramique relativement abondant montrant une occupation couvrant le $l^{\mathrm{er}} \mathrm{s}$. av. J.-C. L'étude du mobilier permet une autre approche du contexte économique et matériel. Elle met l'accent sur l'apparent contraste entre un mobilier dit de qualité et son contexte très fonctionnel. Un trou de poteau a néanmoins fournit un mobilier résiduel plus ancien, du IIIe ou $\|^{e} s$. av. J.C. Les petits enclos nord ne livrent pas de matériel céramique. Ils sont en revanche recoupés par des fosses dont la plus ancienne est datée de la période augustéenne. L'ensemble de poteaux sud enfin a permis de recueillir un matériel résiduel montrant des céramiques de tradition indigène; aucune tegula n'y a été remarquée.

Les faciès de la céramique domestique et de la céramique peinte s'inscrivent dans la tradition celtique de La Tène Finale. Un grand nombre de formes ovoïdes en pâte grossière, écuelles en pâte grise fine, ovoïdes peints présentent un évident lien de parenté non seulement avec les mobiliers des sites proches, mais aussi avec les sites plus éloignés des Alpes (Bâle, Genève-Furger-Gunti, Berger 1980), de la vallée de la Saône (Tournus-Perrin 1976) et du Massif Central (Roanne, Feurs, Aulnat entre autres-Perrichon, Sanial, Ranchon 1977; Lavendhomme, Guichard 1998). Sur ce fonds commun, de nombreuses nuances se dessinent, et il est délicat de tenter de définir des aires culturelles régionales à partir de simples constats d'affinités typologiques, par ailleurs souvent contradictoires. Concernant Chassieu, les similitudes les plus probantes ont été établies avec Lyon, puis Vienne et Larina (Desbat 1989 et alii; Chapotat 1970; Perrin 1990), laissant entrevoir une " identité " allobroge, à considérer toutefois avec la plus grande prudence.

La comparaison du faciès céramique de Chassieu avec celui d'un site d'habitat bien étudié et de même période, Feurs, met l'accent sur la très forte représentation des céramiques fines à Chassieu.

S'il n'est pas exclu de mettre ce phénomène en relation avec l'implantation géographique du site, et la proximité, prouvée ou vraisemblable, de certains ateliers de production (olpés par exemple), cette explication ne semble toutefois pas satisfaisante. Elle ne permet pas, entre autres, de justifier la densité des découvertes de céramique peinte, céramique de luxe ou votive, dans le contexte d'espace utili-

(7) Deux bracelets en pâte de verre, l'un de section hémisphérique, de couleur bleu foncé, l'autre triangulaire, de couleur pourpre, de diamètres intérieurs respectifs de 4 et $6 \mathrm{~cm}$, proviennent de prospections de surface hors cmprise, à hauteur des greniers, l'un vers l'ouest, l'autre en extrémité de berme est. Ces objets révélateurs d'une occupation de type laténien, soulignent ponctuellement une partie de l'extension de cette implantation. taire (greniers) défini par la fouille (Frascone, Jacquet, Widlak 1993, p. 19).

\section{LES PREMIÈRES TRACES D'IMPLANTATION}

Un matériel céramique résiduel témoigne d'une occupation antérieure au $\mathrm{I}^{\mathrm{er}}$ s. av. notre ère. Le comblement d'un poteau (561), sur la zone des greniers, a révélé plusieurs fragments pouvant être attribués à une séquence chronologique plus ancienne, vers le $\mathrm{III}^{\mathrm{e}}$ ou le $\mathrm{II}^{\mathrm{e}}$ s. av. J.-C.

Un vase à piédestal et de la céramique ampuritaine, associés à un vase ovoïde à panse grattée semblent en effet attribuables à une phase plus ancienne (Frascone, Jacquet, Widlak 1993, p. 6).

\section{LA ZONE DES GRENIERS (FIG. 9 ET 10)}

Près de 110 trous de poteaux (de 0,20 à $0,80 \mathrm{~m}$ de diamètre) ou de piquets (d'à peine $0,20 \mathrm{~m}$ de circonférence) ont été fouillés et ont permis la restitution de plans de greniers auxquels semblent s'associer quelques quelques négatifs de parois, des aires empierrées et deux silos. La densité des vestiges, qui montre une certaine permanence de l'occupation, nuit à l'interprétation. Ce sont les dimensions de certains négatifs et la cohérence de leurs alignements qui ont guidé la restitution des plans. La mise en relation d'autres creusements est moins évidente, d'autres axes pouvant être tracés en plusieurs endroits sans qu'aucun bâti ne s'en dégage.

Les édifices restitués font s'opposer deux ensembles : à l'oucst, un groupc de 3 grenicrs dc grandcs dimcnsions (les greniers 1,2 et 3 qui mesurent respectivement 9,6, 19 et $22 \mathrm{~m}^{2}$ ) auxquels s'associent les foyers et les silos, et à l'est deux greniers de plus petits modules (greniers 4 et 5 , de 2,25 et $4,2 \mathrm{~m}^{2}$ ).

\section{Le groupe ouest}

L'hypothèse de greniers surélevés peut être avancée pour 2 des ensembles; les avant-trous des poteaux, de forme ovale, varient de 0,50 à $0,80 \mathrm{~m}$ de diamètre, les poteaux de 0,30 à $0,40 \mathrm{~m}$ (grenier 1 ) et de 0,40 à $0,50 \mathrm{~m}$ (grenier 2). Un clayonnage formant une clôture (?) est observć sur lc côtć nord (951); de 0,10 à $0,15 \mathrm{~m}$ de large pour $0,10 \mathrm{~m}$ de profondeur, celui-ci montre un profil hémispérique, au fond duquel s'individualisent quelques piquets (diam. : 0,06 à $0,08 \mathrm{~m})$.

D'autres vestiges s'organisent autour de ces derniers et signalent une évolution de l'occupation. Deux modestes 


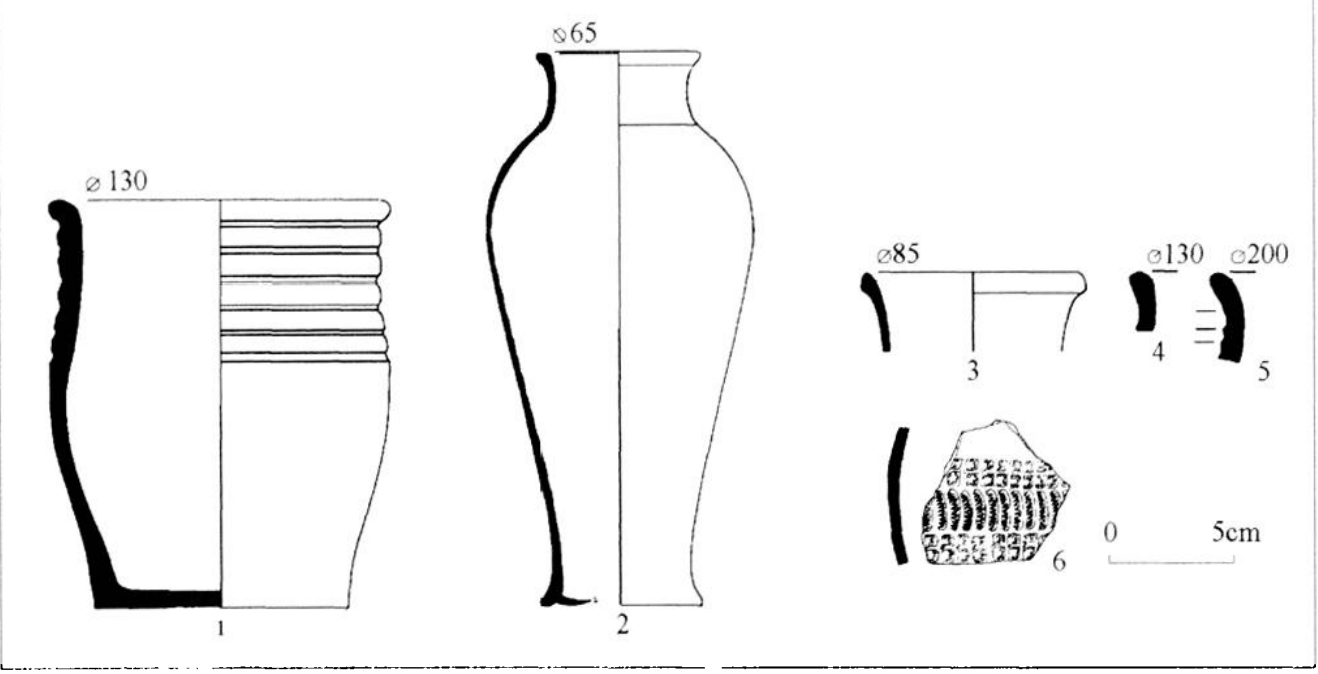

Fig. 10. (1) céramique commune sombre issue de la mare 867, (2) céramique peinte issue du trou de poteau 532, (3-6) céramiques communes sombres issues du trou de poteau 520.

foyers se superposent en effet au grenier 1; leur présence paraît incompatible avec les supports en bois de l'édifice. Deux silos ont été excavés autour du grenier 2. Le silo 517 (diam. : 1,2 m) recoupe l'un des poteaux du grenier 2 matérialisant ainsi une phase postérieure à l'édifice. Des comblements limoneux bruns se succèdent, stériles, alors que les derniers recueillent les restes d'un foyer. Le second silo (st 506 : diam. : 0,80 à $0,90 \mathrm{~m}$, prof. : $0,70 \mathrm{~m}$ ) est un dolium enterré. Quelques fragments de panse mêlés au comblement de fond sont suivis du dépôt tête-bêche du bord et du haut de panse. La fosse, une fois comblée à plus des trois quarts, a finalement accueilli un foyer.

Le grenier 3, en revanche, montre des supports plus légers de 0,15 à $0,20 \mathrm{~m}$ de diamètre. Son petit côté nord présente les traces d'un négatif de paroi qui laisse supposer l'existence d'un avant-corps de bâtiment (952). A l'ouest, de nombreux trous de poteaux et de piquets sont encore non interprétés; un troisième négatif de paroi y est relevé et n'a pu être associé à aucun bâti (953). La fonction de la fosse 96 , située au centre du grenier, est difficilement identifiable : d'un diamètre appréciable $(1,70 \mathrm{~m})$, elle atteint les $45 \mathrm{~cm}$ de profondeur; son comblement homogène brun gris et la rareté du matériel ne permettent pas d'avancer d'hypothèse valable.

\section{Le groupe est}

Les deux autres édifices sont de plus petits modules et s'iso-

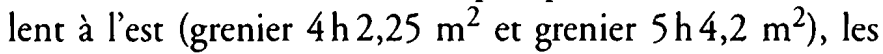
diamètres des poteaux et les profondeurs ne dépassant pas les $0,25 \mathrm{~m}$.

Entre les deux groupes, on remarque 2 aires empierrées et une fosse.
Les deux aires empierrées 594 (L : 2,2 m, larg. : 1,6 m) et 549 (long. : $2,9 \mathrm{~m}$, larg. : $1,5 \mathrm{~m}$ ), profondes d'une quinzaine de centimètres, ont été utilisées concomitement (on note plusieurs recollages de vases entre elles) (fig. 11.). Une fosse ovale, 601, de faible dimension et d'une quinzaine de centimètres de profondeur, a révélé un unique niveau brun comportant plusieurs fragments de meule. Leur fonction est à définir.

Les deux aires empierrées (549 et 594) ont fourni à elles seules près de la moitié des vestiges mobiliers recueillis (503 tessons). S'ajoute à cet ensemble cohérent un certain nombre de lots, généralement très restreints, issus de structures diverses plus ou moins isolées, rattachées à cet horizon par leur situation stratigraphique ou les caractéristiques de leur mobilier.

Celui-ci laisse apparaître une certaine homogénéité; dans leur quasi-totalité, les céramiques domestiques s'inscrivent dans la tradition de La Tène finale, dans une séquence chronologique qui couvre le Ier $^{\mathrm{s}}$. av. J.-C. : la céramique commune, pour les deux tiers à pâte grossière ou grise fine, puis la céramique à pâte claire, la céramique peinte et, plus rare, la céramique campanienne. Un certain nombre d'indices morphologiques, comme les cols de vases ovoïdes moulurés, le profil des écuelles, incitent, avec une certaine prudence, à envisager à l'intérieur de cette fourchette une phase plutôt tardive, entre le milieu du siècle et les débuts de la période augustéenne. Les importations semblent confirmer cette hypothèse; campaniennes et olpés à pâte claire ne constituent certes pas des fossiles directeurs très précis, mais la piètre qualité des premières dénote une production déjà décadente (Laroche 1987. Sanial, Ranchon 1977, Perrin 1990, Vaginay 1988 in Frascone, Jacquet, Widlak 1993, p. 3-6).

Plusieurs plaques en fer fragmentées et six fragments de meule ont également été mis au jour dans ce secteur. Les éléments de parure sont nombreux; la fragilité aux chocs de certains d'entre eux sont peut-être la raison de leur présence sur ce secteur de travail. Un petit fragment de bracelet, sectionné 


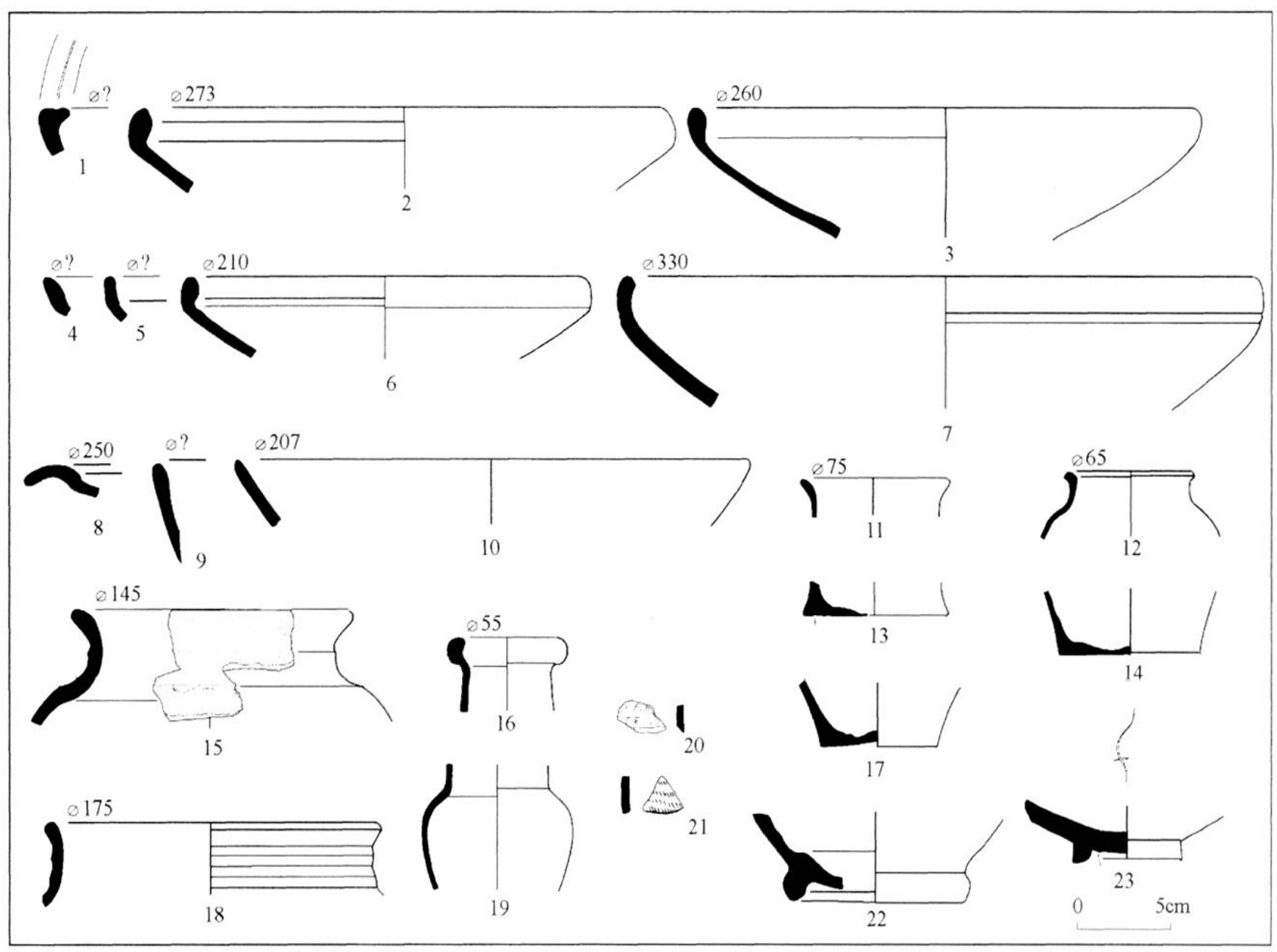

Fig. 11. Mobilier issu des aires empierrées 549 et 594 - céramiques grossières (1, 15, 20 et 21), céramique fine (2-7, 10, 17, 18 et 23), campanienne (8 et 9), céramique peinte (11-14), céramique à pâte claire (16, 19 et 22).

net d'un côté, arraché de l'autre, se compose d'une tôle de bronze enroulée sur un cœur en terre cuite fine noire de section triangulaire. Si la face interne est plate, deux des angles présentent un décor de courtes incisions parallèles; on note de très petits morceaux de tiges du même métal dans ce même secteur. Quatre fragments de bracelets en pâte de verre de couleur pourpre présentent des sections hémisphériques (3) ou triangulaire (1); les diamètres intérieurs sont petits (de $4,5 \mathrm{~cm}$ à $6 \mathrm{~cm}$ ). Une perle (diam. $2,4 \mathrm{~cm}$ ), légèrement irrégulière, offre une couleur ocre fonçé avec de fines torsades jaunes enroulées et prises dans la masse.

Enfin, deux monnaies ont été mises au jour : un potin au sanglier se rapprochant du type des Lingons (1 ${ }^{\text {er }}$ s. av. J.-C. - réf. LT 8319 ou Sch/D 134 (variantes) et un denier cavare (ou allobroge?) (1/er s. av. J.-C. - réf. LT 2895) ${ }^{8}$.

\section{LES ENCLOS NORD}

A $150 \mathrm{~m}$ au nord, des enclos circulaires de petite taille se sont développés sur un même espace ( 475 et 478 : diam. respectifs $1,60 \mathrm{~m}$ et de $2 \mathrm{~m}$ ). Ils sont déterminés par des

(8) Étude M. D. Frascone, AFAN. fossés présentant indifféremment des profils en forme de $\mathrm{U}$ ou de $\mathrm{V}$, de faibles dimensions (larg. : $0,20 \mathrm{~m}$ à $0,30 \mathrm{~m}$, prof. : $0,10 \mathrm{~m}$ à $0,30 \mathrm{~m}$ ) (fig. 12 ).

Un autre enclos (480/483) est d'un module plus important (côtés : $9 \mathrm{~m}$ sur $6 \mathrm{~m}$, larg. : $1 \mathrm{~m}$ à $1,50 \mathrm{~m}$, prof. : $0,60 \mathrm{~m}$ ) et présente un accès sur le nord; l'une des coupes du fossé montre clairement la trace d'un poteau. L'intérieur de l'enclos a été détruit par le creusement de deux larges fosses datées du dernier tiers du $\mathrm{I}^{\text {er }}$ s. av. J.-C. alors que son comblement final a révélé du matériel du $\mathrm{I}^{\mathrm{er}} \mathrm{s}$. av. J.-C.. L'interprétation de l'ensemble en est largement affectée et il est tentant d'y voir des enclos à incinération, mais aucune trace de sépulture n'a pu être observée.

On remarque également la présence d'édifices légers sur pieux qui semblent antérieurs. Deux plans se dessinent : huit pieux de $0,05 \mathrm{~m}$ sont mis au jour à l'extrémité ouest de l'enclos 483 et forme un édifice de $3,40 \mathrm{~m}$ sur $1,90 \mathrm{~m}$; d'autres pieux se retrouvent à l'est des ensembles d'enclos. 


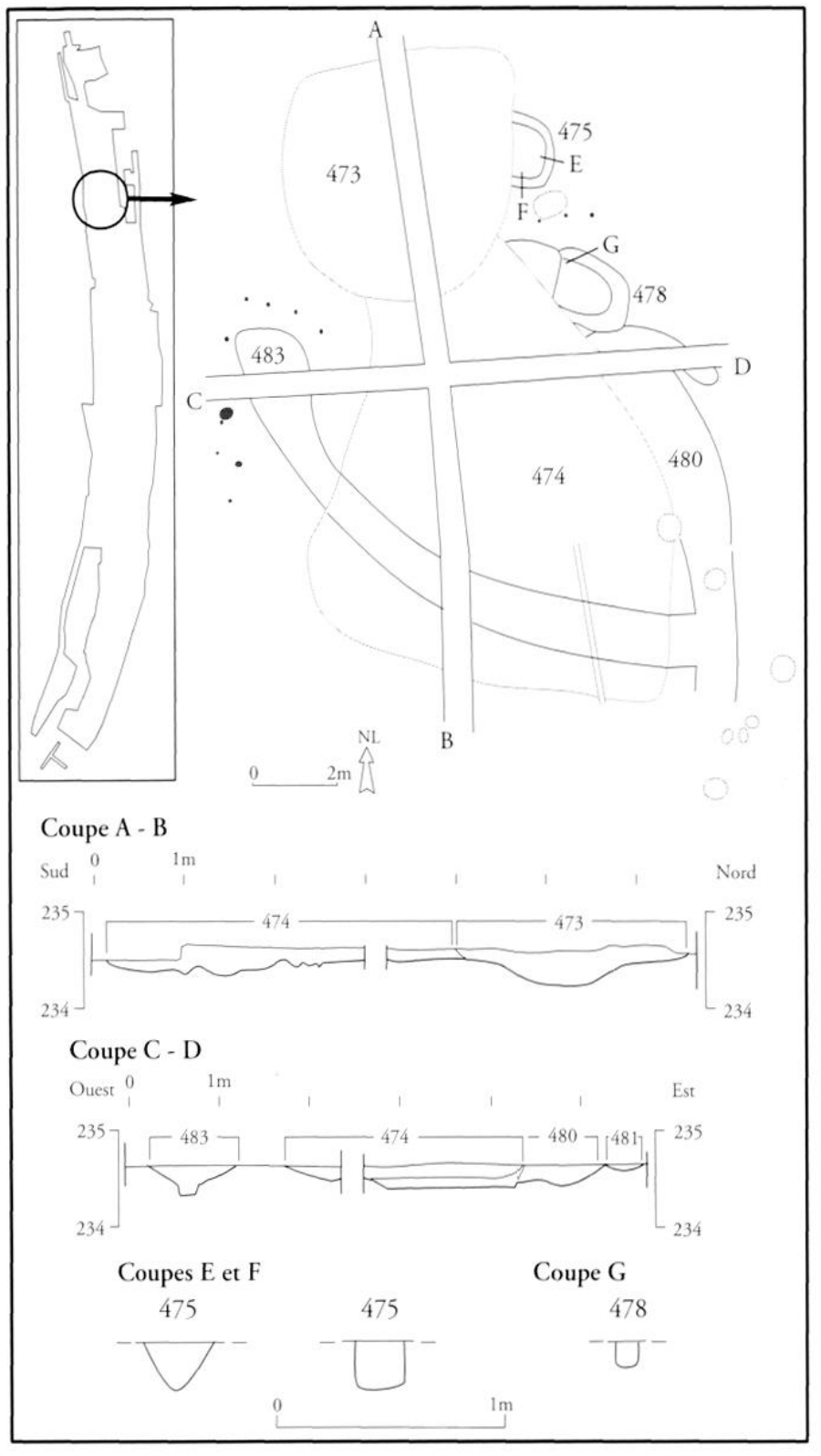

Fig. 12. Les enclos nord (en traits noirs) recoupés par des fosses postérieures (en pointillés).

\section{DES BÂTIMENTS SUR POTEAUX (FIG. 13)}

Au sud, des trous de poteaux de 0,20 à $1 \mathrm{~m}$ de diamètre avec quelques calages de galets en surface se concentrent sur une zone de $35 \mathrm{~m}$ sur $25 \mathrm{~m}$ de côté. Bien que ce secteur n'ait été que décapé et nettoyé, un bon nombre d'alignements paraissent évidents et dessinent des espaces quadrangulaires parmi lesquels un foyer très arasé s'intercale (354). Deux fossés partiellement arasés (316 et 317), forment un enclos immédiatement au sud; ils sont recoupés par des vestiges datés des débuts de notre ère et pourraient être associés à cet ensemble.
Quelques petits tessons de céramique issus du nettoyage des trous de poteaux évoquent une tradition indigène; aucun fragment de tegula n'y a été mis au jour.

Côté sud, les deux fossés 316 et 317 ont permis de collecter d'autres fragments de céramique, dont 2 bords éversés arrondis et un décor digité (316).

\section{UN HABITAT ORIGINAL DU HAUT- EMPIRE (DE LA PÉRIODE AUGUSTÉENNE AU MILIEU DU I ${ }^{\text {er }}$ S. AP. J.-C.)}

A partir de la période augustéenne, les secteurs occupés lors du I ${ }^{\text {er }}$ s. av. notre ère sont abandonnés, alors que de nouvelles installations se développent au nord et au sud (fig. 14). Durant les premières décennies de notre ère, l'expansion semble rapide et simultanée. Des secteurs réservés aux édifices alternent avec des aires plus ouvertes ponctuées d'alignements de trous de poteaux. En dépit de leur éloignement, de nombreuses similitudes se dégagent entre deux groupes d'habitat (l'un au nord, l'autre au pôle sud). où s'associent les même types de vestiges : édifices sur solins, excavations, fours artisanaux, foyers, enclos sur poteaux... Les prospections menées largement au-delà de l'emprise de la rocade ont révélé qu'à peine un tiers du site avait été décapé. La densité de matériel recueilli lors de ces ramassages de surface montre une certaine cohérence avec les observations effectuées lors de la fouille. De fortes concentrations de tuiles ont en effet été observées aux abords des édifices de chaque habitat.

Parallèlement, des zones d'activités métallurgiques s'individualisent autour du groupe nord alors que les prospections pédestres montrent une très importante concentration de scories à l'est des greniers laténiens. Sur l'emprise, deux forges d'ampleur inégale se succèdent, chacune comportant un foyer de forge ainsi qu'une aire de vidange et de travail. Le matériel issu des niveaux d'utilisation se semble pas atteindre la période claudienne dénotant un abandon relativement précoce de cette activité par rapport à l'habitat contemporain.

Les niveaux d'abandon marquant la destruction des édifices sur solins, ont livré de nombreux fragments de meules ainsi qu'un abondant matériel céramique tibéroclaudien. Si l'occupation du site se poursuit au moins pendant les deux siècles suivants (voir $\$ 4$ ), le milieu du premier tiers du $I^{\text {er }} s$. de notre ère montre un arrêt brutal de l'expansion. 


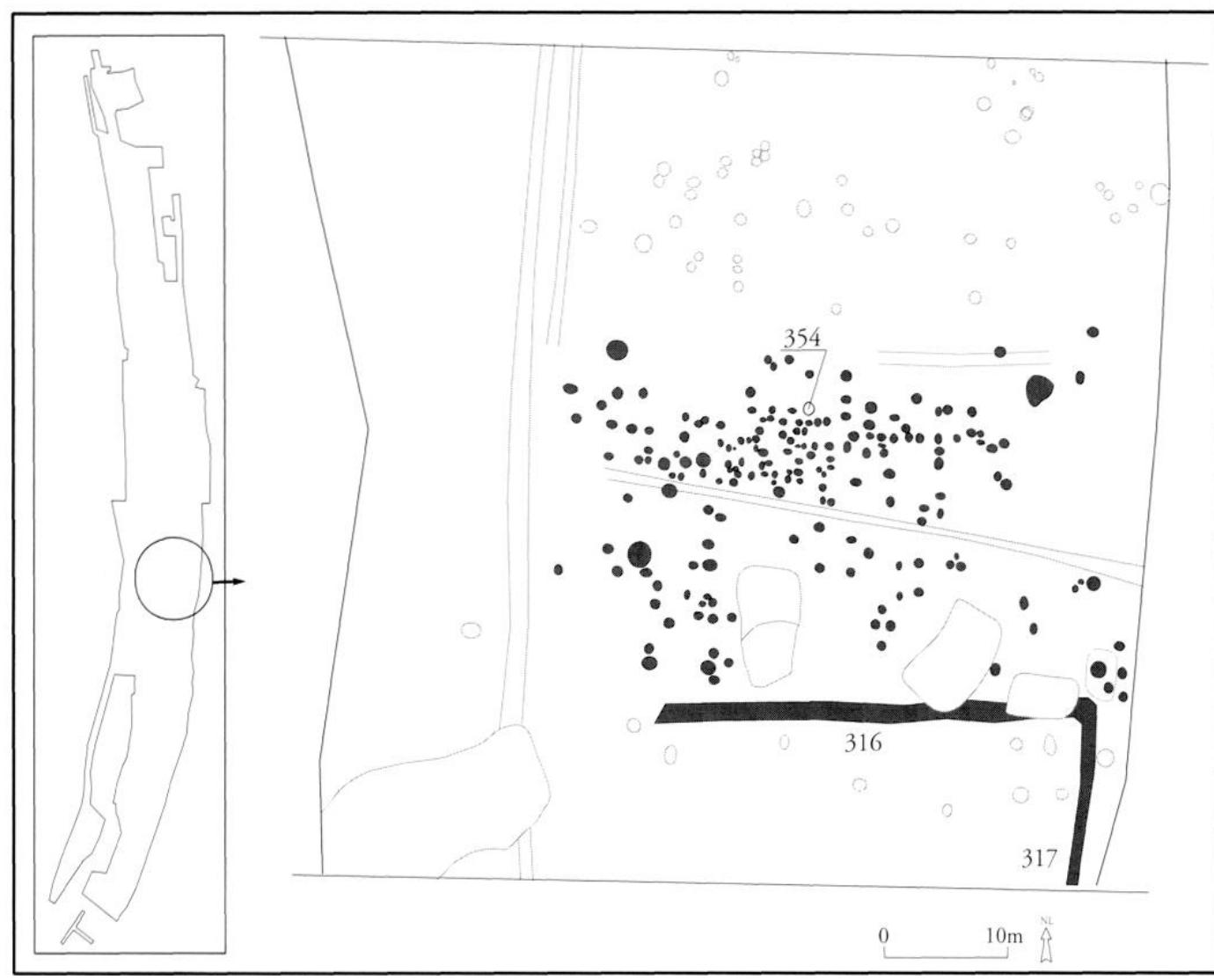

Fig. 13. Les bâtiments

sur poteaux et l'enclos $316 / 317$.

\section{LE GROUPE NORD}

On remarque des traces d'activité sur presque $200 \mathrm{~m}$. Le groupe nord comporte un édifice sur solins (208) bordé de deux fosses oblongues (184 et 195) et un four artisanal (176). Quelques structures annexes, des fosses et de nombreux foyers, se concentrent alentour de ce noyau central. Deux enclos et de longs alignements de poteaux s'étendent vers le nord, prolongeant l'emprise du groupe nord d'une manière plus diffuse. Deux forges (successives?) s'y sont développées au sud; la description et l'analyse de ces vestiges sera développée dans le paragraphe consacré à la métallurgie.

- L'édifice 208 (fig. 15 et 16).

L'édifice 208 est matérialisé par un espace de $5 \mathrm{~m}$ par $6 \mathrm{~m}$, au sol non aménagé, bordé, à l'est et à l'ouest, de deux solins de tegulae brisées (205 et 197).

Leur conservation est inégale; le solin 205 est conservé sur $2 \mathrm{~m}$ de longueur, pour 0,30 $\mathrm{m}$ de large alors que 197 se développe sur une longueur de $6 \mathrm{~m}$. Son extrémité nord est renforcée par un aménagement quadrangulaire (de 1,5 m de côté), composé de tuiles disposées de façon particulièrement soignée pouvant faire penser à un accès. Une fine couche de limon brun jaune contenant du charbon de bois et de la terre cuite couvre la surface ainsi délimitée. Des fragments de tuiles et de céramiques disposés à plat (us 6) confortent l'hypothèse de l'existence d'un niveau de circulation à peine érodé, scellée par un limon argileux verdâtre dû à une stagnation d'eau.
- Les fosses mitoyennes.

Deux fosses oblongues bordent l'édifice 208 à l'est et au sud (184 et 195). Leur situation les associe définitivement à l'édifice bien que leur fonction soit encore à élucider. Bien que de profils similaires, leur comblement differe totalement; leur abandon n'est d'ailleurs pas simultané. Quelle interprétation donner à ces fosses? Une aire de travail pourrait être imaginée (184); l'instabilité du sol face aux intempéries laisse alors supposer une couverture légère qui aurait pu s'appuyer sur l'élévation de 208. La raison d'être de la fosse 195 reste tout aussi obscure (fosse d'extraction pour la construction de l'édifice 208 ou pour les foyers de forge successifs situés à proximité immédiate, puis assainissement du côté sud de 208 ?). L'épaisse couche charbonneuse pourrait, peut-être, être interprétée comme un dépotoir lié à l'utilisation du foyer de forge. L'absence de tuiles à tous les niveaux du comblement semble indiquer un abandon antérieur à celui de l'ensemble 184-208.

L'excavation aménagée 184 : la fouille a révélé une structure de forme ovale, orientée nord-sud (long. : $5 \mathrm{~m}$, larg. : 3,50 m, prof. : $0,50 \mathrm{~m}$ ). Un fond plat et des bords marqués ouvrent au nord sur une pente nettement adoucie. Bien qu'aucun trou de poteau n'y ait été observé, le fond révèle un calage de petits galets et de tuiles situé sur le côté sud. De même, sur la partie médiane, on observe un limon gris homogène, très compact, avec de petits fragments de tuiles, des galets et du charbon de 


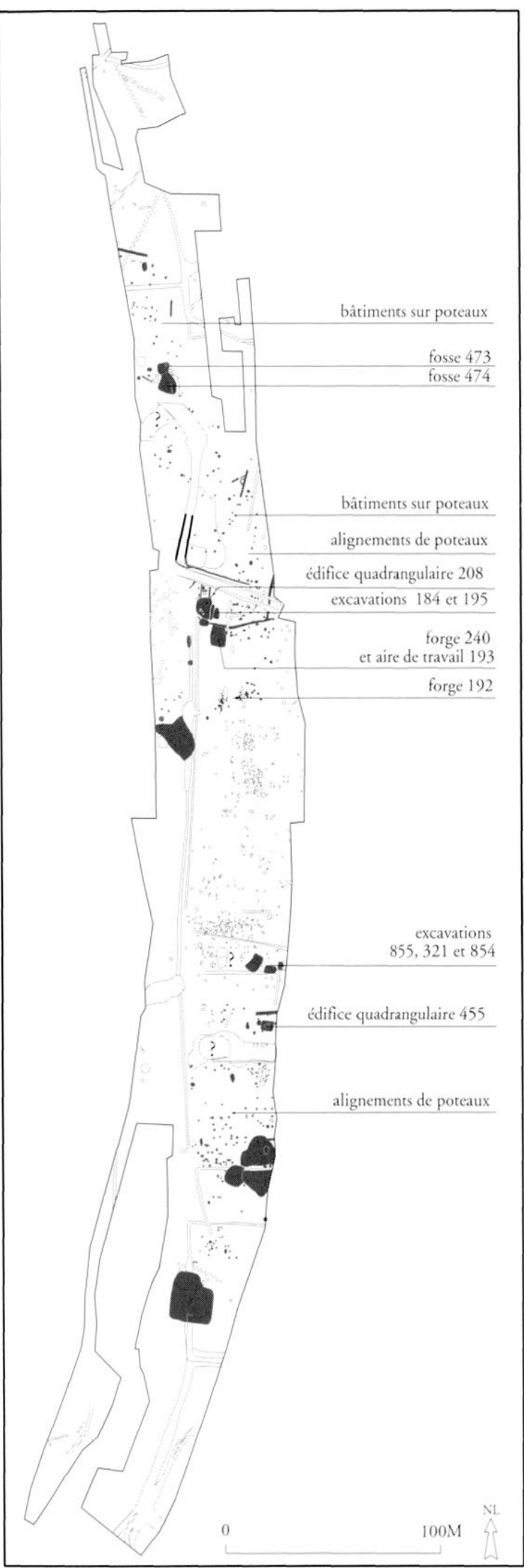

Fig. 14. Plan synthétique des occupations de l'époque augustéenne jusqu'au milieu $d u I^{r}$ s. de notre ère. bois (us 3). La fosse semble ainsi être restée sufisamment ouverte pour accueillir un niveau de circulation.

Lors de la phase d'abandon, un comblement épais présente des petits fragments de tuiles, de nombreux petits galets et quelques gros blocs (us 5), éléments absents du sous-sol à cet endroit. On peut supposer que le nombre et l'homogénéité de ces éléments soient les reliquats non solubles de l'effondrement d'une élévation en matériaux périssables (celle de 208 ?). Des dizaines de tuiles fragmentées colmatent l'ensemble et débordent du creusement sur 208. Il s'agit ici du niveau de destruction d'une toiture, probablement celle de 208 (voir § 4).

La fosse 195 : une autre fosse (195), de plan ovale, à fond plat, a été observée le long du bord sud de l'édifice 208 (long. : 4,25 m, larg. : 3,5 m, prof. : 0,45 m). Le glissement des bords précède une couche de charbon de bois très importante, assez compacte, accompagnée de cendres et de quelques scories. Les couches marquant l'abandon de la structure témoignent d'un phénomène de sédimentation due à l'eau.

Hors couche de destruction, on note un matériel céramique fragmenté, encore très marqué par les traditions indigènes : des cèramiques semi-fine ou plus grossière à lèvre éversé, à décor côtelé, ou lissé, un fragment de campanienne $B$, mais également de la céramique commune claire et un tesson de sigillée de la Graufesenque.

- Le four 176.

Le four 176 se situe à quelques mètres à l'est de l'édifice $208^{9}$. Aucune trace de chauffe n'a été observée : ce four semble n'avoir jamais servi... Le laboratoire et la chambre de chauffe sont construits avec des fragments de tuiles empilés, liés à l'argile et plaqués contre le loess préalablement excavé (fig. 17 et 18). L'épaisseur des parois n'excède pas $12 \mathrm{~cm}$; soignée, l'élévation est faite d'assises de tegulae et d'imbrices brisées. L'ouvrage devient moins régulier à $0,30 \mathrm{~m}$ du fond où plusieurs tuiles sont saillantes. C'est à ce niveau, correspondant à la partie supérieure de l'ouverture de l'alandier, que se situe l'emplacement de la sole. Lalandier repose sur deux jambages de tuiles empilées, tandis que deux tegulae entières forment le linteau. Une autre tegula, qui tapisse le sol entre les piédroits, devait faciliter l'enfournement du combustible. La fosse, quant à elle, descend en pente douce face à cette ouverture, tandis que ses parois latérales sont plus abruptes.

Les comblements sont identiques dans les deux parties $\mathrm{du}$ four : les apports volontaires, avec de larges fragments de tuiles et d'amphores, alternent avec des couches d'accumulation ou d'effondrement des parois (limons clairs, sable, fines couches de charbon (us 2, 6).

(9) Long. : 2,70 m, diam. laboratoire : 0,6 m, prof. : $0,7 \mathrm{~m}$,/fosse : long. : $1,2 \mathrm{~m}$, larg. : 0,9 m, prof. : $0,75 \mathrm{~m}$. 


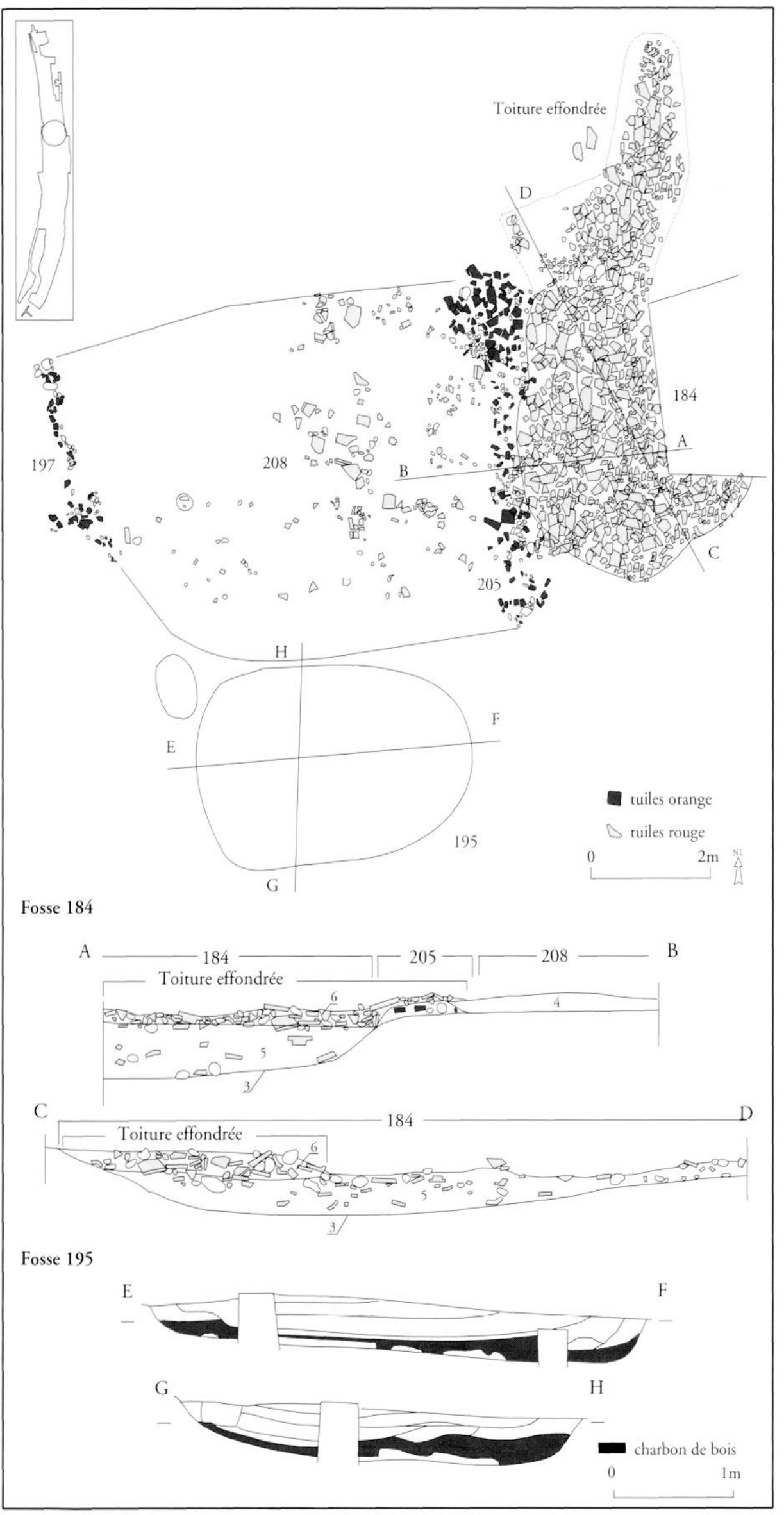

Fig. 15. L'édifice 208 bordé des excavations 184 et 195 . 


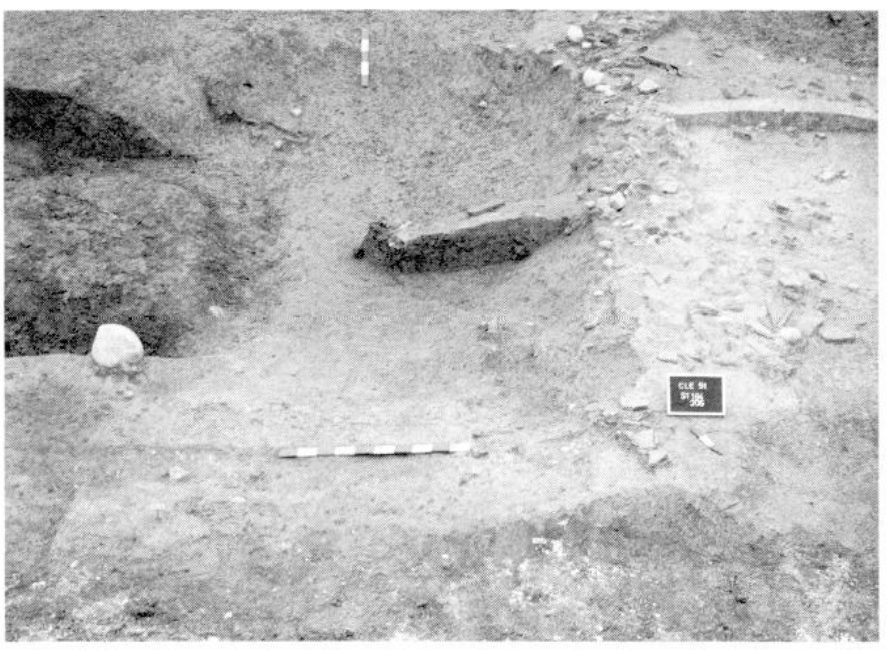

Fig. 16. Excavation 184 après fouilles, le solin de l'édifice 208 est à droite.

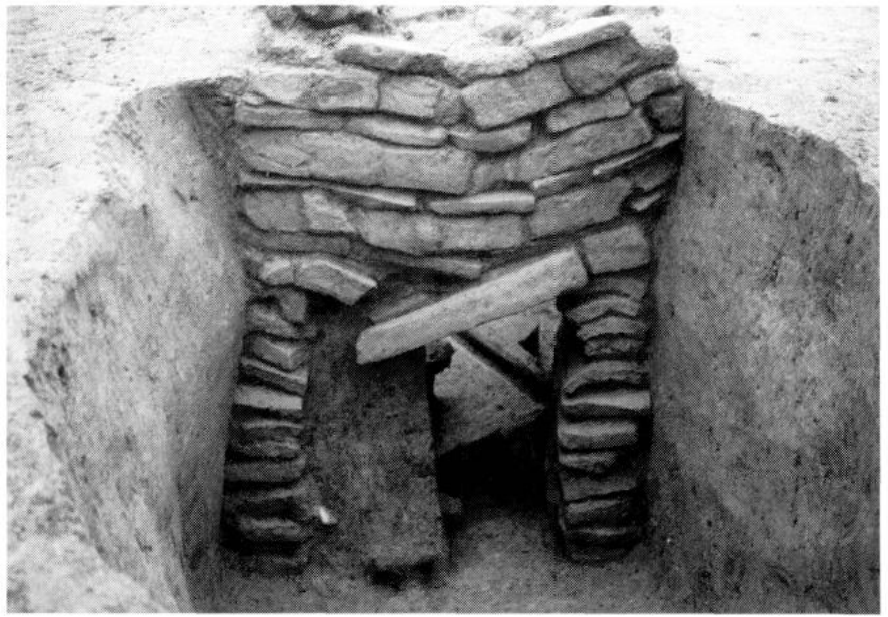

Fig. 18. Four 176 a : alandier, détail.

- Les foyers et petites fosses indéterminées.

Une trentaine de foyers et quelques petites fosses indéterminées, ont été observés autour du groupe nord ${ }^{10}$ (fig. 19). La majeure partie se trouve aux abords de l'édifice 208, alors que quelques autres sont plus isolés au nord. Les foyers sont de simples cuvettes de plan souvent quadrangulaire, à peine rubéfiées, qui ne semblent remplir aucune fonction artisanale.

En ce qui concerne les foyers, les côtés varient de $1,30 \mathrm{~m}$ à $0,40 \mathrm{~m}$, pour des profondeurs de $0,05 \mathrm{~m}$ à $0,25 \mathrm{~m}$; les fonds sont plats et les parois évasées. Les comblements bruns ont parfois permis de recueillir des fibres de charbon de bois, qui constituent la majorité des prélèvements anthracologiques

(10) Certains vestiges présentés ici (foyers et plus loin trous de poteaux) pourraient, individuellement, être postérieurs à la période considérée; un grand nombre d'entre eux, regroupés aurour des édifices du $\mathrm{I}^{\mathrm{er}} \mathrm{s}$., semble néanmoins accompagner la brusque croissance des habitats.

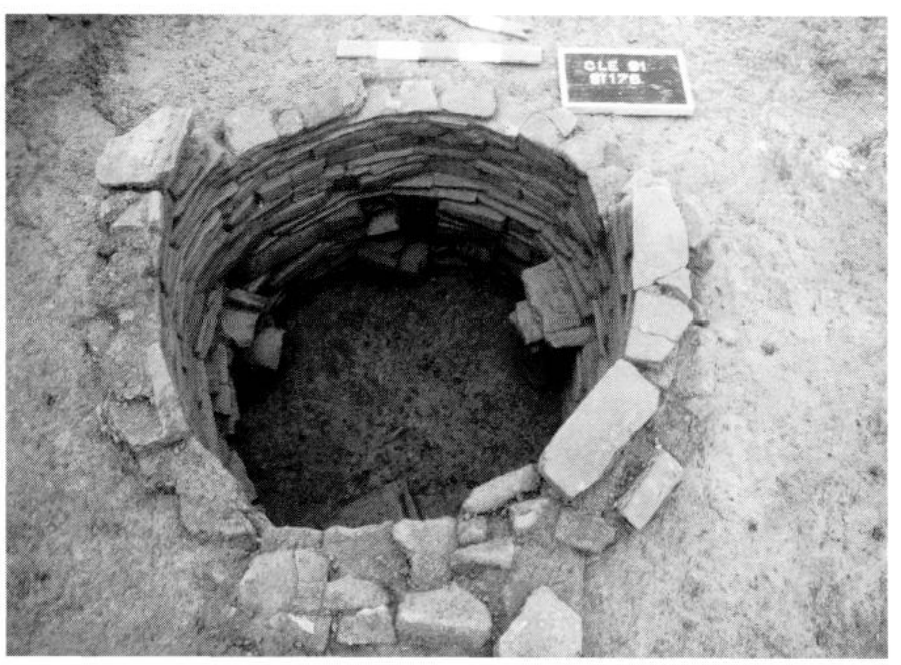

Fig. 17. Four 176 : laboratoire, détail.

analysés. Trois fosses, de $0,60 \mathrm{~m}$ à $1,90 \mathrm{~m}$ de côté, peu profondes (de $0,10 \mathrm{~m}$ à $0,25 \mathrm{~m}$ ), à fond plat, ont révélé des comblements de limon brun avec des inclusions de charbon de bois, de la terre cuite, de petits galets et de quelques scories.

- Fossés d'enclos et palissades.

Un enclos et plusieurs ensembles de trous de poteaux, certains s'organisant en de long alignements, d'autres formant des bâtiments, s'étendent vers le nord. Leur extension nord semble limitée par le fossé 18 alors que leur orientation est similaire à celle observée sur le réseau de fossés incliné à $17^{\circ}$ Est (fig. 20).

Un enclos limité par des fossés (183 : larg. max. : $1 \mathrm{~m}$, prof. : $0,35 \mathrm{~m}$ ) dessine un espace qui inclut l'édifice 208 , la fosse 184 ainsi que plusieurs foyers; il exclut en revanche la fosse 195 et l'activité métallurgique. Le petit côté nord-sud se connecte sur la branche est-ouest $2 \mathrm{~m}$ avant l'extrémité orientale de ce dernier.

Le comblement de ce fossé, composé d'un limon fin, brun jaune, contenant de nombreuses inclusions, révèle des céramiques communes sombres de pâte de tradition indigène, à bords éversés, des céramiques communes claires, dont un mortier à lèvre pendante, ainsi qu'une petite barre en bronze de section rectangulaire $(L: 5,4 \mathrm{~cm})$ et des scories.

Des alignements ou des bâtiments se dessinent. Ces restitutions, basées soit sur des suites évidentes de vestiges alignés selon un espacement régulier, soit sur des blocages identiques, n'offrent pas d'arguments chronologiques; certains d'entre eux peuvent donc être postérieurs à la première moitié du $\mathrm{I}^{\mathrm{er}} \mathrm{s}$. de notre ère.

Du sud au nord, on note de longs alignements dont nous n'avons le plus souvent que deux des côtés sur 9 à $20 \mathrm{~m}$ de longueur (1 et 2), ainsi qu'un petit édifice à quatre poteaux, 


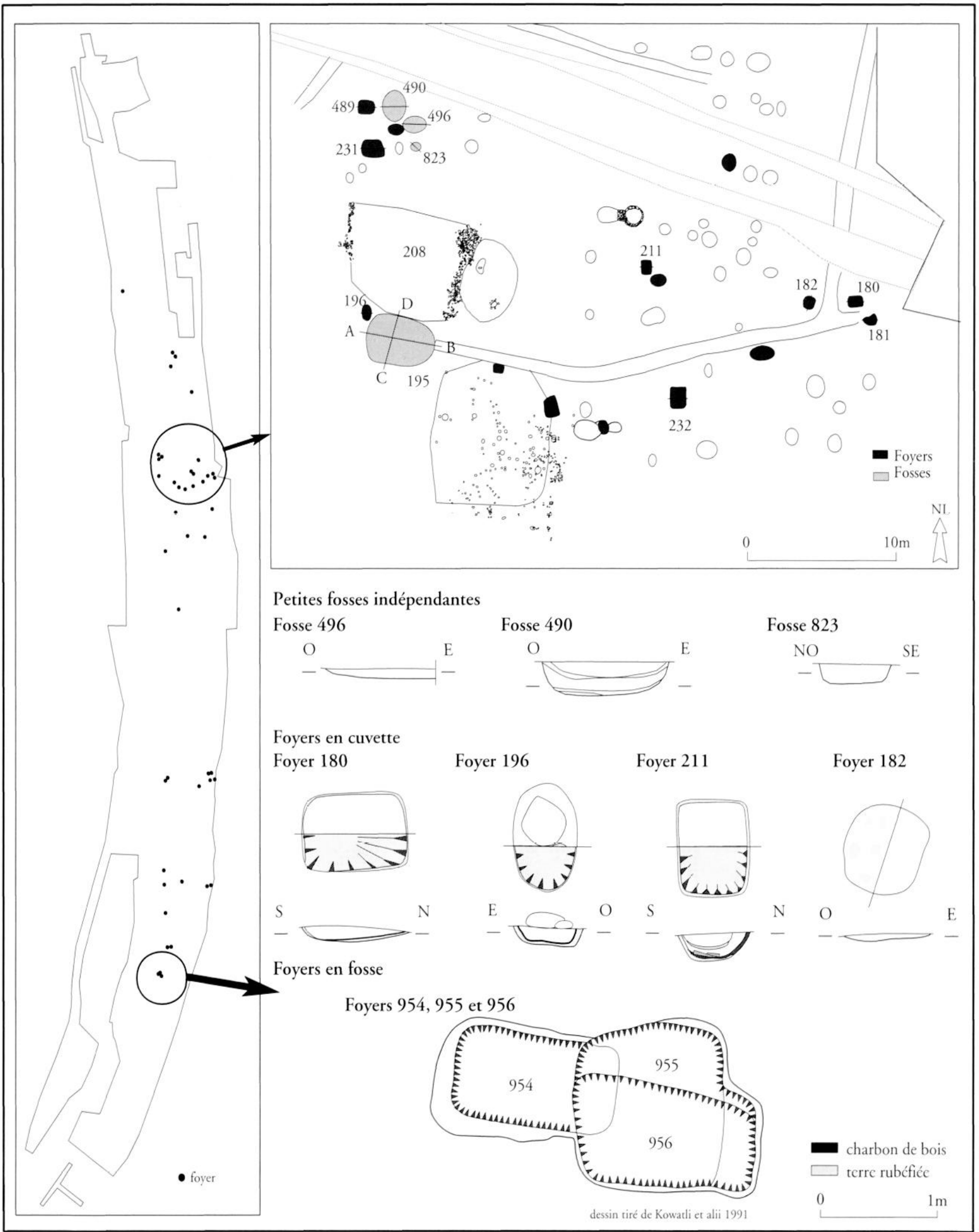

Fig. 19. Exemples de fosses et de foyers. 


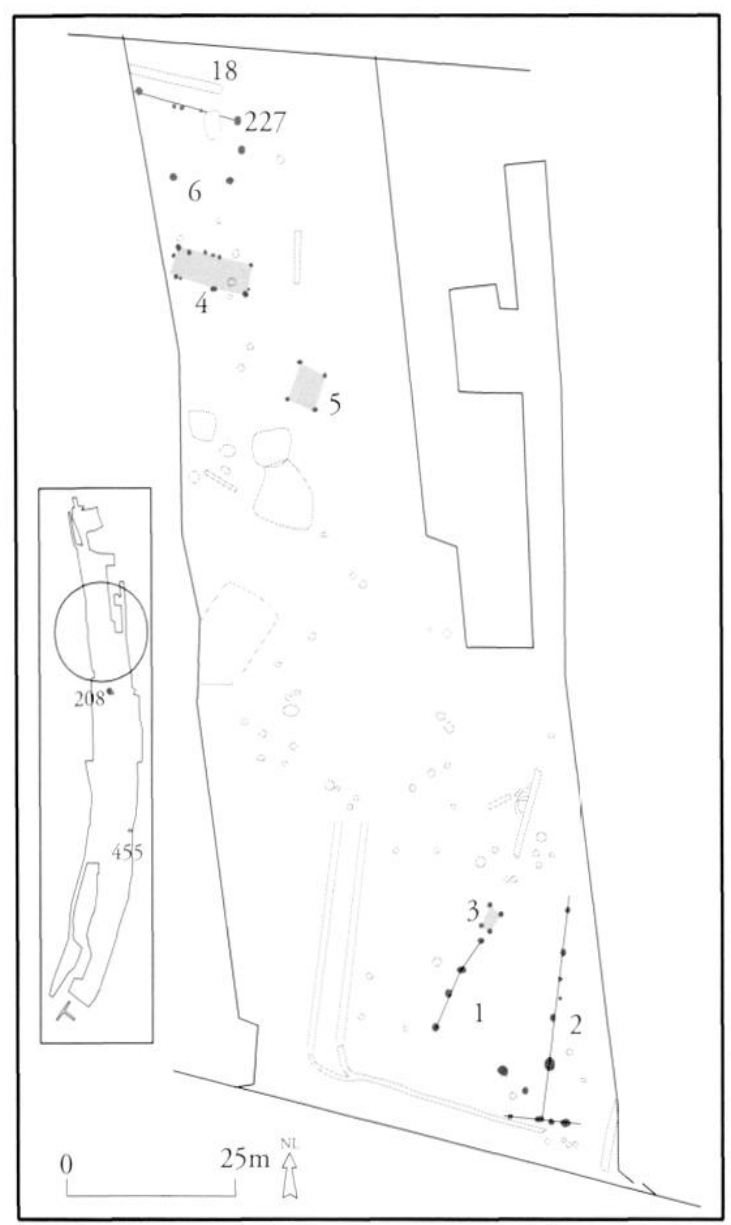

Fig. 20. Secteur nord, proposition de restitution des alignements de poteaux.

de $3 \mathrm{~m}$ sur 1,5 m (3). Les creusements sont souvent très peu nets, surtout matérialisés par des calages de surface, composés de galets et de fragments de tegulae. Le matériel céramique est rare et seul les trous de poteaux de l'alignement 2 ont livré quelques fragments de sigillées (106: Drag. 24/25).

Plus au nord encore, 17 poteaux dessinent un édifice de $10 \mathrm{~m}$ sur $4 \mathrm{~m}$; les diamètres des poteaux varient de $0,10 \mathrm{~m}$ à $0,80 \mathrm{~m}$, les plus larges étant placés aux angles (4). Près de là, un édifice quadrangulaire à 4 poteaux fait suite, selon la même orientation ( 5 : côtés de $5,50 \mathrm{~m}$ sur $4,50 \mathrm{~m}$ ).

Le fossé $18 \mathrm{~s}$ 'étend sur $15 \mathrm{~m}$ de long (larg. : $1 \mathrm{~m}$, prof. : 0,3 m); il est doublé au sud par un alignement de 5 poteaux (6). L'un des poteaux tient une place à part : sur le fond de ce dernier, une tegula entière et incurvée tient lieu de fond de calage (227 : long. : 1,10 m, larg. : 0,80 m, prof. : 0,25 m). Deux fragments d'une autre tegula sont disposés de chant sur les bords du creusement.

\section{LE GROUPE SUD}

A une centaine de mètres vers le sud, s'est développée une seconde zone d'habitat mise au jour sur près de $100 \mathrm{~m}$. La fouille a révélé de nombreuses similitudes avec la zone nord. On y relève tout d'abord un édifice quadrangulaire bâti sur solin (455) bordé d'un four artisanal identique à celui du groupe nord (458); un second four, de type différent, est observé plus à l'ouest (468). Trois larges fosses de plans rectangulaires s'isolent à peu de distance vers le nord, à la différence de celles du groupe nord, mitoyennes à l'édifice 208. Dernière similitude, de nombreux foyers et quelques petites fosses sont implantés aux abords de l'édifice 455 , alors que de longs alignements de poteaux s'étendent vers le sud.

- L'édifice 455 (long. : 4,50 m, larg. : 3,30 m) dont les élévations s'appuyaient sur des solins de petits galets et de tuiles fragmentées, présente un profil incurvé. Un limon argileux vert très compact, auquel se mêlent du gravier et de petits fragments de tuiles (us 2), tapisse le fond de la structure et semble proche du niveau de circulation. Deux fosses, l'une intérieure (808), l'autre extérieure (811), lui sont associées mais restent non interprétées (stockage, aire de battage,... ?) (fig. 21 et 22).

Plusieurs dépôts limoneux engorgent peu à peu l'intérieur de l'édifice, dont un dernier niveau brun vert qui témoigne d'une stagnation de l'eau (us 3,4,6). C'est le même phénomène d'engorgement progressif que l'on observe sur la fosse 808 , dont le fonctionnement simultané avec 455 ne fait aucun doute. La toiture effondrée colmatera l'ensemble (voir § 4).

La grande majorité du matériel issu des niveaux inférieurs de 455 présente un faciès caractéristique de la période augustéenne (us 2 et 4). Seules deux productions, une sigillée sudgauloise et une cruche à lèvre moulurée en commune claire, laissent entrevoir un contexte un peu plus récent, probablement de la fin du principat d'Auguste, ou même du début du règne de Tibère. Ce lot se compose majoritairement de céramiques communes. Deux groupes typologiques se distinguent. On note un groupe à pâte siliceuse fine et dégraissant presque invisible à l'œil nu, cuite en mode B. Les surfaces sont souvent lissées, les teintes varient de gris-clair à noire. Cette catégorie présente surtout des vases ouverts et des couvercles. Le second groupe se compose d'une pâte grossière, d'aspect sableux contenant un abondant dégraissant composé de cristaux de quartz et souvent de mica. Les surfaces proposent une grande variété de teintes.

Parmi les vases hauts et fermés en commune sombre à pâte grossière $(82,7 \%$ des tessons), on note des vases à col tronconique lissé ou des vases ovoïdes à col mouluré et lèvre évasée en bourrelet ainsi que l'apparition des vases ovoïdes carénés. Le répertoire de formes ouvertes se compose d'écuelles et de grandes jattes, héritages de la tradition gauloise. La céramique claire $(7,7 \%)$, les amphores (dont 2 Haltern 70 ) et les dolia $(7 \%)$, les céramiques fines $(1,7 \%$, dont 1 terra nigra, des bols de Roanne) complètent l'ensemble (Desbat et alii 1979, Desbat et alii 1989, Genin 1986, Godart 1992, Laroche 1987, Perrin 1976, Perrin 1990, Vaginay 1988 in Frascone, Jacquet, Widlak 1993, p. 8-9). 


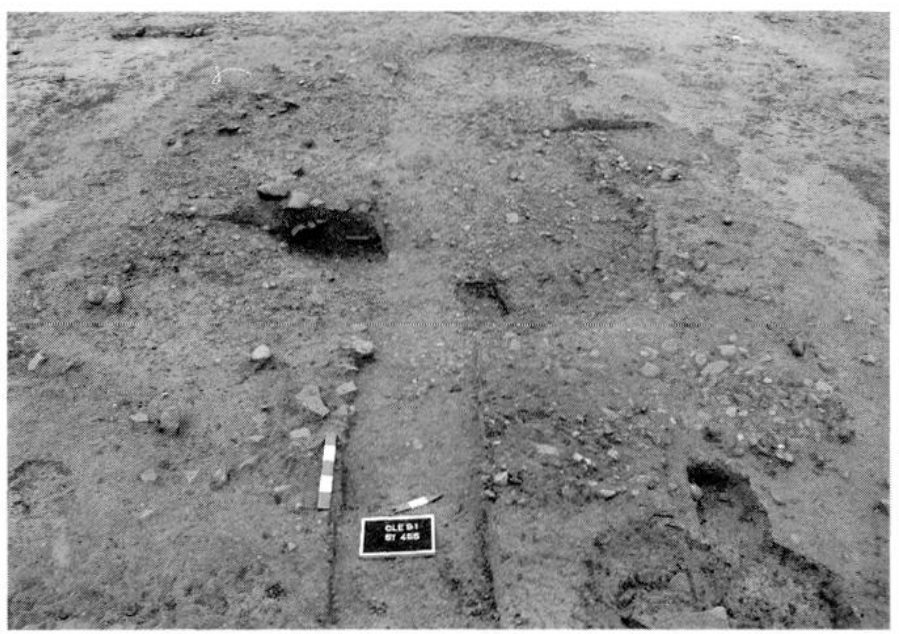

Fig. 21. Edifice 455, après fouille; niveau de sol incluant la dépression centrale, enclavé de solins, surtout visibles au premier plan et à droite.

- Les fours artisanaux.

Deux fours artisanaux se trouvent à proximité. L'un se situe sur le côté ouest de l'édifice $455^{11}$ (fig. 23) et ses parois ne sont conservées que sur trois à quatre assises de hauteur. Malgré une moindre conservation, sa structure générale est en tous points identique à celle du four du groupe nord, alors que quelques détails montrent des choix techniques différents entre les deux vestiges. Le côté sud qui porte encore des traces de fumigation démontre en revanche que celui-ci a été utilisé. L'autre est un four trilobé très arasé et de petite taille (458), situé à $40 \mathrm{~m}$ au sud-ouest, masqué par un radier postérieur, et dont la présence à proximité de l'occupation du $\mathrm{I}^{\text {er }}$ s. ap. J.-C. est mal appréhendée (fig. 24 et 25).

468 : La base four présente encore quelques tuiles très fortement chauffées, irrégulièrement disposées et empilées de manière à pouvoir supporter une sole. Le fond est encore recouvert par une couche de charbon de bois que l'on retrouve, plus épaisse, sur le fond de la fosse d'enfournement. Sur la moitié nord de la chambre de chauffe, le parement a disparu et seules les faces internes de l'alandier sont conservées; les négatifs de parois permettent d'y observer un léger creusement qui pourrait laisser supposer l'existence d'un bloc de pierre formant une partie du jambage. Détail remarquable, l'emploi de tuiles à gros dégraissant calcaire a également, et seulement, été observé dans les niveaux de destruction de la toiture l'édifice 455 . Le rare mobilier recueilli semble dater son abandon dans le courant du ler s. ap. J.-C. : tessons de céramique à décor côtelé et fragments de sigillée de La Graufesenque.

458 : Entre des bords fortement rubéfiès, deux supports de sole parallèles s'avancent en éperons jusqu'au centre de la structure. Sa destruction semble être due à un feu trop vio-

(11) Long. : 3,35 m, diam. laboratoire : 1,25 m/fosse : diam. : 1,2 m, prof. : $0,3 \mathrm{~m}$. lent, ses niveaux d'abandon, très charbonneux, ont révélé de nombreux fragments de terre cuite imbriqués les uns dans les autres. Le matériel, rare, s'intègre néanmoins dans un contexte $\mathrm{I}^{\mathrm{er}} \mathrm{s}$. : un tesson de céramique commune claire et 3 tessons de céramique commune sombre à pâte grossière, dont 2 décors côtelés.

- Des « excavations aménagées ".

Ces 3 excavations $(855,321,854)$ ont été observées à une dizaine de mètres au nord de l'édifice 455 , sur l'enclos $316 / 317^{12}$. Les deux premières ont été recoupées à la pelle mécanique révélant des profils réguliers en auge à bords droits et des fonds plats réguliers tapissés pour l'une d'une fine couche verdâtre hydromorphe, pour l'autre d'une couche brune charbonneuse peu épaisse. Quels rôles attribuer à ces vestiges? A l'observation des profils, sont à rejeter l'extraction de matériau, le dépotoir ou le silo. La fouille, trop rapide, n'a pas permis de constater ou d'infirmer la présence de poteaux. En l'absence d'autres pistes, l'hypothèse de constructions semi-enterrées ou de vides sanitaires a été émise.

Parmi les limons de comblement brun foncé, on note un matériel céramique de tradition indigène (céramique commune sombre, dont un décor côtelé, et de la commune claire), associé à la présence de tegulae. Un peson, grossièrement taillé à partir d'une tuile, provient du dernier niveau de 855 (diam. : $6,5 \mathrm{~cm}$, perf. : $1,5 \mathrm{~cm}$ de diam.).

- Les fosses et les foyers.

Une quinzaine de foyers, aux profils identiques à ceux mentionnés sur la zone nord, et 7 petites fosses non interprćtćcs sont obscrvćs sur lc groupe sud, souvent autour de l'édifice 455 et de ses annexes (four et fosses). Toutefois, un ensemble de structures rubéfiées situées plus au sud differe : trois foyers en fosse se recoupent et présentent des dimensions plus importantes (long. : de 1,3 à 1,6 m, larg. : 0,70 à $0,80 \mathrm{~m}$, prof. de 0,20 à $0,60 \mathrm{~m}$ ).

- Fossé et alignements de poteaux.

Un seul fossé, arasé sur son extrémité ouest, s'insère parmi les structures de cette période (456). A l'instar du fossé d'enclos 183 bordant l'édifice 208, celui-ci longe le côté nord de l'édifice 455 sur une longueur de $8 \mathrm{~m}$ (larg. : 0,8 m, prof. : $0,35 \mathrm{~m}$ ). De même, au sud de l'édifice 455 , on observe plusieurs zones de trous de poteaux matérialisant l'extension de l'emprise humaine bien au-delà du noyau formé par 455. Les alignements qui peuvent être restitués suivent l'axe nord-sud adopté par le groupe sud (1 et 2) (fig. 26).

(12) 855 : long. : $6 \mathrm{~m}$, larg. : $3 \mathrm{~m}$, prof. : $0,35 \mathrm{~m} ; 321$ : long. : $8 \mathrm{~m}$, larg. : $5 \mathrm{~m}$, prof. : $0,35 \mathrm{~m}$ et 854 : long. : $3 \mathrm{~m}$, larg. : $2 \mathrm{~m}$, prof. : non fouillé. 


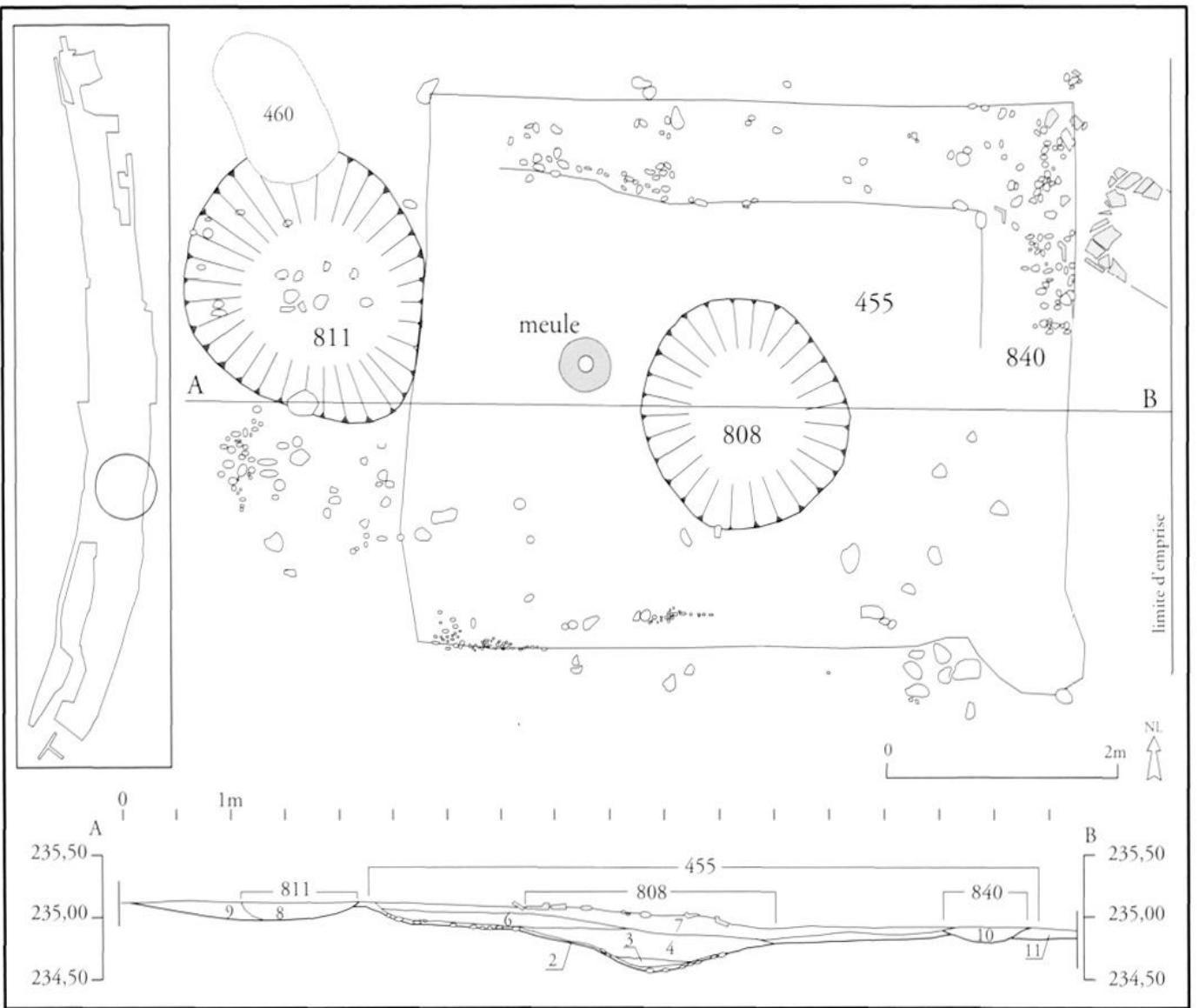

Fig. 22. Le sol 455 et les fosses 808 et 811 .

Le fossé 456 a révélé un fragment en verre millefiori, petit élément circulaire aux faces aplaties, divisé par une fine rainure dans le sens de la hauteur. Cette pièce s'apparente au verre mosaïqué daté des derniers siècles avant notre ère. Des exemplaires similaires représentant des masques inspirés du théâtre grec ornaient meubles ou architectures dans le bassin méditerranéen, où un visage féminin a été daté du $1^{\mathrm{er}} \mathrm{s}$. av. J.-C. (non ill.) (Essautier 1993).

Son décor, visible sur les deux faces, a retenu notre attention : si le pourtour est composé de deux cercles concentriques rouge puis vert, l'intérieur révéle un visage pris dans la masse même, puisque visible aussi sur toute l'épaisseur. On y distingue la bouche cernée de rouge, les ailes du nez, les yeux, pupilles et sourcils, les mèches de cheveux noirs; ce visage semble avoir été composé par la juxtaposition de fines lamelles de pâte de verre, ocre blanches pour la peau et noires pour les traits (exceptés la bouche et le bas du visage, cerclés de rouge). L'une des faces a été polie pour obtenir un aspect tout à fait lisse.

Un morceau de granite rosé (long. $24 \mathrm{~cm}$, côtés de $9 \mathrm{~cm}$ en moyenne) offre un profil ovoïde irrégulier et présente deux faces lissées (broyeur?).

\section{LA FORGE}

L'analyse des données de fouilles a permis d'identifier une activité métallurgique en plusieurs points du site
(Dieudonné-Glad 1993) ${ }^{13}$. Deux forges d'ampleur différente ont ainsi été mises au jour au sud de l'édifice 208, chacune comportant des aménagements sur pieux associés à des dépotoirs et un foyer de forge. Plus loin, en limite nord de l'aire d'occupation humaine, une large fosse (473) a recueilli de nombreuses scories. Elle matérialise peut-être une autre zone d'activité métallurgique dont les témoins nous échappent (hors emprise?).

Les vestiges qui peuvent être associés à cette activité sont de plusieurs types : ceux directement liés au processus chimique et physique de la métallurgie, les scories et les battitures, et ceux liés aux structures artisanales comme les parois de four en place, qui donnent la possibilité de préciser la localisation de l'atelier sur le site. Les scories recueillies à Chassieu sont des scories de fer, mais ne sont pas du type " scories lourdes coulées", caractéristiques de la transformation du minerai en métal. L'absence quasi totale de scories de type "réduction ", mais la présence abondante de "fonds de four ", de parois vitrifiées, ainsi que de battitures évoquent plutôt une activité de forge.

Les occupants de cet habitat ne pratiquaient donc pas la métallurgie primaire, consistant à extraire le fer de son minerai.

(13) Cette partie est une synthèse des données de fouille collectées par l'équipe sur le terrain et de l'interprétation et l'analyse des vestiges proposées par Mme Nadine Dieudonné-Glad (Dieudonné-Glad 1993). 


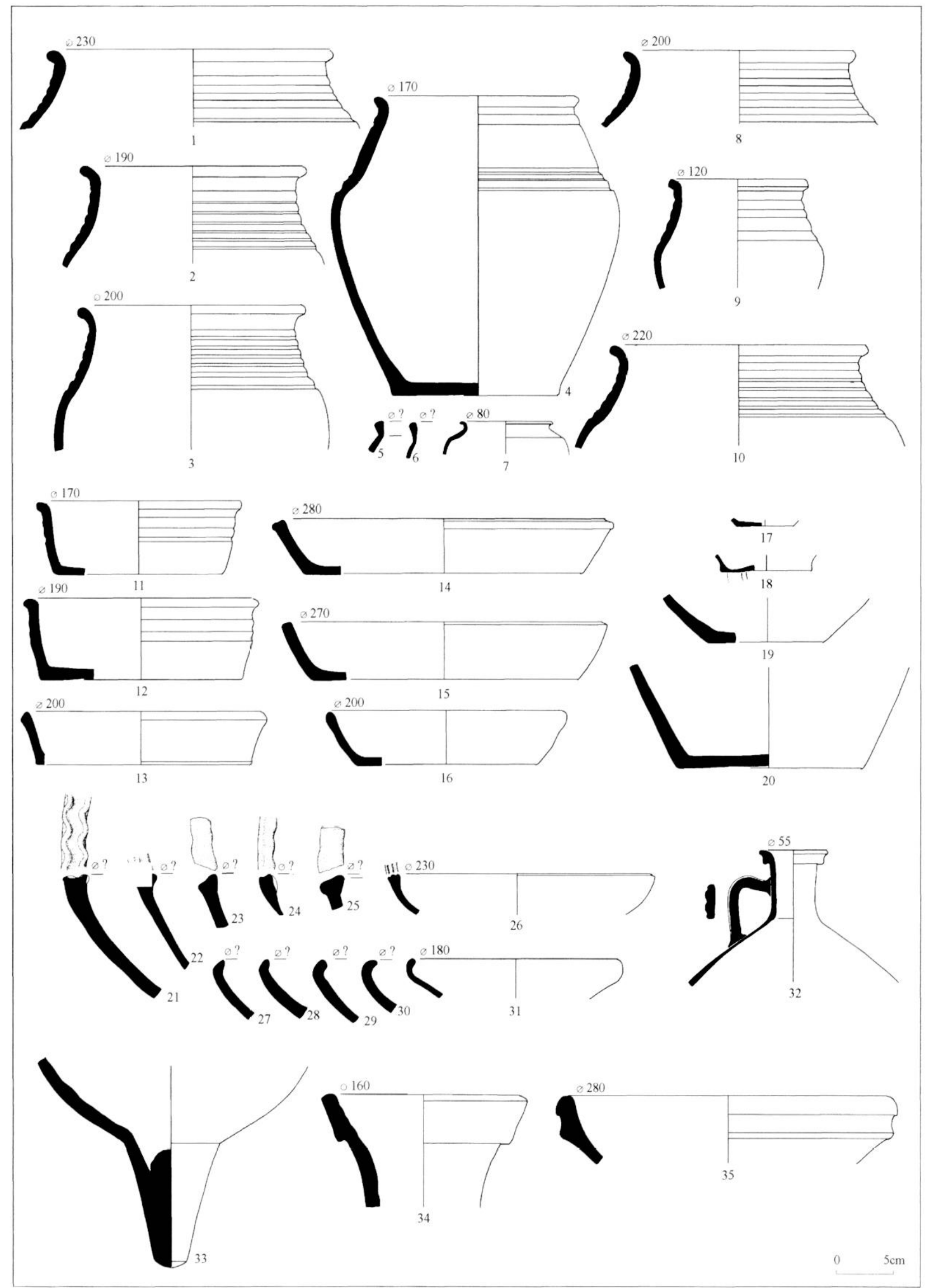

Fig. 23. Mobilier issu de la couche 455.2 (antérieur à la destruction) - céramique commune sombre (1-31), céramique commune claire (32), amphore (33 et 34), mortier (35). 


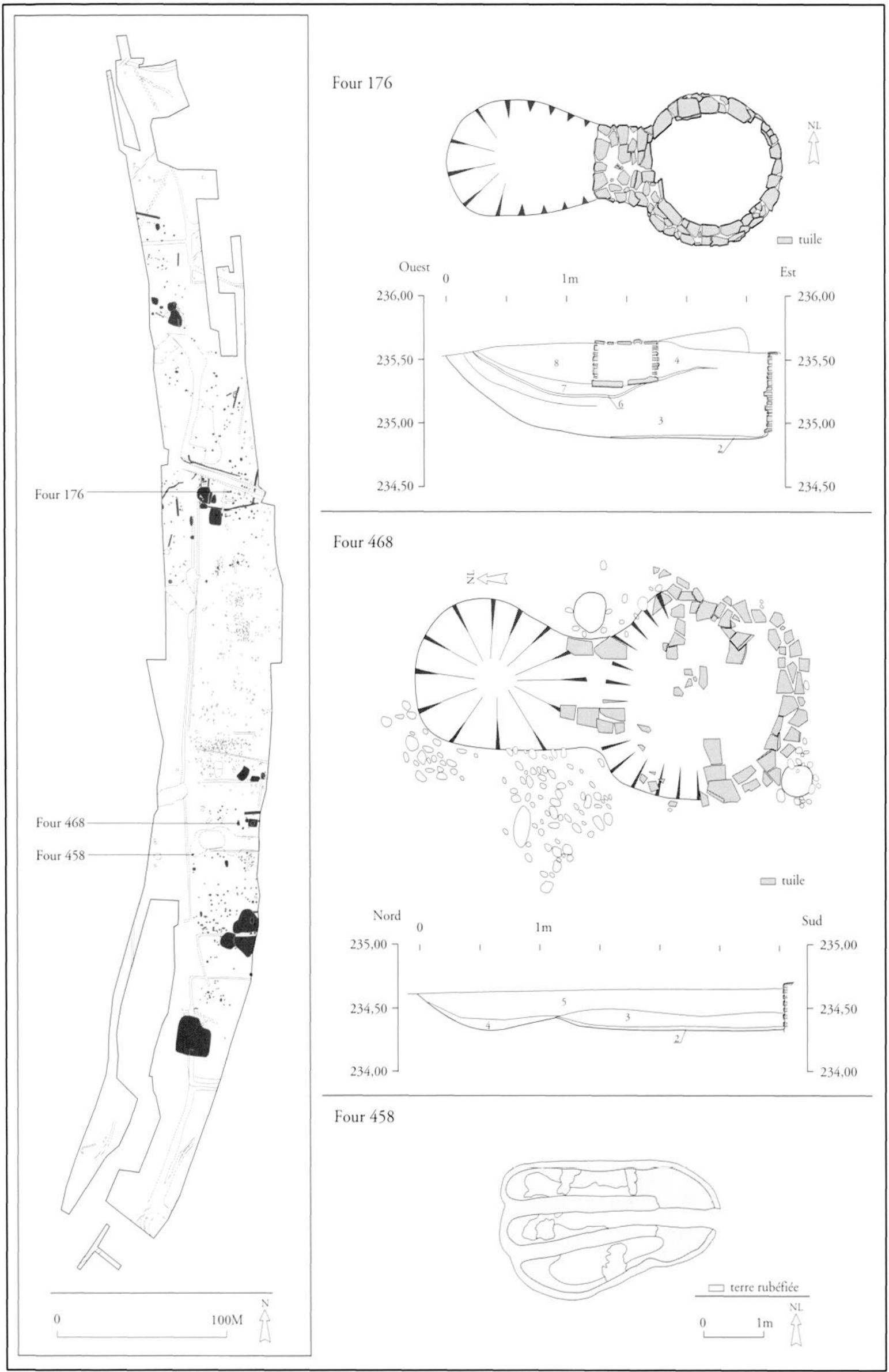

Fig. 24. Plan

et coupe

des fours 176 ,

458 et 468 . 


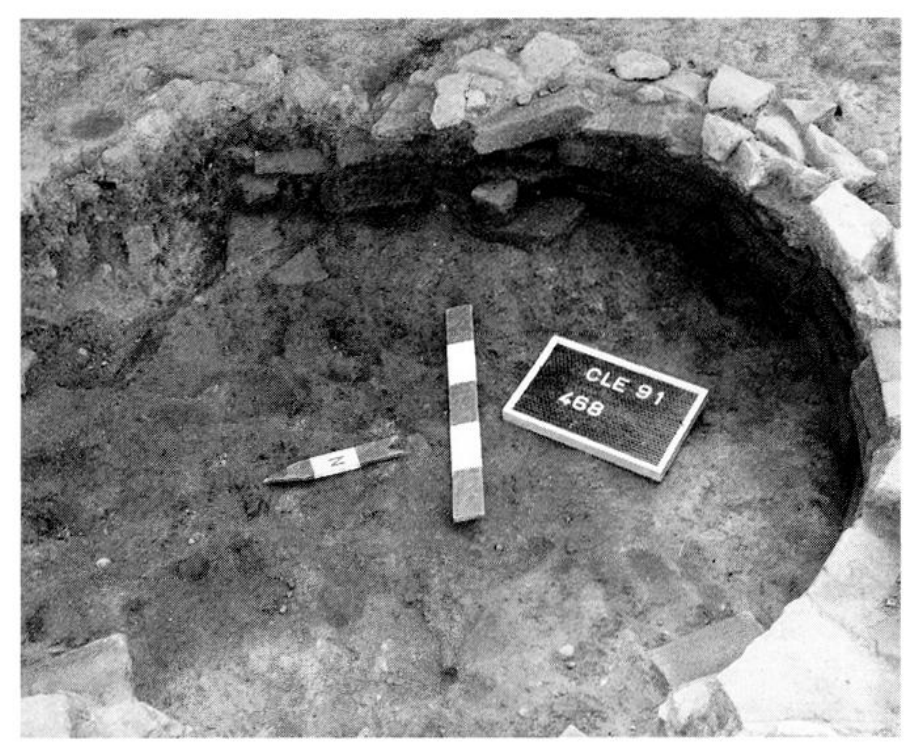

Fig. 25. Vue de la chambre de chauffe du four 468.

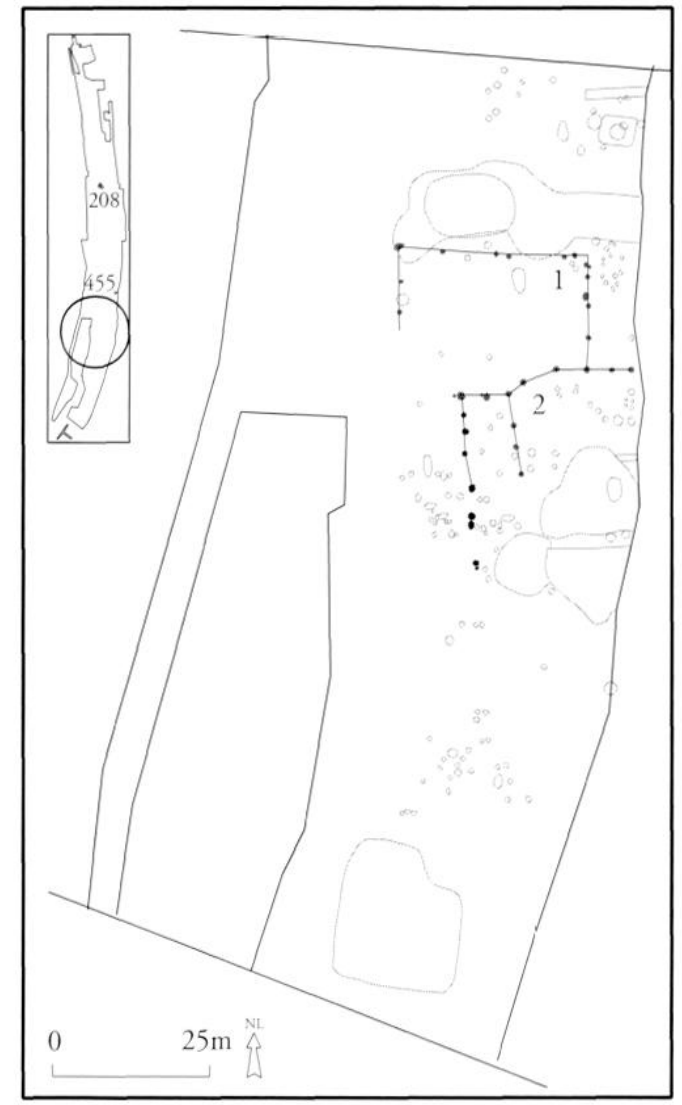

Fig. 26. Secteur sud, proposition de restitution des alignements de poteaux.

Ils se procuraient du métal prêt à être travaillé, peut-être sous forme de lingots, pour en faire des outils; ou bien ils se contentaient de réparer et d'entretenir les outils qu'ils avaient acquis par ailleurs et de fabriquer les petits éléments métalliques nécessaires à la vie quotidienne.
Pourtant, aucune production n'est clairement associée aux foyers. Bien que les fragments métalliques recueillis sur le site soient de petite taille, corrodés et souvent non identifiés, différentes analyses ont été tentées. Les analyses métallographiques, qui ont été menées sur certains objets ont révélé l'emploi de fer de qualité très variable, parfois aciéré. L'étude du seul outil mis au jour et associé au contexte métallurgique (un poinçon issu de la fosse 236) a permis de montrer que la technique de la " soudure " était connue, mais n'était pas pratiquée d'une manière parfaite. Les éléments métalliques du site, quel que soit leur lieu de production et bien que répondant aux besoins locaux, sont de qualité moyenne.

\section{La petite forge}

Une forge de taille modeste est implantée à $70 \mathrm{~m}$ au sud-est de l'édifice 208, et à proximité de la zone des greniers occupée lors de la période précédente. Elle comporte le foyer 192, la fosse-dépotoir 829 et l'aire de travail 414 (fig. 27).

Le foyer 192 se présente sous la forme d'une tache circulaire de $1,10 \mathrm{~m}$ de diamètre, rubéfiée sur $0,10 \mathrm{~m}$ d'épaisseur et très arasée. Contiguë à l'ouest, la fosse d'accès 830 déborde sur 192. Son comblement contient de nombreux charbons de bois et des scories.

A trois mètres vers l'est, des fosses-dépotoirs à fond plat ont reçu des déchets de travail ( 829 : long. $2,5 \mathrm{~m}$, larg. $2 \mathrm{~m}$, prof. $0,40 \mathrm{~m}$ et 846 diam. $1 \mathrm{~m}$, prof. $0,20 \mathrm{~m}$ ). Le niveau de comblement principal de 829 (us 2,3) comporte de nombreuses inclusions de charbon de bois, parfois en lentilles, et de terre cuite, avec des galets, des fragments de parois de four et des scories (près de $35 \mathrm{~kg}$ sur la moitié de la fosse). La couche supérieure se compose de scories (us 4) sous un limon brun charbonneux. Le comblement de la fosse 846 se révèle peu différent et se confond avec celui de sa voisine.

L'aire de travail 414 est située $6 \mathrm{~m}$ vers l'ouest. Trois concentrations de charbon de bois, de terre cuite et de scories (diam. : $0,60 \mathrm{~m}, 0,80 \mathrm{~m}$ et $1,30 \mathrm{~m}$ ) ont pu être individualisées parmi un ensemble de pieux inorganisés (diam. : 0,05 à $0,20 \mathrm{~m}$ ); un second groupe de pieux, formant une palissade, longe deux des fosses sur $5 \mathrm{~m}$ à l'ouest, avant de former un retour au nord et disparaître.

\section{La grande forge}

La seconde zone d'activité métallurgique, située $25 \mathrm{~m}$ au nord de la précédente, est à proximité immédiate de l'habitat nord. De plus grande ampleur, elle associe comme précedemment un foyer de forge (240) et une aire servant de dépotoir où l'on remarque la présence d'un bâti léger (193) (fig. 28).

\section{- Le foyer}

Létat de conservation du foyer n'a pas permis de dresser un plan de l'intérieur de la cuve pour la comparer aux dimen- 


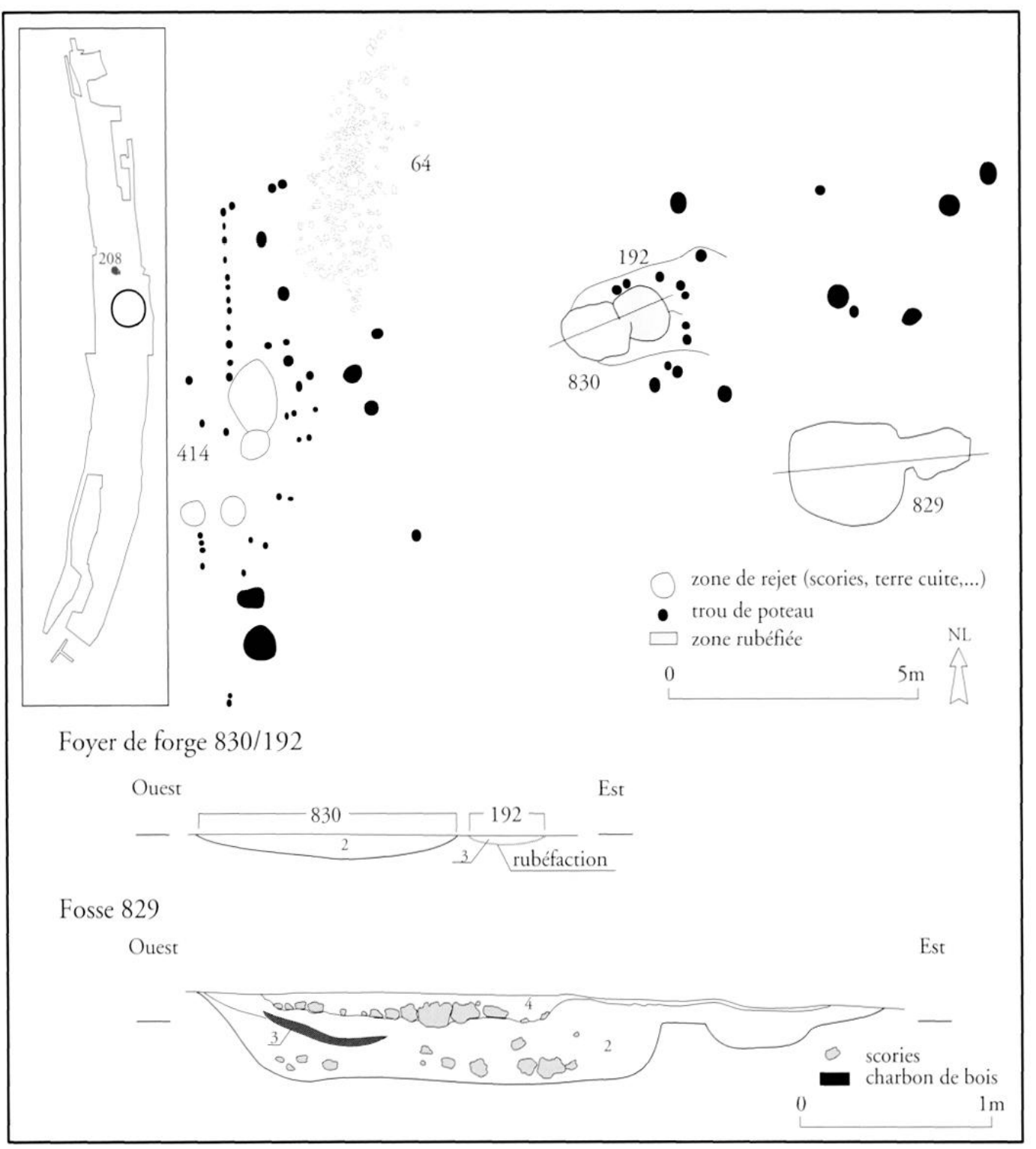

Fig. 27. Le foyer de la forge 192 et ses annexes:

fosses de déchargement (830) et dépotoirs (829), aire de rejet et de travail (414).

sions des scories en calotte; celles-ci, assez denses, offrent des diamètres variant le plus souvent de 8 à $10 \mathrm{~cm}$, avec quelques extensions extrêmes de 6 à $15 \mathrm{~cm}$, pour un poids souvent compris entre 200 et 400 grammes. Leur forme et leurs dimensions permettent de restituer ceux des foyers utilisés à Chassieu, une taille plutôt petite (fig. 29).

Le foyer, circulaire, est encadré de deux fosses à remplissage charbonneux. La base du foyer, d'un diamètre irrégulier (de $0,90 \mathrm{~m}$ à $0,70 \mathrm{~m}$ ), est fortement indurée comme en témoigne la présence d'un niveau gris bleuté. Le niveau supérieur se compose d'un limon noir contenant du charbon de bois et une forte concentration de scories.

Contiguës, les fosses 236 (long. : 1,50 m, larg. : 1,20 m, prof. : $0,25 \mathrm{~m}$ ) et 254 (diam. : $0,85 \mathrm{~m}$, prof. : $0,15 \mathrm{~m}$ ) sont similaires à la fosse $830 \mathrm{du}$ foyer précédent. Leur comblement se compose de différentes lentilles de limon très charbonneux, de fragments de terre cuite, de galets, dans lesquels apparaissent de nombreuses scories. Seuls deux poteaux (diam. : 0,20 m) ont été repérés autour de ces structures et n'apportent aucun indice sur d'éventuelles couvertures.

Le seul outil identifiable qui provient de l'une des fosses entourant le foyer de forge 240 (fosse 236) et mérite une mention particulière; il s'agit d'un poinçon en fer, de section presque carrée, avec deux côtés opposés arrondis; la pointe possède une section triangulaire. Son talon est légèrement bombé. La structure de cet objet, et la présence d'une pointe en acier trempé (bainite) lui donnent en effet les caractères d'un outil. Il se compose de plusieurs bandes de métal d'assez bonne qualité mais assez médiocrement assemblées (acier et fer doux). Cependant, aucune trace de martelage prolongé à froid n'est visible sur le talon, deux hypothèses sont donc en- 


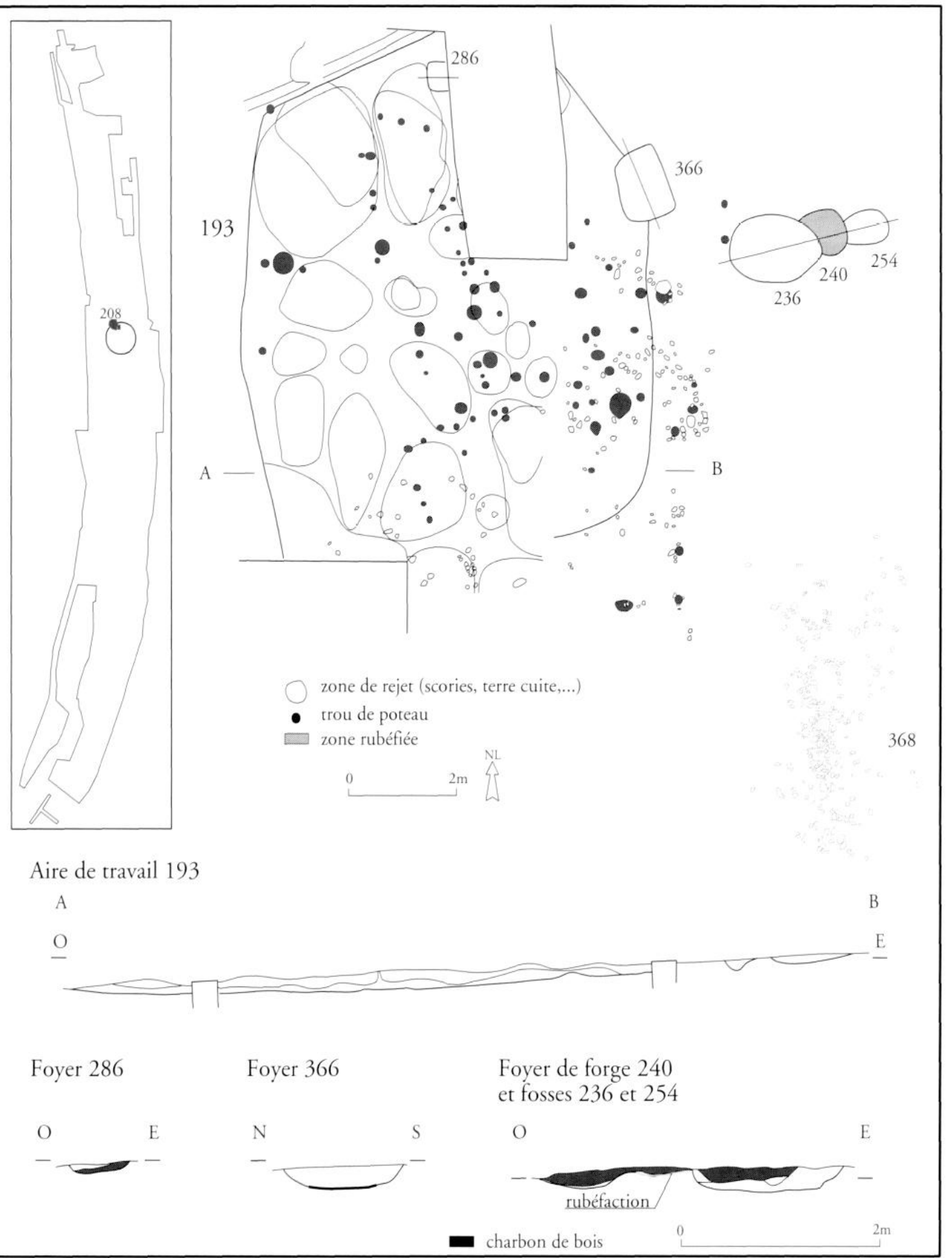

Fig. 28. Le foyer de la forge

240, fosses de déchargement 236

et 254 , aire de travail 193

et épandage de galets 368.

visageables : d'une part cet outil peut être neuf et a donc de grandes chances d'avoir été fabriqué sur le site; d'autre part, il est possible que ce ne soit pas un outil travaillant par percussion posée.

- L'aire de travail 193

Au moins 19 zones de concentration de charbon de bois, de terre cuite, de fragments de parois de four et de scories de $0,80 \mathrm{~m}$ à $3 \mathrm{~m}$ de côtés (prof. : $0,02 \mathrm{~m}$ à $0,14 \mathrm{~m}$ ) se répartissent sur une zone de $8 \mathrm{~m}$ sur $9 \mathrm{~m}$; la cohérence de l'ensemble confirme une occupation régulière. Bien qu'aucune structure construite n'ait été clairement repérée, tout se passe comme si l'artisan nettoyait régulièrement son atelier et accumulait ses " rejets " à proximité. La présence de petits morceaux de métal à demi façonnés, parmi les scories et les fragments de parois de four, vient appuyer cette hypothèse. Seule l'enclume ne paraît avoir laissé aucune trace. Aucune fosse, ni trou de poteau n'a pu être identifié comme l'emplacement du billot, situé, en général, à proxi- 


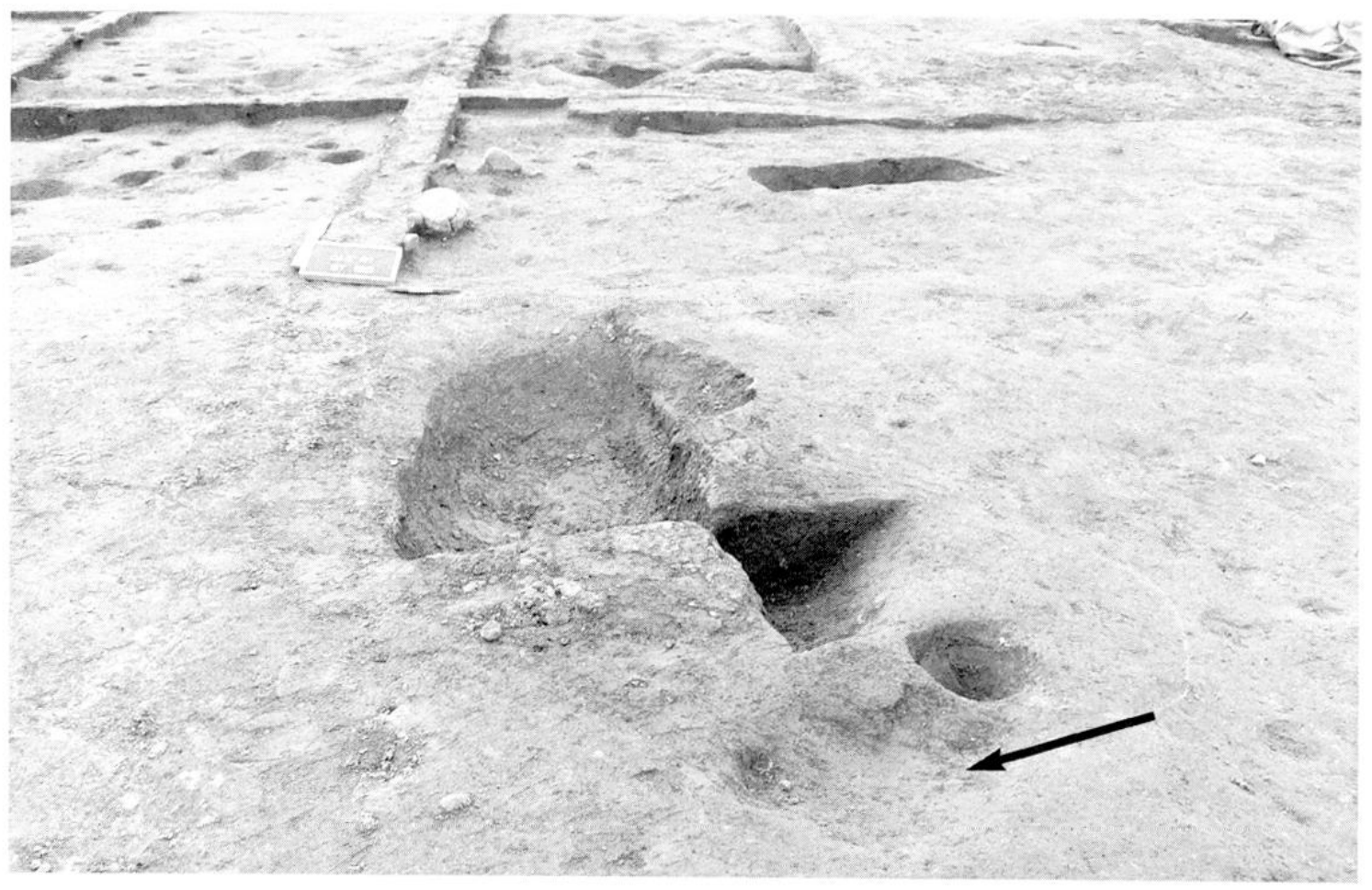

Fig. 29. Vue du foyer de la forge 240 et de l'aire de travail 193.

mité immédiate du foyer de forge. Au total, l'aire 193 a permis de rassembler la plus grande quantité de scories du site, avec plus de $55 \mathrm{~kg}$, ce qui reste quand même très modeste par rapport au poids atteint par les ferriers de sites, dont l'activité est essentiellement tournée vers la fabrication de métal. Plus de 60 scories en calotte (ou fonds de four) ont été découvertes, tandis qu'une vingtaine seulement se trouvaient à proximité du four 192. Ces scories provenant du nettoyage du foyer après une série d'utilisations, il est très possible que le foyer 240 ait fonctionné plus longtemps ou plus souvent que le foyer 192. Deux modestes foyers de plan rectangulaire complètent l'ensemble, sans qu'il soit possible de préciser leur fonction : foyers d'appoint pour le travail métallurgique ou activité totalement étrangère.

Entièrement vidée, l'aire révèle un fond irrégulier, avec, au nord, quatre creusements ovoïdes plus marqués, de $2,40 \mathrm{~m}$ à $0,80 \mathrm{~m}$ de longueur; globalement la profondeur reste faible : de $0,05 \mathrm{~m}$ à $0,10 \mathrm{~m}$. Sur la moitié est, perturbée par un sondage, plus de 70 trous de piquets sont apparus. La majorité d'entre eux s'alignent selon des axes similaires à celui du foyer (côtés conservés sur 1,40 $\mathrm{m}$ à $2 \mathrm{~m}$ de long). Les poteaux à plus fort diamètre sont rares et n'offrent aucune organisation, à l'exception du bord extérieur est de 193, où s'alignent quatre d'entre eux.
Chaque concentration, constituée de fragments de parois de four, de charbon de bois et de scories, correspond probablement à une vidange du foyer.

Les fragments de parois sont constitués d'argile, le plus souvent vitrifiés sur place. Certains gardent la trace d'une mise en forme : ils présentent des angles droits. On peut donc penser que les parois des foyers étaient construites en briques de terre crue, qui cuisaient au fur et à mesure de l'utilisation du four et se vitrifiaient en surface lorsque la température devenait forte (probablement supérieure à $1000^{\circ}$ ). Les variations de température endommageant rapidement les parois, cellesci devaient être régulièrement réparées. Les battitures, petits éclats de fer oxydé ou de scorie inférieurs au millimètre et produits par le martelage n'ont pas été recueillis lors de la fouille. Cependant, les sacs ayant servi à stocker les scories contenaient des battitures qui ont pu être identifiées à l'aimant. Celles recueillies sont essentiellement des battitures plates.

- Le matériel céramique : l'ensemble de la céramique commune sombre, de la céramique peinte et des amphores témoigne d'un faciès très précoce. Toutefois, la présence dans la couche supérieure d'un vase du type Drag $18 / 31$ nous autorise à penser que l'abandon ne peut être daté, au plus tôt, que vers 30 ap. J.-C.

La céramique commune sombre est largement prépondérente (57,2\% des tessons); les deux groupes typologiques présentés lors de la description du matériel des niveaux inférieurs de 455 se retrouvent içi. On peut donc noter la forte proportion 
des vases à pâte fine et une prédominance des formes fermées dans la catégorie des pâtes grossières. La céramique commune claire et les céramiques fines, un Drag. 18/31 et deux tessons peints, sont très minoritaires (respectivement $8,9 \%$ et $1,6 \%)$. En revanche, les fragments d'amphores sont nombreux (32\%), bien que seulement 7 formes soient identifiées (Dressel 1 italiques) (Frascone, Jacquet, Widlak 1993, p. 9).

Un fin fragment de tôle de bronze a également été recueilli (long. max. $0,9 \mathrm{~cm}$ ). Une coulée de verre peu translucide, de couleur verte, d'aspect rugueux, avec quelques concrétions, s'y associe.

\section{Des témoins isolés}

Deux larges fosses situées à une centaine de mètres de la plus grande forge ont révélé une quantité de scories dans leurs comblements. La fosse 474 détruit les enclos circulaires datés du siècle précédent tandis que 473 la recoupe; on y trouve une relative abondance de vestiges métallurgiques, sans qu'aucun aménagement significatif n’ait été observé alentour. Il y avait peut-être à cet endroit un autre foyer de forge, disparu ou hors emprise.

- La fosse 474 (long. : $8 \mathrm{~m}$, larg. : $5 \mathrm{~m}$, prof. max. : 0,40 m) montre un plan anguleux, un profil à bords évasés et un fond plat irrégulier. Son comblement se compose d'un limon brun gris homogène avec quelques galets et quelques scories. Elle est abandonnée vers l'époque augustéenne. Elle est recoupée par la fosse 473 (diam. : $5 \mathrm{~m}$, prof. : 0,70 m), de profil plus incurvé. Ses comblements limoneux bruns ont permis de recueillir $9,5 \mathrm{~kg}$ de scories associées à des parois et des fonds de four sur le tiers de la superficie fouillée.

Sept catégories de céramiques y sont représentées (fig. 30) : céramiques fines (vases à parois fines et céramique peinte : $5,5 \%$ des tessons), céramiques communes (claire $(10,2 \%)$, sombre noire fine $(12,2 \%)$ et grossière $(60,1 \%)$, et grands récipients de stockage et de transport (dolia et amphores : $12 \%$ ). L'absence de céramique sigillée ne constitue pas un argument déterminant pour l'établissement de la chronologie absolue de ce lot. Cette carence semble plutôt liée à la spécificité du site, sur lequel les céramiques fines sont systématiquement sous-représentées.

Les vases en céramiques peintes évoquent les " bols de Roanne ", dont la production se développe au cours du règne d'Auguste. Le répertoire de céramiques communes offre des formes anciennes (écuelles et grandes jattes caractéristiques de La Tène qui perdurent dans les contextes gallo-romains anciens); on remarque une marmite tripode, forme rare à La Tène, beaucoup plus fréquente sous Auguste. Parmi les formes hautes et fermées on note l'apparition des pots ovoïdes à col côtelé à lèvre droite ou faiblement évasé. Ce matériel nous permet donc de retenir comme fourchette chronologique la période augustéenne (Frascone, Jacquet, Widlack 1993, p. 7-8). Un fragment de bracelet en pâte de verre, de section semi-circulaire et de couleur bleu foncée, a été mis au jour en surface.

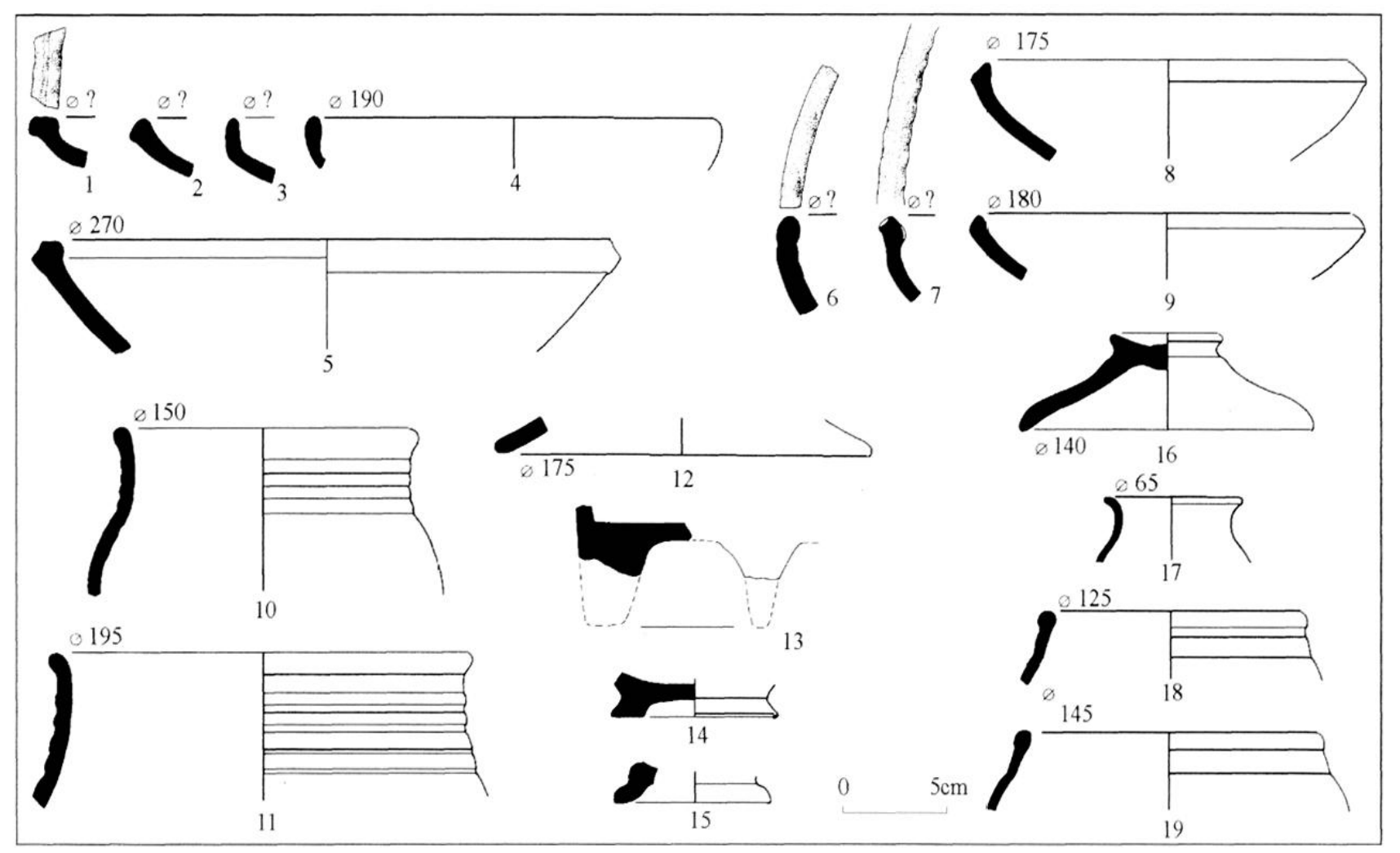

Fig. 30. Mobilier issu des fosses 473 et 474 (nettoyage) - céramique commune sombre (1-13), céramique fine (14), céramique peinte (15), mobilier issu de la fosse 474 (fouille), céramique grossière (16-25), céramique peinte (26). 


\section{LA SURVIE DE L'ÉTABLISSEMENT JUSQU'AU BAS-EMPIRE}

La destruction d'une partie des vestiges entre la fin du règne de Tibère et la période claudienne concrétise l'arrêt de l'expansion du site. De fait, le matériel céramique postérieur à la première moitié du siècle est quasi inexistant. Quelques rares éléments témoignent pourtant d'une permanence de l'occupation jusqu'au moins le $\mathrm{III}^{\mathrm{e}}$ s. ap. J.-C. Les édifices 208 et 455 ainsi que les fours artisanaux sont détruits. D'autres vestiges apparaissent : de larges édifices excavés montrant des traces d'aménagements extérieurs ou intérieurs, des fossés d'enclos ou des palissades occupent encore les zones nord et sud (fig. 31).

\section{LES BOULEVERSEMENTS DU MILIEU DU ${ }^{\text {er }}$ S. AP. J.-C.}

Les édifices 208 et 455 subissent un abandon simultané, matérialisé par la présence d'épais nivẹaux de tuiles, auxquels se mêlent de nombreux fragments dé-céramique et de meules brisées.

\section{- L'édifice 208}

Les tuiles qui colmatent l'excavation 184 proviennent de la couverture de l'édifice 208. Le nombre d'imbrices et de tegulae recueillies dépasse en effet la superficie de celleci alors que quelques éléments posés à plat recouvrent le niveau de circulation de 208 et le solin 205 (fig. 32-34).

La majeure partie du mobilier céramique (1445 tessons) provient de plusieurs des couches d'abandon de l'excavation 184 , ainsi que de la couche d'occupation de 208. L'homogénéité de cet ensemble prouve que nous avons affaire à des phénomènes d'accumulation certainement très rapprochés dans le temps. Un échantillon de céramique sigillée et de paroi fine permet de dater cet ensemble de la période claudienne $(2,7 \%$ des tessons).

La céramique commune claire $(37,2 \%)$ et notamment les mortiers confortent cette datation. La céramique commune sombre se caractérise quant à elle par son faciès archaïque $(46,3 \%)$. On y remarque quelques pâtes fines, dont une imitation d'assiette campanienne Lamboglia et deux petits vases ovoïdes carénés (184.6) mais les céramiques à pâte grossière, au profil haut et fermé, dominent; parmi les ovoïdes, la variante à col côtelé et à lèvre éversée ou cn bourrelet est majoritaire. Dans cette catégorie, on note à présent des récipients bas, assiettes, jattes parfois carénées et marmites. Les amphores représentent $11,3 \%$ des tessons (Dres. 1 pour le transport du vin, Dres. 20 pour l'huile et Dres. $7 / 11$ pour le garum) (Desbat et alii 1989, Genin 1986, Godard 1992, Laroche 1987 in Frascone, Jacquet, Widlak 1993, p 10-11).

11 fragments de meule en basalte se mêlent aux céramiques. Quatre fins fragments de verre de couleur bleu fonçé, ainsi qu'un autre de teinte verdâtre, sont associés. Seuls quelques clous ont été mis au jour parmi les tegulae et des fragments de lamelles perforées en bronze de 2 à $5 \mathrm{~cm}$ de longueur (perforations de 2 à $3 \mathrm{~mm}$ tous les $\mathrm{cm}$ ).

- Le four 176 :

D'après le matériel céramique recueilli, le comblement du petit four 176 parait avoir lieu dans le même laps de temps. Ce four, bâti avec soin et resté inutilisé, illustre la soudaineté de l'abandon.

Les fragments de céramiques communes issues du four 176 ne différent pas de celles livrées par les autres ensembles. Seule la forme Drag.16, trouvée presque au fond du four, nous apporte une précision chronologique, et nous autorise à dater son comblement au plus tôt dans les années 30-40 ap. J.C. (Frascone, Jacquet, Widlak 1993, p. 10-11). Un seul fragment de verre, épais et curviligne, de couleur vert-clair, a été mis au jour (goulot?).

- L'édifice 455

Cet édifice de l'habitat sud subit également une destruction. Un niveau de tuiles couvre la totalité de sa surface marquant l'abandon définitif de la structure (us 7). Le matériel montre de grande similitude avec celui de l'édifice 208 (fig. 35).

Cet ensemble présente un échantillon représentatif des céramiques de la fin du règne de Tibère et du début du règne de Claude. C'est le seul lot céramique de Chassieu où la céramique commune claire ( $40 \%$ des tessons) est presque aussi abondante que la commune sombre $(42,3 \%)$. Ce fait le distingue très nettement des niveaux inférieurs, pour lesquels la céramique commune claire ne dépasse pas $10 \%$ de la totalité des tessons (fig. 36).

Le répertoire des communes claire est le plus varié de tous les ensembles de Chassieu (cruches à goitre, à lèvre chanfreinée ou en cupule-non représentée). On remarque quelques céramiques fines $(6,4 \%)$ dont des formes de sigillées sud-gauloises (Drag 15/17, Drag 18/31) et 2 fragments de parois fines, dont un bol très semblable à ceux des productions de La Butte à Lyon. Les amphores représentent $8,6 \%$ des tessons mais sont difficilement identifiées (peut-être une Dressel 2/4) (Desbat et alii 1979, Godard 1991 in Frascone, Jacquet, Widlak 1993, p. 10).

La totalité d'un catillus, deux autres fragments de meule, et un fragment de mortier en granite ocre brun (diam. : environ $13 \mathrm{~cm}$ ) ont également été mis au jour entre le niveau de circulation et les éléments de la toiture effondrée. Un crochet en fer, un clou-bouton à tête losangée étirée et plusieurs clous, ainsi qu'une tige recourbée en bronze (long. : 10,5 cm), accompagnent l'épandage des tuiles. 


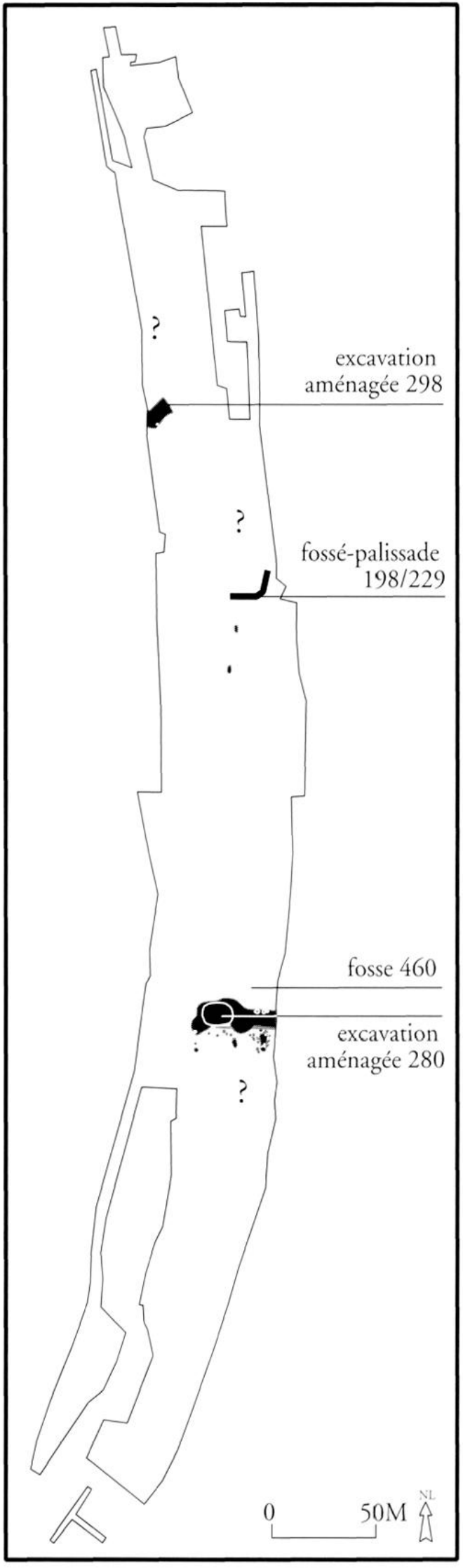

Fig. 31. Plan synthétique des occupations postérieures

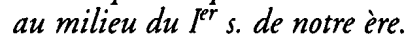

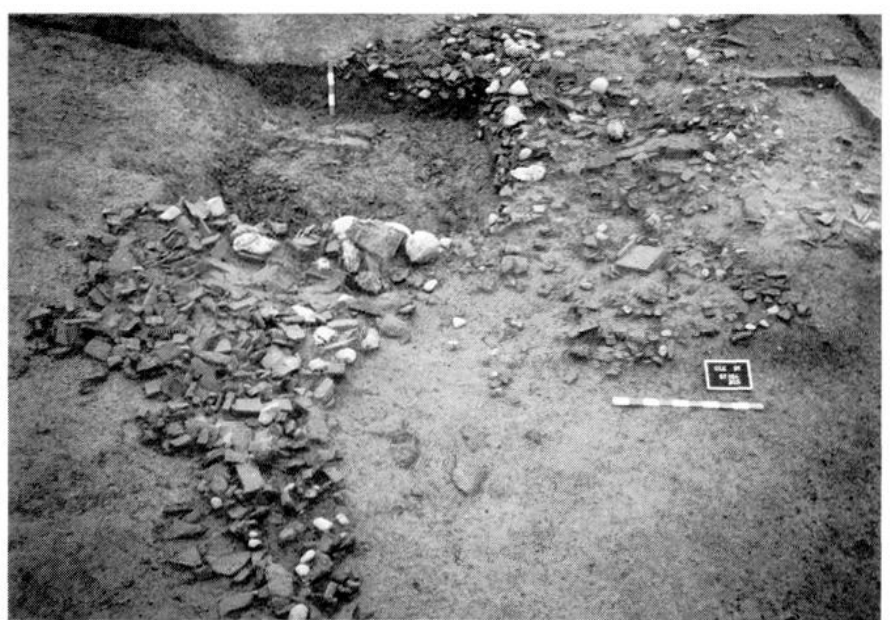

Fig. 32. Vue de la toiture effondrée de l'édifice 208 dans l'excavation 184.

\section{UN RENOUVEAU DISCRET}

Deux larges structures excavées pourvues d'un niveau de sol, des fossés d'enclos, une palissade et une fosse témoignent de la permanence de l'occupation. La partition entre groupe nord et groupe sud reste valable, les mêmes espaces que précédemment étant occupés par des structures montrant quelques similitudes. Néanmoins, seuls les éléments sud ont livré des indices de chronologie absolue; au nord, les datations s'appuient surtout sur quelques positions stratigraphiques.

\section{Le goupe nord}

Lélément le plus imposant est une large excavation aménagée située au nord de l'habitat (298). Autour de l'ancien édifice 208 et de la grande forge, on note surtout la présence d'un enclos ouvrant vers le nord-est auquel mène un chemin empierré.

- L'excavation aménagée 298 : la large excavation (298: long. : $10 \mathrm{~m}$, larg. : $9 \mathrm{~m}$, prof. : de $0,40 \mathrm{~m}$ à $0,50 \mathrm{~m}$ ) montre un profil peu accentué : au sud et à l'est, le bord est en pente douce. La fouille n'a révélé aucun trou de poteau et pourtant un niveau d'utilisation brun vert avec de nombreux galets et des petits fragments de tuiles tapissent le fond (us 2). Un foyer circulaire au profil en cuvette y est installé et présente deux utilisations clairement différenciées ( 311 : diam. : 0,70 m, prof. : $0,38 \mathrm{~m}$ ). Le remblai final est similaire au niveau d'abandon de l'excavation (fig. 37).

La céramique antique est résiduelle, elle permet donc difficilement d'affiner la datation. On note quelques tessons de céramiques communes sombres et claires, dont une lèvre éversée à bord horizontal, une sigillée de La Graufesenque et un fond d'amphore gauloise. 


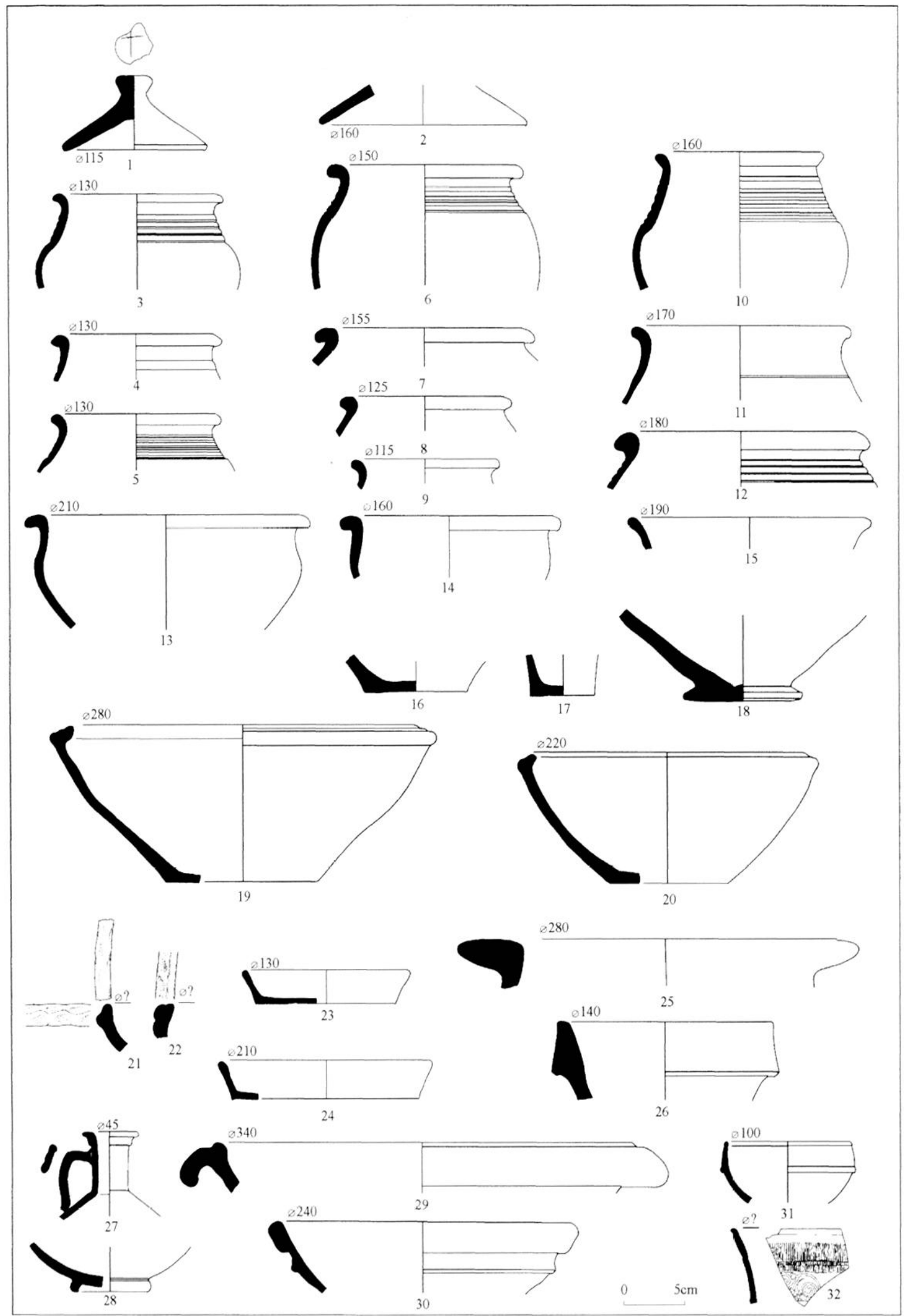

Fig. 33. Mobilier issu du sol 208

(couche d'abandon)

- céramique

commune sombre

(1-27),

dolium (28),

amphore (29)

céramique

commune claire

(30 et 31).

mortier (32 et 33),

sigillée (34 et 35). 


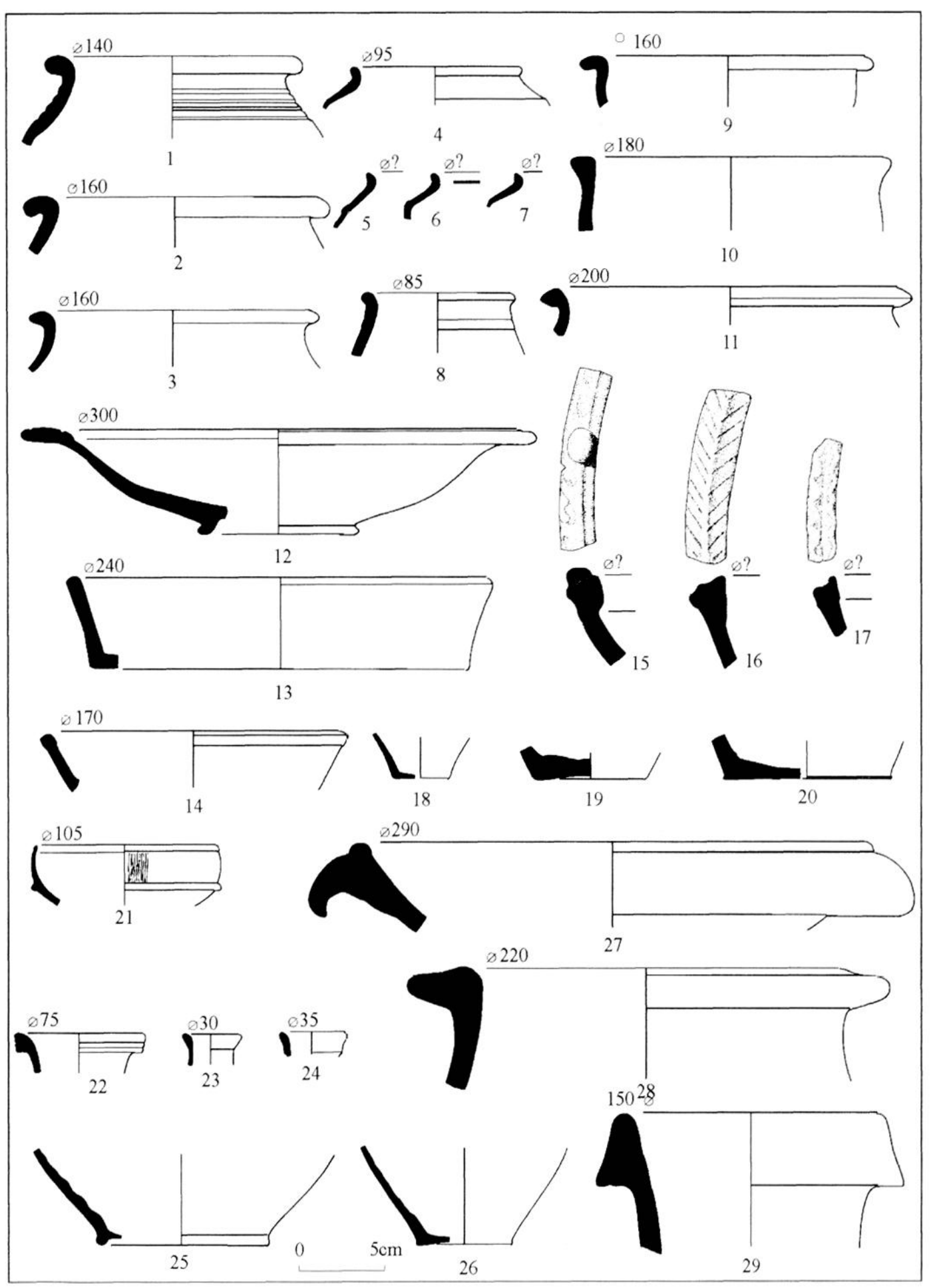

Fig. 34. Mobilier issu de la couche 184.5 (toiture effondrée - céramique commune sombre $(1-20)$, sigillée (21), mortier (27), céramique commune claire (22-26), dolium (28), amphore (29).

- Fossés et empierrements.

Les fossés 198 (larg. : 1,40 m, prof. : 0,15 m) et 229 (arasé) recoupent l'édifice 208 et l'excavation 184; ils forment un enclos ouvert sur le nord-est dont on perçoit deux limites, de $18 \mathrm{~m}$ de long est-ouest et $10 \mathrm{~m}$ nord-sud. II présente un accès au sud, dont les abords sont soulignés de part et d'autres par un foyer.

Le fossé 198 révèle des céramiques commune sombre à décor côtelé, aux bords faiblement éversés, dont un vase élancé à haut col, un départ de panse caréné, une écuelle à bord droit, de la commune claire. Le fossé 229 livre 1 panse au décor de deux bandes lissées, de la commune claire et un fragment de sigillée moulée, érodé, de La Graufesenque.

Deux empierrements, constitués de galets calibrés empiètent sur les zones de forge ( 64 : long. : $2 \mathrm{~m}$, larg. : $0,9 \mathrm{~m}$ ) et 414 (368 : long. : $2,5 \mathrm{~m}$, larg. : $0,7 \mathrm{~m}$ ). La prolongation de leur axe mène à l'accès des fossés d'enclos 198/229. 


\section{Le groupe sud}

Au sud, quelques vestiges illustrent une réoccupation du secteur après la destruction de l'édifice 455 . Une petite fosse dépotoir (460) révèle un lot de céramiques et de verrerie; une seconde excavation entourée de radiers est mise au jour à peu de distance (280).

- La fosse dépotoir 460 (fig. 38).

La fosse 460 (long. : 1,40 m, larg. : 1,05 m, prof. : 0,09 m) recoupe l'aire de travail 811 . Cette fosse ovoïde irrégulière livre un matériel varié. Aucun ossement n'a été observé.

460 a permis de collecter les fragments de 25 vases représentant 306 tessons, 5 verreries et quelques fragments métalliques, dont un clou décoratif. La présence d'un Drag 15/17 donne un terminus post quem des années 30-40. Céramiques claires et céramiques sombres sont largement majoritaires (respectivement 40 et $47 \%$ des tessons). On note l'absence des vases ovoïdes à col mouluré et la présence d'exemplaires carénés; une assiette présente une lèvre de section angulaire légèrement éversée. La sigillée et les vases de stockage sont anecdotiques.

La verrerie, anecdotique ailleurs, est ici représentée en abondance : une coupe à calotte sphérique (diam. $16 \mathrm{~cm}$ ) translucide verdâtre à bord droit arrondi, au pied manquant, est décorée d'une séries de côtes verticales très saillantes - une seconde coupe plus fragmentée bleu translucide, similaire à la précédente, mais aux côtes plus épaisses - une fiole translucide bleue à haut col avec un départ de panse partiellement conservé; le bord, quelque peu irrégulier, présente un rebord oblong déversé à l'horizontale - 7 fragments de panse translucides bleu-vert à décor de côtes peu marquées - un fragment translucide presque blanc. Les coupes à côtes verticales, de type Isings 3 ou Morin-Jean 68 , sont datées des I $^{\text {er }}$ et II $s$. II $s^{\prime}$ agit d'une vaisselle domestique répandue en Gaule, de provenance italique, ou rhénane (Arveiller-Dulong, Arveiller 1985, p. 43-44, 315; Sternini 1991, p. 151-152, pl. 57).

Une plaque métallique assez fine, pliée en boule, de teinte blanche, de composition dense (plomb ?), est également issue de cet ensemble.

\section{- L'excavation aménagée 280}

Une seconde large excavation ( 280 : long. : $14 \mathrm{~m}$, larg. : $10 \mathrm{~m}$, prof. : $0,60 \mathrm{~m}$ ) a été mise au jour au sud de l'édifice 455, ainsi qu'un radier la contournant sur trois côtés. Lorigine anthropique ne fait aucun doute : le creusement présente un fond plat et des bords entamant nettement la moraine (fig. 39).

Deux larges creusements (diam. 0,80 m), vestiges de fosses ou de trous de poteau, ont été observes, l'un sur le bord sud, l'autre en limite du tiers sud sur la coupe opposée; tous deux coupent le niveau de sol (us 11), mais sont comblés par les premiers niveaux d'abandon. Aucun autre creusement similaire n'a été noté sur le reste de la structure qui a été vidée de moitié.
L'occupation est matérialisée par un fin niveau limono-sableux brun foncé à noir, hétérogène, très compact, avec de petits fragments de tuiles et de galets, de cailloutis et de gravier (us 4). La première couche d'abandon est de teinte plus claire et de texture moins compacte (us 11). Sur ce niveau longeant le bord sud, on note d'importants amas de galets, associés à des fragments de tuiles et de pierres calcaires de modules supérieurs (us 5); ces matériaux, identiques à ceux observés dans le comblement de l'excavation 184, pourraient être associés à ce qui reste des élévations, ou à des calages d'éléments porteurs (le bord nord est perturbé par une haie actuelle). Divers remblais sablo-limoneux marquent ensuite l'abandon de la structure (us 6, 12 à 15).

Le matériel est constitué de céramique commune sombre, dont un fragment d'écuelle au bord vertical, de la céramique commune claire à lèvre en bandeau (jatte ?), un tesson de céramique sigillée à décor en frise, deux tessons à glaçure plombifère, des amphores.

- Les sols exrérieurs

Un sol extérieur, composé d'une seule assise de petits galets calibrés et de fragments de tuiles, est contemporain de l'excavation 280 (390). Il la contourne sur 3 de ses côtés; une coupe effectuée au travers de ce radier montre également qu'il est recouvert par l'us 5 (coupe C-D). Il est toutefois difficile d'évaluer l'étendue originelle de cette semelle, l'érosion étant probablement à l'origine de sa disparition sur le côté sud, ce que semble illustrer le reliquat de sol 388. Sur la partie orientale, quelques dépressions du terrain ont permis la conservation d'une réfection matérialisée par un niveau de tuiles fragmentées (392: ép. : 0,20 m) (fig. 40).

Des palissades limitent le radier 390 au nord et au sud. Au nord, on remarque une suite de poteaux associée à un niveau de gros galets, dont la relation stratigraphique avec le radier n'est pas établie $(809,807,470)$. En revanche, au sud, la palissade 383 , qui borde également l'édifice 280, recoupe ce sol de galets (long. : $28 \mathrm{~m}$, larg. : $0,25 \mathrm{~m} / 0,2 \mathrm{~m})$.

Un niveau limono-sableux compact brun, avec des fragments de tuiles et des petits galets, recouvre finalement l'ensemble des radiers ainsi que la palissade 383 (391).

Parmi les différents niveaux de radiers, on remarque que les céramiques fines sont relativement bien représentées $(8,2 \%$ des tessons). Outre la forme Drag. 37 produite probablement dans le centre de la Gaule, il faut noter la présence de la sigillée claire $B$ dont les débuts de la production se situent dans la première moitié du $\|^{e} s$. La céramique commune sombre provenant du niveau de tuiles (us 392) diffère peu du mobilier décrit précédemment $(47,4 \%)$; on voit pourtant apparaître des pâtes bien cuites, gris-bleutées, contenant un gros dégraissant blanc. Les tessons d'amphores appartiennent sans doute au type espagnol Dressel 20 (7,6 \%). De ce fait, il serait prudent de retenir pour la constitution des radiers, une large 


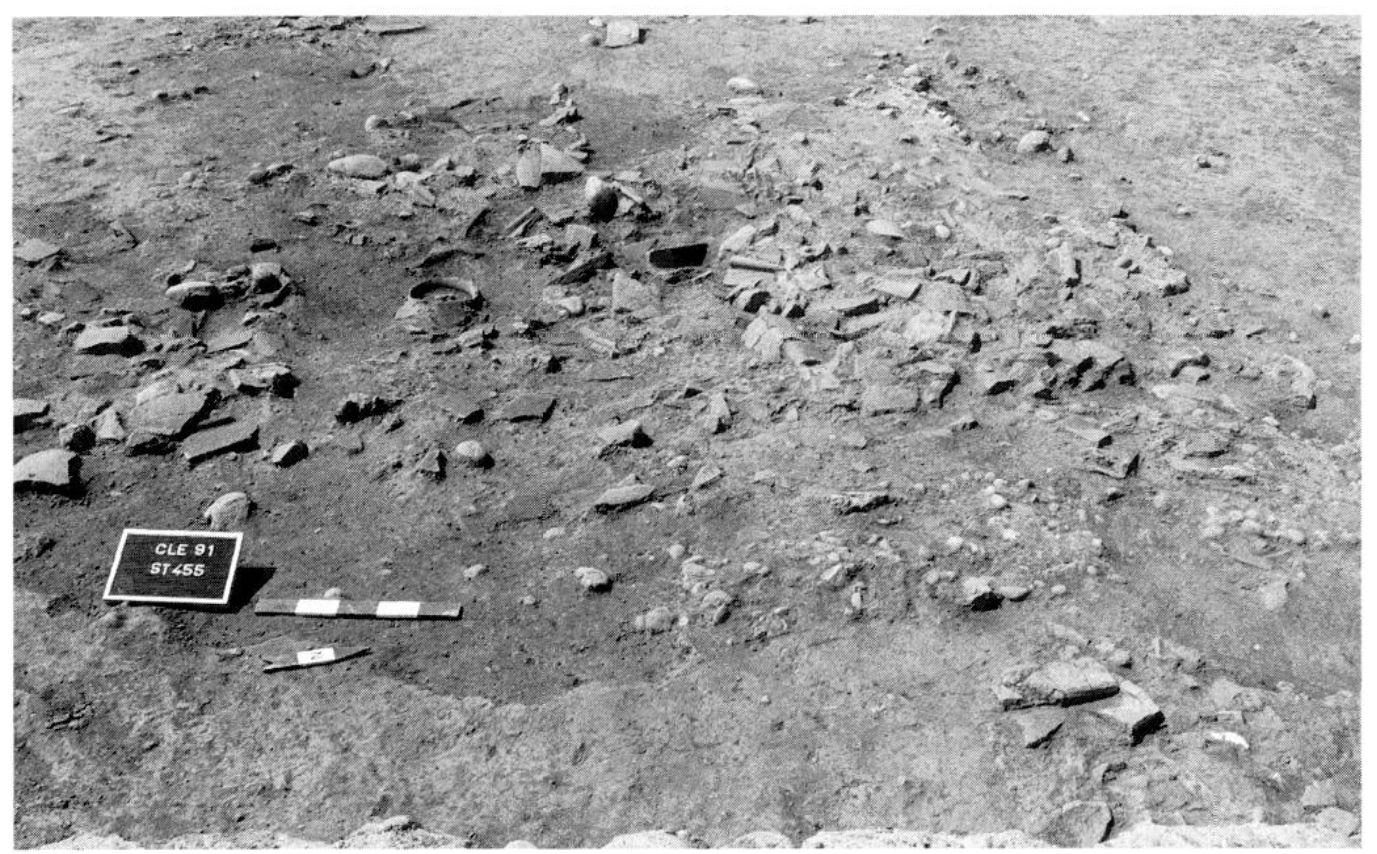

Fig. 35. Vue de la toiture effondrée de l'édifice 455.

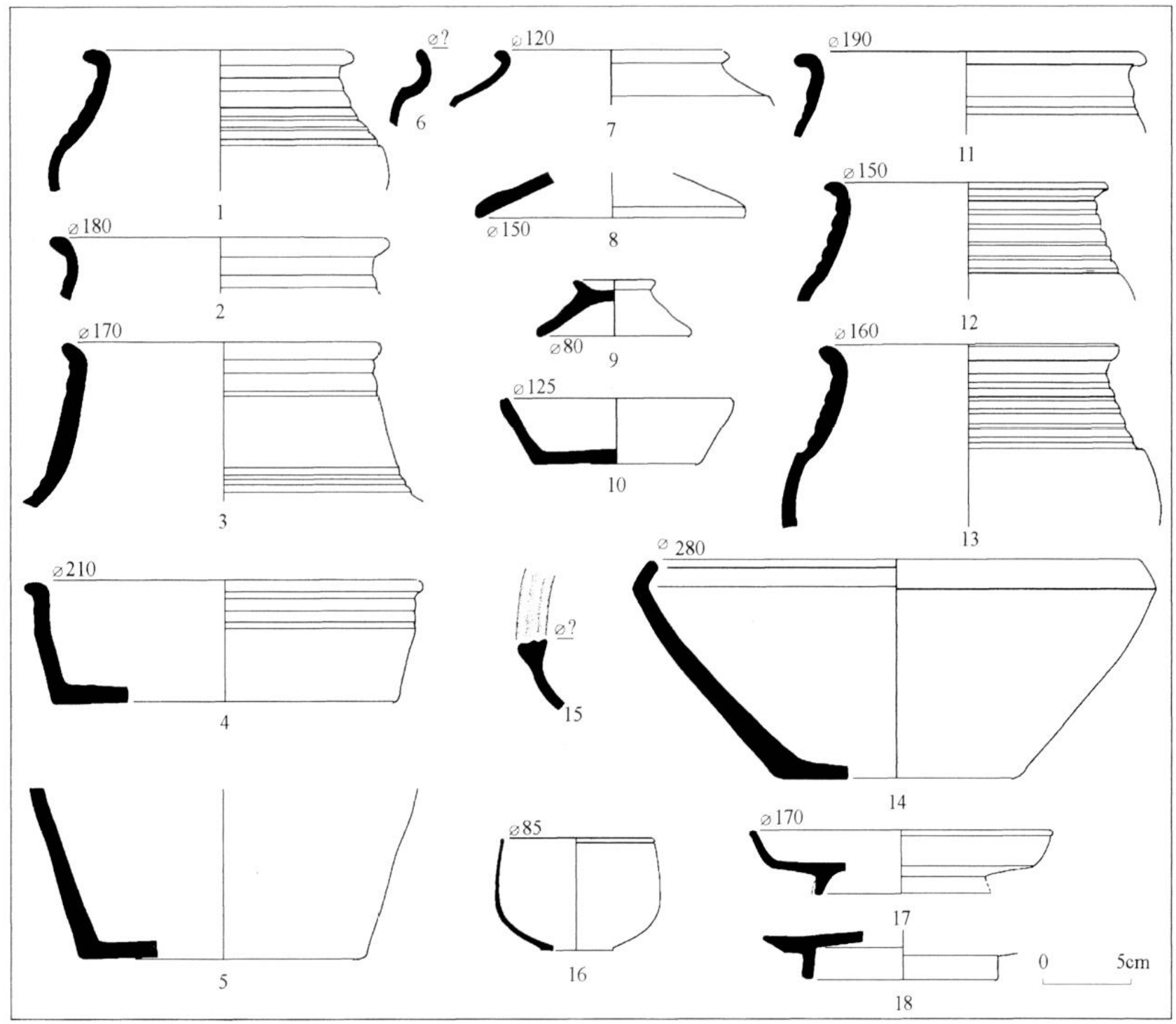

Fig. 36. Mobilier issu du sol 455 (couche d'abandon) - céramique commune sombre (1-15), paroi fine (16), sigillée (17 et 18). 


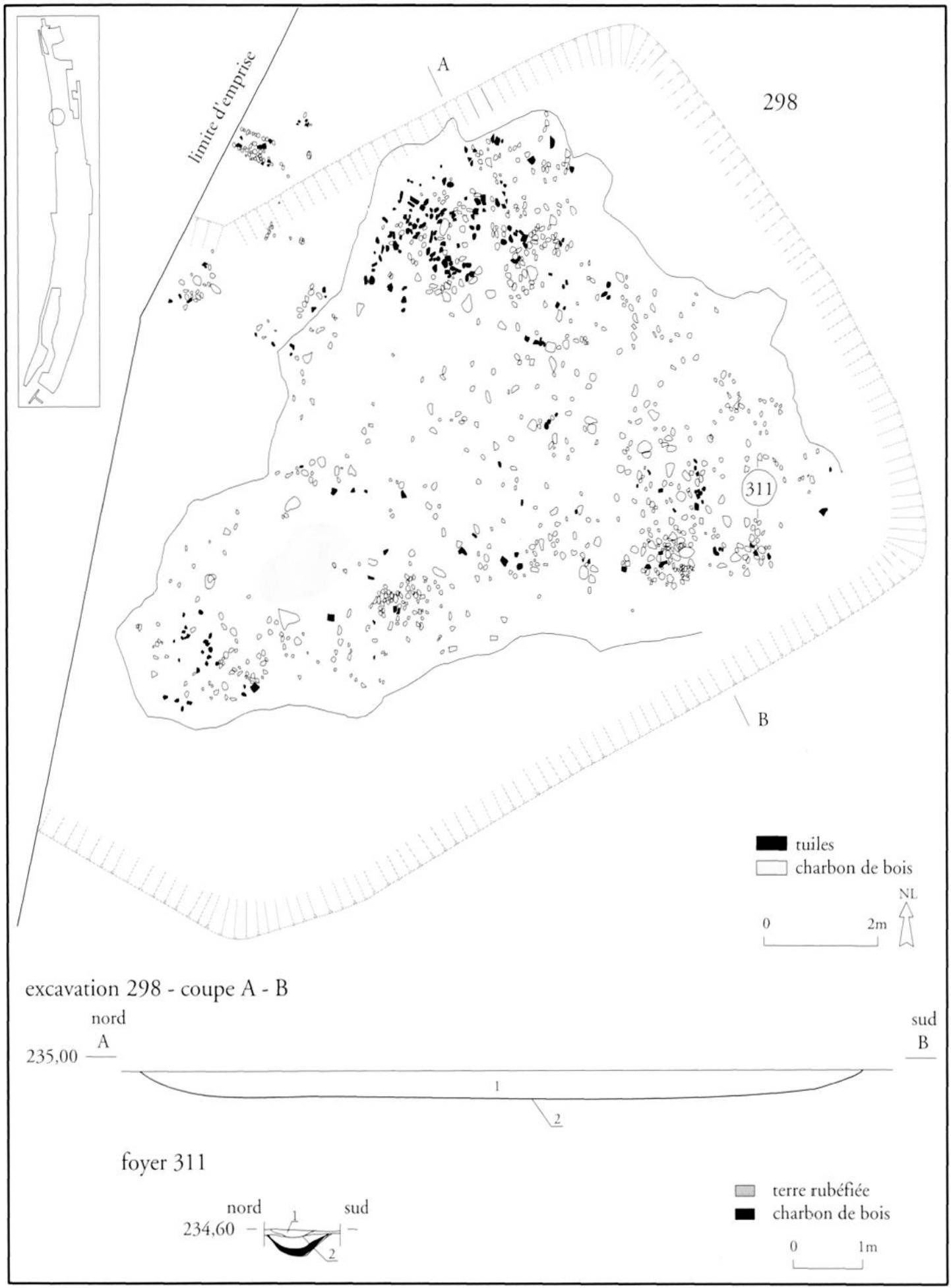

Fig. 37. Excavation 298 avec un niveau de sol et un foyer (311). 


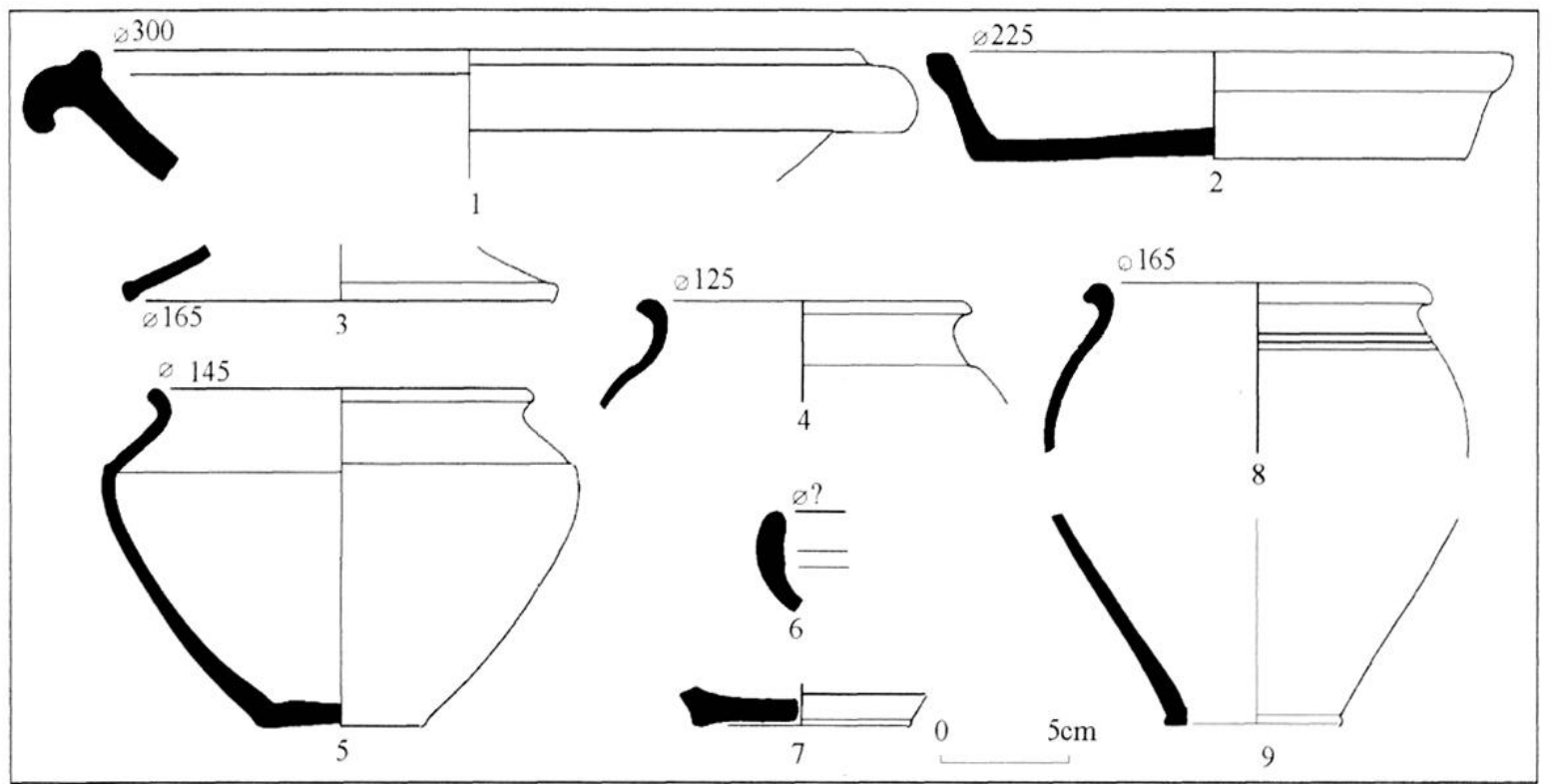

Fig. 38. Mobilier issu de la fosse 460 - mortier (1), céramique commune sombre (2-9).

fourchette comprise entre le milieu du Ier s. ap. J.-C. et 250 ap. J.-C. (Frascone, Jacquet, Widlak 1993, p. 13).

Outre la céramique typique du $\|^{e}$ s., le niveau d'abandon 391 a livré un sesterce qui fixe la date de colmatage des sols au plus tôt entre 244 et 249 ap. J.-C. (Philippe I l'Arabe) ${ }^{14}$.

De nombreux éléments métalliques en fer, fragmentés, sont issus de ce même contexte : 5 fragments de section plate avec parfois un rivet (montants?), 4 crochets d'un diamètre d'environ $3 \mathrm{~cm}$ (éléments de rotation, poignées?), deux clou-boutons à tête de céramique hémisphérique grise fine et plusieurs fragments de lamelles et de nombreux clous à tête plate.

Des fragments de bronze sont également présents : des tiges plates, des lamelles, un anneau (diam. : $3,4 \mathrm{~cm}$ ), un bouton décoratif de forme ogivale et un bord droit de récipient à lèvre repliée sur l'intérieur.

Un fragment de panse en verre translucide légèrement verdâtre, avec un décor de fines côtes peu saillantes, ainsi qu'un fragment translucide, épais, de couleur blanc jaunâtre, de facture peu soignée, avec de nombreuses bulles et une anse coudée de couleur verte, section plate et peu soignée, sont également issus de ce contexte.

5 petits fragments de meules en basalte complètent ce matériel.

\section{CONCLUSION}

Le décapage archéologique à Chassieu-Genas "L'Épine " a permis de mettre au jour, sur 4 hectares, une occupation datée du $\mathrm{I}^{\mathrm{er}} \mathrm{s}$. av. J.-C. au milieu du $\mathrm{III}^{\mathrm{e}} \mathrm{s}$. de notre ère.

(14) Étude M. D. Frascone, AFAN. (fig. 41). Deux charnières chronologiques s'y dessinent. La fouille révèle d'abord plusieurs secteurs d'un établissement rural de la fin de l'Âge du Fer. La première rupture se situe à l'époque augustéenne et modifie en profondeur l'organisation du site. Une occupation du Haut-Empire scindée en deux pôles se développe de part et d'autres de l'implantation précédente; elle étend son emprise bien au-delà des habitats par le biais de réseaux de fossés étendus. La seconde rupture intervient durant le second tiers du $\mathrm{I}^{\mathrm{er}} \mathrm{s}$. ap. J.-C. ; plus qu'une réorganisation spatiale, elle provoque la destruction de certains édifices ainsi qu'une apparente baisse de la fréquentation dont les derniers témoins sont datés du III ${ }^{\mathrm{e}} \mathrm{s}$.

A l'intérieur de chacun des ensembles gallo-romains, le choix d'une architecture exclusivement de terre et de bois, surprend. On remarque des bâtiments quadrangulaires sur solins, de larges excavations aménagées... D'une manière globale, c'est toure l'organisation du site qui reste à interpréter.

\section{D'UN ÉTABLISSEMENT INDIGENE AUX HABITATS DU HAUT-EMPIRE}

Le matériel céramique indique que le passage de l'établissement indigène aux habitats du Haut-Empire s'est effectué sans rupture chronologique. Il semble pourtant difficile de préciser les termes de cette évolution : modification graduelle ou plus radicale? On note que les secteurs nouvelle- 


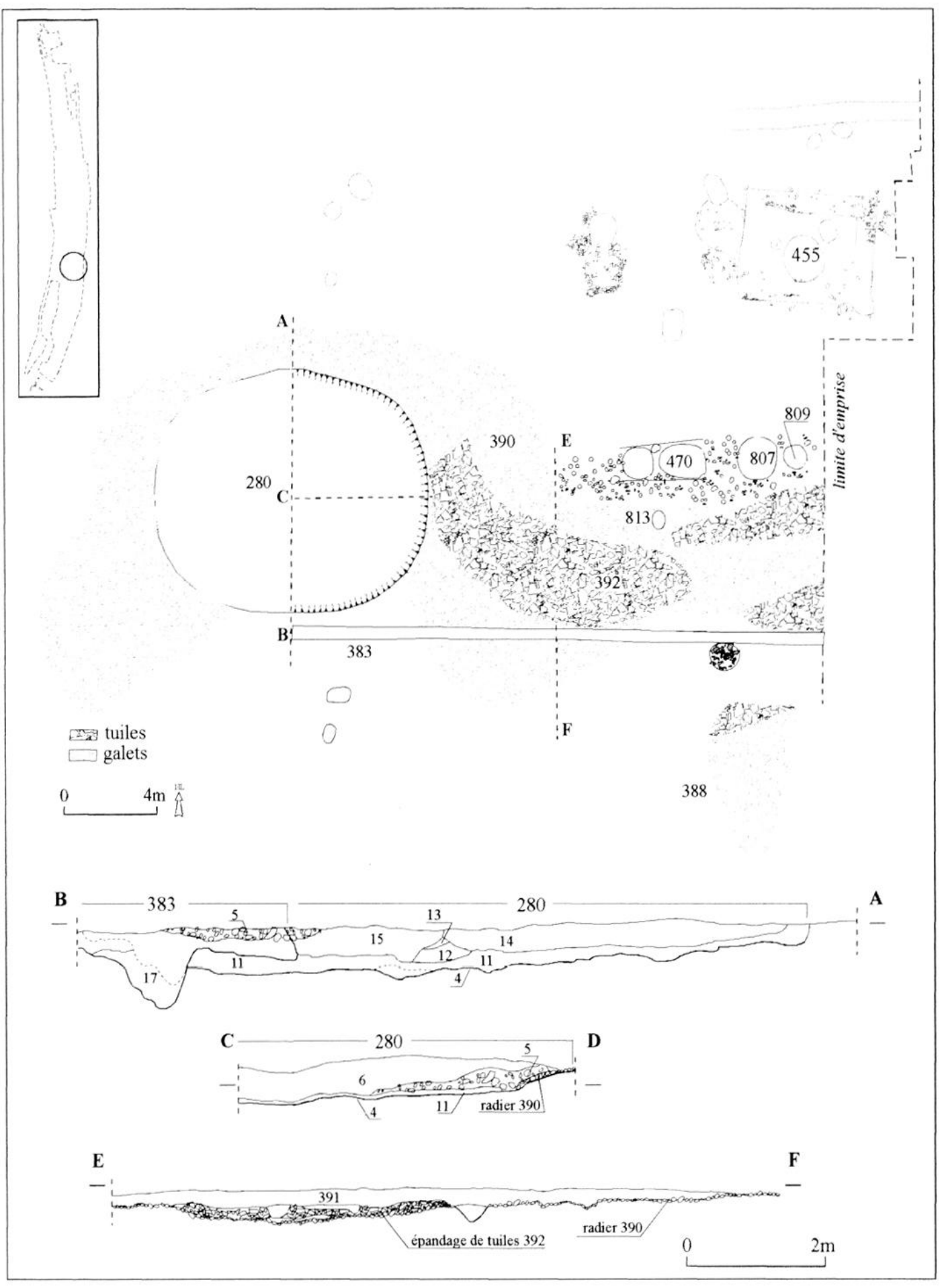

Fig. 39. Excavation 280 et radiers 390 et 392. 


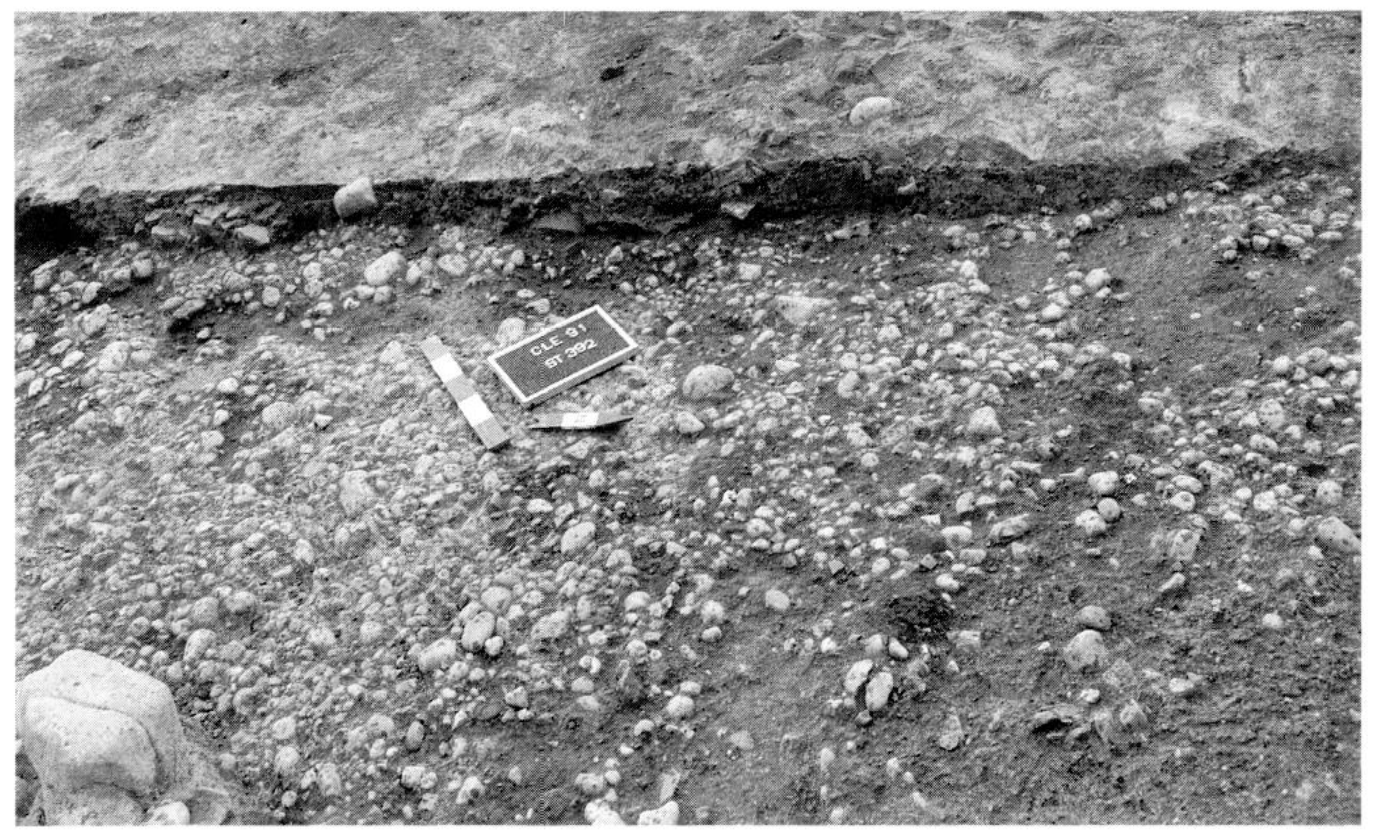

Fig. 40. Vue du radier autour de 280.

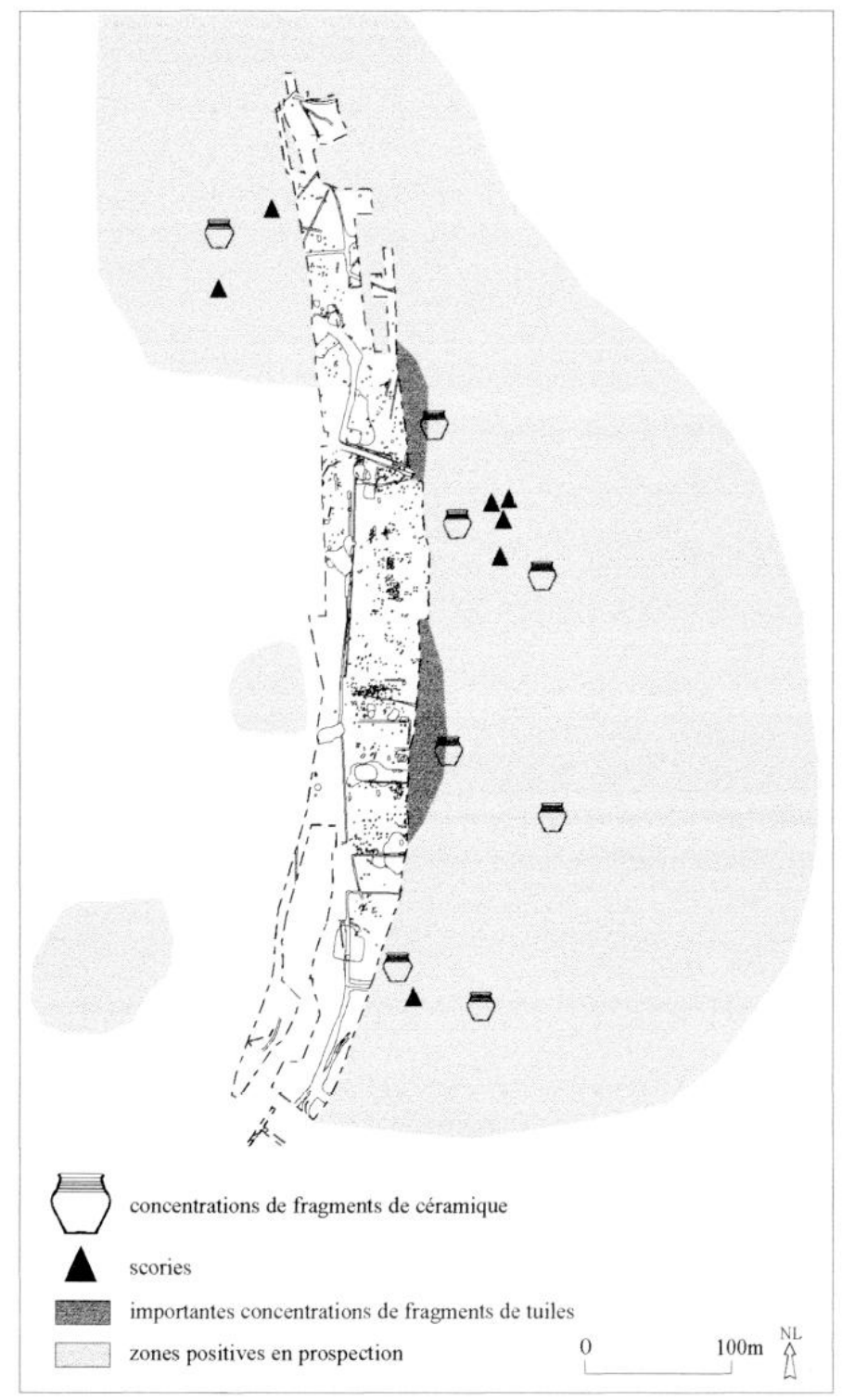

Fig. 41. Résultats

des prospections de surface menées hors emprise, étendue reconnue des occupations et concentrations de mobilier. 


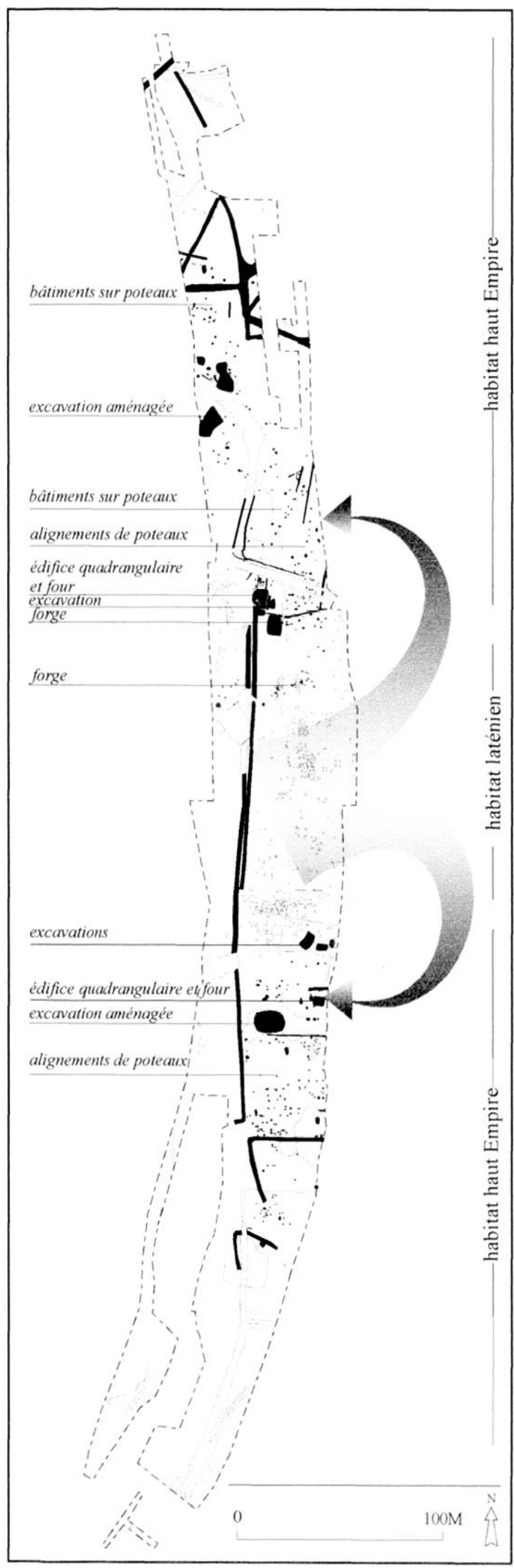

Fig. 42. Vision synthétique de l'évolution de l'habitat entre la période laténienne et le Haut-Empire. ment occupés au début de notre ère évitent en effet deux des zones les plus anciennement habitées (le secteur des greniers et celui d'un bâti sur poteaux). Malgré les importantes ruptures de la période augustéenne puis des années 30-40 ap. J.-C., le faciès céramique montre une forte influence indigène jusqu'au milieu du $\mathrm{I}^{\text {er }}$ s. ap. J.-C. (fig. 42).

- La permanence du cadre de l'implantation.

Le décapage effectué sur $700 \mathrm{~m}$ permet l'observation d'un transect important, qui reste pourtant limité en regard de l'extention réelle du site. Les prospections pédestres effectuées lors de la phase terrain indiquent en effet une superficie au moins trois fois supérieure à celle mise au jour. La collecte du matériel a montré plusieurs concentrations de fragments céramiques et de tegulae vers l'est. Elles sont notamment importantes au niveau des zones les plus densément occupées sur le décapage. En revanche, le sommet de la butte ne révèle que peu d'indices mais le rôle de l'érosion est içi mal connu.

Le site de "L'Épine " semble prendre naissance durant le $\mathrm{I}^{\mathrm{er}}$ s. av. J.-C., peut-être même dès le $\mathrm{II}^{\mathrm{e}}$ s., en pays allobroge, aux confins nord de la Transalpine. L'établissement rural du ${ }^{\mathrm{er}}$ s. av. J.-C., matérialisé par le secteur des greniers et dont nous ignorons le contexte global, semble devoir être considéré comme le point originel à partir duquel se développent les structures des premières décennies de notre ère. Les secteurs bâtis les plus anciens, greniers ou bâtiments sur poteaux, sont en effet épargnés par les occupations postérieures, qui se développent respectivement au nord et au sud. Les vestiges concernés ne donnent aucun indice sur les raisons foncières de ce respect des surfaces occupées antérieurement; il est possible que la période de transition a vu coexister le déclin de l'une et l'essor de l'autre. Si ces légers déplacements entre occupations sont fréquents (Bayard, Collard 1996), celui de "L'Épine " répond à une volonté doublement affirmée, de part et d'autre de l'implantation du Irr s. av. J.-C. On observe alors l'installation d'une orientation originale de l'habitat nord, identique à l'actuel chemin de Brigneux $\left(17^{\circ} \mathrm{E}\right)$; à partir de ce noyau central et vers le nord, les fossés divergeront régulièrement vers l'est. La mise en place d'une orientation différente (nord-sud), déjà établie sur l'habitat sud, et reconnue par ailleurs dans le Velin, illustre peut-être l'intégration progressive du site dans un contexte élargi.

D'après le matériel céramique, la continuité chronologique est assurée; la principale expansion du site entre le $\mathrm{I}^{\text {er }}$ s. de notre ère et les années tibéro-claudiennes, semble suf- 
fisamment courte pour exclure une interruption de quelques années et une reprise dans les mêmes cadres. Peu de lots sont enregistrés, mais tous les faciès céramiques sont représentés, des ensembles de tradition laténienne, à l'apparition de vases de tradition gallo-romaine, jusqu'à la disparition des céramiques du ${ }^{\text {er }}$ s. av. J.-C. remplacées par d'autres productions localcs ct importations du monde antique.

La céramique elle-même témoigne d'une autre continuité, celles de traditions indigènes persistantes, caractères anciens encore affirmés à l'époque augustéenne et pour les décennies suivantes. Lors de la période claudienne par exemple, un matériel céramique au décor laténien coexiste avec des vases de faciès gallo-romain (commune sombre grossière au haut de panse cannelé), alors que les ensembles sigillées restent relativement anecdotiques par rapport aux ensembles urbains contemporains de Vienne ou de Lyon (Desbat et alii 1979, Genin 1986, Godard 1992 in Frascone, Jacquet, Widlak 1993). Un site rural créé seulement à partir du deuxième quarr du $\mathrm{I}^{\text {er }}$ s. ap. J.-C. à Château-Gaillard, dans l'Ain, montre une tendance similaire, avec la prédominance de la céramique commune sombre, tout en conservant de nombreuses références aux répertoires des formes laténiennes (Motte 1987). Malgré tout, il convient de rester prudent sur la signification de telles survivances. La forte proportion de céramiques de tradition ancienne pourrait être moins le fait d'influences laténiennes dont la persistance serait à remarquer que d'une évolution standard des ensembles céramiques du début de notre ère. Ainsi, des ensembles issus de cadre privilégié comme ceux la villa de Saint-Romain-de-Jalionas (38) présentent de fortes similitudes avec les lots de Chassieu ${ }^{15}$.

- Les ruptures chronologiques et structurelles.

Le glissement de l'établissement du Irr s. av. J.-C. vers l'habitat du Haut-Empire s'est effectué dans le respect des espaces de l'implantation précédente. Deux ruptures sont néanmoins sensibles à l'intérieur de la principale séquence d'occupation du site. La plus importante, d'un point de vue structurel, date de la période augustéenne. Les années 30/40 de notre ère voient ensuite un net recul de l'occupation et une survie limirée, sur l'emprise, jusqu'au moins le III $\mathrm{s}$.

La rupture augustéenne : des groupes de structures apparaissent sous Auguste, presque adossés à l'occupation ancienne; les bâtiments, les fours, les palissades, les batteries

(15) Comm. M. R. Royct, SRA Rhône Alpes. de foyers, les alignements de poteaux, les enclos se juxtaposent d'une manière similaire au nord et au sud. L'activité métallurgique accompagne - ou précède légèrement l'éclosion de la nouvelle occupation. Ces implantations s'ouvrent sur l'extérieur grâce à des fossés d'enclos. L'extension spatiale du site par l'établissement de ces réseaux de fossés, ainsi que la réorganisation des unités d'habitat, semblent être un acquis majeur du $I^{\text {er }} s$.

Aucun édifice en dur n'est reconnu; les matériaux périssables restent les seules composantes du bâti. Seule l'apparition des tegulae dans les niveaux d'édifices ou de fours, dont l'abandon est daté au plus tard des années 30 et 40 , dénote un apport d'influence romaine. Les tuiles sont en effet absentes de l'établissement du I ${ }^{\text {er }}$ s. av. J.-C. ; elles n'apparaissent pas plus dans les comblements des structures les plus précoces de la période suivante, les fosses 473 et 474 ou les forges, datées de la période augustéenne.

La typologie céramique témoigne de probables changements dans les réseaux commerciaux et dans les habitudes quotidiennes. Si, durant la période laténienne, le matériel céramique de Chassieu L'Épine reflète bien la situation de carrefour de la région lyonnaise, l'évolution du $\mathrm{I}^{\text {er }} \mathrm{s}$. est tout autre. "...le début de la période gallo-romaine voit se développer une situation a priori paradoxale, où Chassieu, à proximité immédiate de la métropole lyonnaise en pleine expansion, affiche, et ce tout au long du premier siècle, un faciès céramique pauvre et peu perméable aux influences extérieures. " (Frascone, Jacquet, Widlack 1993, p. 20).

La rupture du milieu de siècle : elle se matérialise par des niveaux de destruction datant de la fin du règne de Tibère ou de celui de Claude. Pour le Haut-Empire, la confrontation du faciès céramique avec les grands ensembles urbains régionaux, Lyon en premier lieu, montre un contraste évident, lié à des causes complexes. D'abord, la faible part des productions fines et des importations est peut-être en rapport avec le caractère particulier du site (habitat ou artisanat rural). Ensuite, la persistance, déjà soulignée, des traditions laténiennes reflète peut-être l'appartenance à une aire culturelle plus large, comme en témoignent les nombreux parallèles typologiques avec Aoste, mais aussi Vienne. Sans doute existe-t-il aussi des points communs avec le mobilier de " La Dent " ̀̀ Meyzieu, mais ils sont difficiles à apprécier, en raison de l'absence de stratification de cet ensemble, couvrant au moins quatre siècles d'occupation (Godard 1992, Laroche 1987, Monnier 1990 in Frascone, Jacquet, Widlak 1993, p. 19-20). 
Par la suite, les vestiges attribués à une poursuite de l'occupation se font beaucoup plus discrets, les éléments datants restant rares. Les différentes unités stratigraphiques de la large excavation 280 et ses radiers ont permis la mise au jour d'un mobilier daté à partir du II ${ }^{e}$ s. jusqu'au milieu du III $^{e} s$.

La séquence chronologique allant de la conquête de la Gaule jusque parfois le troisième quart du $\mathrm{I}^{\text {er }}$ s., avec un mode de construction encore fortement influencé par les traditions indigènes, a été mise en évidence dans une synthèse sur l'évolution de l'habitat rural du nord de la région Rhône-Alpes (Vicherd 1995). Le milieu du $\mathrm{II}^{\mathrm{e}}$ s. de notre ère semble être une période de mutation. Des "fermes indigènes " de création laténienne du sud de l'Ain, comme Le Recourbe (Vicherd, Motte, Pichon 1985) ou Beligneux (Vicherd, Baudrand, de Klijn 1981), évoluent durant la seconde moitié du siècle. Au "Pré de la Cour " en limite de l'Ain et de l'Isère (Vital 1985), l'habitat voit un important changement au cours du troisième quart du siècle. A SaintPriest " Champ Dolin ", dans la banlieue est de Lyon, un petit bâtiment à vocation agricole accompagné de deux incinérations naît et disparaît au ${ }^{\text {cr }} s$ (Coquidé 1995)... La seconde moitié du ${ }^{\text {er }} s$. de notre ère est un moment charnière en matière de restructuration des campagnes. L'histoire du site de "L'Épine " répond bien à cette évolution commandée par des mutations politiques, économiques et sociales sensibles par ailleurs.

\section{UNE ARCHITECTURE PARTICULIÈRE}

Le bâti observé à “ L'Épine " est marqué de traditions indigènes. Des références, souvent régionales, permettent de trouver quelques comparaisons avec d'autres implantations rurales.

\section{- Les édifices quadrangulaires et les fours}

Les deux édifices quadrangulaires (208 et 455) bâtis sur solins et mis au jour au nord et au sud du site ont trouvé d'intéressants parallèles laténiens; la ressemblance, non pas du mode de construction, mais du plan au sol et du matériel, est intéressante. Celle-ci illustre la persistance des traditions indigènes dans des catégories de vestiges dédiés aux activités domestiques. Des édifices très similaires ont ainsi été étudiés en Hongrie (Budapest-Gellérthegy) (Audouze, Buchsenschutz 1989, p. 150). Dans ce cas, un bâtiment quadrangulaire de plan ramassé, d'environ 5 à $7 \mathrm{~m}$ de longueur, abrite des céramiques, des meules, un four ou un foyer (domestique) et pour l'un d'entre eux une " fosse artisanale ". La fonction attribuée à cet ensemble est habi- tuellement domestique : cuisine, mouture, stockage... A "L'Épine ", on constate la même association de mobilier à usage domestique (nombreuses céramiques communes, larges fragments de meules brisées), à l'intérieur d'un espace quadrangulaire de quelques mètres de côté. L'édifice 455 présente également une fosse intérieure, ainsi qu'une seconde extérieure.

Ici, les fours se situent à l'extérieur. Leur matériau de construction, les tegulae ou imbrices brisées, témoigne en revanche du remploi d'éléments romains. La dimension des chambres de cuisson $(0,75 \mathrm{~m}$ et $1,25 \mathrm{~m}$ de diamètre) permet de contenir un certain nombre de céramiques communes. Cette production répond alors à un besoin purement local. Cette hypothèse ne peut être vérifiée, puisqu'aucun déchet de cuisson n'a été observé sur le site.

Si les structures sont nettement celles de fours à céramique, leur taille a d'abord paru assez réduitc. Pourtant, des fours de modules semblables et construits avec soin ont été mis au jour dans le quartier Saint-Vincent à Lyon. Ils sont légèrement antérieurs, datés du $\mathrm{I}^{\mathrm{er}} \mathrm{s}$. av. J.-C. ; leur production a été associée, à titre d'hypothèse, à un grand nombre d'olpées découvertes sur le site (Lascoux, Widlak 1994). D'autres fours, datés du I ${ }^{\mathrm{er}}$ s. au III ${ }^{\mathrm{e}}$ s. ap. J.-C., ont été relevés à Roanne. Leur structure est identique à ceux de "L'Épine ", les laboratoires varient de $0,9 \mathrm{~m}$ à 1,3 m de diamètre. Les supports de sole ont pu être observés : un pilier central ou quatre piliers (Lavendhomme 1997, p. 173175). A "L'Épine ", aucune trace de pilier n'est notée; les tuiles saillantes sur les parois de 176 peuvent faire, même partiellement, office de supports.

\section{- Les « excavations aménagées "}

Un autre type "d'excavation " a retenu toute l'attention. La dénomination de "fond de cabane "d'abord accordée à certaines structures du site avait soulevé de nombreuses questions. La définition d'un "fond de cabane " doit en effet répondre à des critères précis, dont certains ne peuvent pas être mis en évidence sur " L'Épine " (la présence des trous de poteaux dans des excavations à bords nets et verticaux). En l'absence d'une autre définition pour désigner les structures en creux avec niveau d'occupation, le terme, maladroit, d'"excavations aménagées " a été préféré.

L'origine anthropique des vestiges a été mise en doute, puis la nature des comblements et l'existence de niveaux de circulation, voir de sol, enfin la possibilité d'élévations, au moins partielles, protégeant ce type d'édifice. Ici, les obser- 
vations archéologiques ont permis de rejeter l'hypothèse de cuvettes naturelles : creusement net, régulier, allant à l'encontre des pendages du terrain encaissant. La fréquente présence de fins niveaux compacts a permis d'envisager des niveaux de sol. Les trous de poteaux n'étant pas le seul choix technique pour fonder une élévation, on peut donc envisager des parois sur sablières, dont la disparition laisse souvent peu de trace.

Quelques exemples régionaux montrent la présence de ce type d'annexe de petit module. Des vestiges offrent des profils similaires, mais témoignent d'élévations sur supports plantés. Dans la villa de Saint-Romain-de-Jalionas "Le Vernai " (Isère), on distingue une " construction légère quadrangulaire profonde d'une quinzaine de centimètres " conservée sur environ $3 \mathrm{~m}$ de longeur, dont la fonction n'a pu être élucidée; à l'inverse de "L'Épine ", on y distingue des poteaux, une banquette latérale en terre battue et un sol aménagé (Royet 1996). A Château-Gaillard "Le Recourbe " (Ain), des petites excavations datés du VI ${ }^{\mathrm{e}}$ s. ap. J.-C. présentaient pour certaines 2 ou 4 trous de poteaux, alors que d'autres, de profils et de comblements identiques, n'en avaient aucun (Vicherd, Motte, Pichon 1985).

Concernant plus précisément le problème de l'existence d'élévations sans support plantés, un élément plus tardif vient étayer nos hypothèses. A Meyzieu, à deux kilomètres vers l'est sur le site rural de " $\mathrm{La}$ Chapelle ", a été mise au jour une excavation médiévale quadrangulaire d'environ $5 \mathrm{~m}$ de côté, sans trou de poteaux sur le fond ou aux abords, mais présentant un niveau d'occupation, marqué par un foyer central; l'existence d'élévations fondées sur des sablières ne semble plus devoir être systématiquement rejetée (Coquidé, Vermeulen 1995).

Quant aux fonctions remplies par ces vestiges, plusieurs hypothèses restent valables : édifices annexes semi-enterrés, aires de travail plus ou moins protégées pour les plus petits...

Des modules plus larges ont été mis au jour. On trouve d'autres exemples donnant d'utiles comparaisons sur l'Est lyonnais; les modes de fondation sont divers, avec ou sans supports plantés. A Meyzieu "Trillet ", à peine $1 \mathrm{~km}$ plus au nord, plusieurs structures excavées du haut et bas Empire sont accompagnées d'enclos quadrangulaires, au moins pour le Haut-Empire. Certaines ont révélé des sols de petits galets, de solins ou quelques trous de poteaux. Les longueurs atteignent parfois $13 \mathrm{~m}$, et on note quelques toitures de tuiles effondrées. Bien que les plus larges datent du III ${ }^{\mathrm{e}}$ s., un édifice de $7 \mathrm{~m}$ de long appartient à la seconde moitié du I ${ }^{\mathrm{er}}$ s. (Frascone, Staniazsek 1992). L'usage de ces édifices à Meyzieu n'est pas défini; plusieurs outils en fer ont été mis au jour dans l'une d'entre elles.

A Meyzieu "La Dent ", quelques kilomètres plus au nord, en bordure du Rhône, la fouille a permis d'observer, aux abords d'une villa, une excavation gallo-romaine de plan oblong, aux bords arrondis (long. : $8 \mathrm{~m}$, larg. : $5 \mathrm{~m}$, prof. moyenne : $0,50 \mathrm{~m}$ ). Centré sur le fond, un " amas de pierres et de galets éclatés par le feu... autour de (laquelle) étaient disposés de nombreux instruments ». Cette structure, interprétée ici comme un atelier de métallurgie, est liée à un indéniable niveau d'occupation. L'élévation semble poser plus de problèmes : «...des pierres en calcaire jaune ou rose étaient disposées régulièrement sur le pourtour... " (Monnier 1990, p. 46). La présence de supports de montants verticaux ou de sablières basses a été avancée; néanmoins, c'est la similitude du profil et des composantes les plus solides du comblement qui nous a retenu : de gros blocs de galets voisinent avec des galets moins importants et de nombreux petits fragments de tegulae, éléments également associés à ce type d'excavation à Chassieu.

A Riorges " rue Pierre Dubreuil " (Loire), un bâtiment semi-enterré du $\mathrm{I}^{\text {er }}$ s. ap. J.-C. présente de fortes analogies avec la stratigraphie observée sur le bâtiment 298. Un niveau de sol noir est surmonté d'un niveau sombre avec de nombreux fragments de tuiles. D'une longueur de $10 \mathrm{~m}$, cet édifice s'appuie sur au moins 11 poteaux, irrégulièrement répartis, et ses parois sont renforcées de planches (Couturier 1994, Lavendhomme 1997, p. 160).

\section{UNE IDENTIFICATION DIFFICILE}

S'il subsiste quelques difficultés à cerner la totalité de l'implantation du $\mathrm{I}^{\mathrm{er}}$ s. av. J.-C., sa structure interne ne differe pas, en apparence, de ce que l'on connait des fermes indigènes : des bâtiments sur poteaux, annexes ou habitats, ainsi qu'un secteur de stockage, sous la forme de greniers surélevés associés à quelques aires de travail. Seul le matériel dénote : les céramiques fines, abondantes dans ce dernier secteur, soulignent nos lacunes quant au contexte global de l'habitat laténien. En revanche, l'organisation de l'occupation qui lui succède à partir de l'époque augustéenne surprend.

L'extension du décapage jusqu'aux limites du site sur l'emprise a donné une première image chaotique : aucune 
organisation apparente, aucun " noyau central ", une succession de fosses et d'espaces moins densément occupés...

La notion d'agglomération, caractérisée par l'existence d'une trame viaire, même irrégulière, et par un regroupement plus ou moins lâche d'habitat complété par divers édifices publics, civiques ou religieux ne correspond pas plus au site de "L'Épine ". L'éclatement spatial des deux unités, la difficulté à cerner un quelconque centre originel et l'absence de lien commun entre ces implantations, hormis un ou deux fossés d'axe nord-sud, ne favorisent pas cette hypothèse.

On ne remarque aucun indice confirmant la présence d'une villa alentour. L'hypothèse que nous ayons affaire à une vaste annexe d'une ou plusieurs villae proches, qu'aucune prospection n'aurait repérée, reste pourtant à vérifier. Néanmoins, l'hypothèse d'une catégorie d'habitat non encore déterminée n'est pas à rejeter.

A "L'Épine ", la répétition de types de structures identiques dans deux ensembles distincts subissant les mêmes aléas historiques, a conduit à considérer la dualité de l'occupation gallo-romaine. L'existence de hameaux agricoles d'origine indigène difficiles à classer est d'ailleurs mentionnée en France et en Angleterre (Chevallier 1976, 4; Whightman 1976 , p. 59, 63). La persistance d'établissement, dits " de type indigène " au $\mathrm{I}^{\mathrm{er}} \mathrm{s}$. de notre ère, est avérée dans des régions où elle coexiste avec des ensembles plus géométriques annonçant les villae classiques des siècles suivants (Collart 1996, p. 140; Pion 1996, p. 62; De Klijn, Motte, Vicherd 1996, p. 276). L'existence de ce mode d'occupation a également été observée à partir du $\mathrm{I}^{\mathrm{er}} \mathrm{s}$. de notre ère : dans les Vosges ou dans le midi méditerranéen en tant qu'agglomération de petites exploitations individuelles (Ferdière 1988a, p. 190-194; Chouquer, Favory 1991, p. 191-192). La présence d'une modeste voie de desserte entre ces deux unités, matérialisée par la mise au jour de séries de doubles tracés orientés nord-sud, reste hypothétique.

Fermes, annexes de villae ou implantations à définir, ce sont également la hiérarchisation de ces sites et leur insertion dans le tissu rural local qui sont concernées. Le milieu naturel, la succession de buttes morainiques alternant avec de larges plaines fluvio-glaciaires, semble avoir influé sur les choix d'implantation : à ce jour, sur le secteur qui nous concerne, on connaît de modestes villae empruntant des plans assez complexes, aux élévations fondées sur des solins de pierre, qui s'établissent en plaine au pied des buttes. Sur les versants, on retrouve des sites d'aspect moins romanisé; les tracés du contournement est de Lyon puis du contournement sud de Meyzieu ont en effet révélé des habitats semblables, bien que de tailles plus modestes, à ceux observés sur le site de "L'Épine " ("Le Trillet ", "La Chapelle "). Faut-il y voir une spécificité de l'occupation des buttes morainiques ou le hasard des décapages?

Pour le Haut-Empire, la confrontation du faciès céramique avec les grands ensembles urbains régionaux, Lyon en premier lieu, montre un contraste évident. D'abord, la faible part des productions fines et des importations peut être en rapport avec le caractère particulier du site (habitat ou artisanat rural). Ensuite, la persistance, déjà soulignée, des traditions laténiennes reflète peut-être l'appartenance à une aire culturelle plus large, comme en témoignent les nombreux parallèles typologiques avec Aoste, mais aussi Vienne. Sans doute existe-t-il aussi des points communs avec le mobilier de " La Dent "à Meyzieu, mais ils sont difficiles à apprécier, en raison de l'absence de stratification de cet ensemble, couvrant au moins quatre siècles d'occupation (Godard 1992, Laroche 1987, Monnier 1990 in Frascone, Jacquet, Widlak 1993, p. 19-20).

Ainsi, le problème du statut social et économique de ce site reste en suspens. Les fonctions de base d'un établissement rural ne sont pas identifiées. Rien ne vient réellement illustrer l'existence d'activités agro-pastorales. Malgré la modestie des édifices, il semble que nous ayons mis au jour un ensemble d'unités habitat structurées et stabilisées, chacune ayant une emprise foncière propre. Cette restructuration peut être traduite en terme d'accroissement ou de rassemblement de population, et donc d'une perte d'espace induisant un regroupement des structures. Notre interprétation ne doit pas être misérabiliste. Ainsi, l'absence de schémas d'implantation purement romains ne doit pas être lue comme une carence, mais comme une préférence à des références indigènes. Dans le même temps, les bouleversements de l'époque augustéenne matérialisent des modifications structurelles, ainsi qu'une évolution de la vie matérielle, qui conduisent à la mutation du site et son adaptation à un cadre plus large. 


\section{BIBLIOGRAPHIE}

Argant 1992 : ARGANT (A. ct J.) - Chassicu L'Épine (Rhône), résultats d'analyses polliniques, faune et macro-restes végétaux. Bron (69), ARPA, ms. inédit (SRA), 1992.

Arlaud et alii 1988 : ARLAUD (C.), BOUVIER (A.), CONVERT (R.), HELLY (B.), MAGNE (M.), VITAL (J.) - Contournement est de Lyon, rapport de prospection et d'inventaire. Région Rhône Alpes, ms. inédit (SRA), 1988.

Arveiller-Dulong, Arveiller 1985 : ARVEILLER-DULONG (V.), ARVEILLER (J.) - Le verre d'époque romaine au musée archéologique de Strasbourg. Réunion des musées nationaux, 1985, 320 p.

Audouze, Buchsenschutz 1989 : AUDOUZE (F.), BUCHSENSCHUTZ (O.) - Villes, villages et campagnes de l'Europe celtique. Bibliothèque d'archéologic, Ed. Hachetre, Paris, 1989, 362 p.

Bayard 1996 : BAYARD (D.) - La romanisation des campagnes en Picardic à la lumière des fouilles récentes : problèmes d'échelles et de critères. in Bayard, Collard, 1996, p. 157-183.

Bayard, Collard 1996 : Bayard (D.), COLLARD (J.-L.) dir. - De la ferme indigène à la villa romaine. La romanisation des campagnes en Gaule. Actes du deuxième colloque de l'association AGER à Amiens (Somme) du 23 au 25 septembre 1993. RAP n spécial 11, 1996, $331 \mathrm{p}$.

Chapotat 1970): CHAPOTAT (G.) - Vienne gauloise, le matériel de La Tène III trouvé sur la colline de Sainte Blandine. Lyon, 1970, 186 p.

Chassieu en Velin 1990 : Chassieu en Velin - Ville de Chassieu, 1990, $267 \mathrm{p}$.

Chaussé 1992 : CHAUSSE (C.) - Contournement de l'est lyonnais, voie nouvelle A42-A43, Chassieu l'Épine - Genas sous Genas (Rhône). Synthèse stratigraphique, région Rhône Alpes, ms. inédit (SRA), 1992.

Chevallier 1976 : CHEVALLIER (G.) - Les sources de la recherche. in Le Vicus gallo-romain, Paris E. N. S., 14-15 Juin 1975, Tours, Caesarodunum (Bull. inst. Er. Lat. er centre de Rech. A. Piganiol, $\mathrm{n}^{\circ} 11, \mathrm{n}^{\circ}$ spécial), 1976, 2-8 p.

Chouquer 1995 : CHOUQUER $(\mathrm{G})$ - Les parcellaires antiques du Velin occidental. ms. inédit (SRA), 1995.

Chouquer, Favory 1980 : CHOUQUER (G.), FAVORY (F.) Contribution à la recherche des cadastres antiques, Paris, Centre de recherches spécialisées d'histoire ancienne - Equipe de recherche associée au CNRS, vol. 31, 1980, 90 p.

Chouquer, Favory 1991 : CHOUQUER (G.), FAVORY (F.) - Les paysages de l'Antiquité. Terres et cadastres de l'Occident romain. Ed. Errance (Hespérides), Paris, 1991, 243 p.

Collard 1996 : COLLARD (J.L.) - La naissance de la villa en Picardie : la ferme gallo-romaine précoce. in Bayard, Collard, 1996, p. 121155 .
Coquidé 1995 : COQUIDE (C.) - Saint Priest, Champ-Dolin, DFS, région Rhône-Alpes, ms. inédit (SRA), 1995.

Coquidé, Sandoz 1992 : COQUIDE (C.) et SANDOZ (G.) - Le site de L'Épine, Communes de Chassieu - Genas, rapport de fouilles, région Rhône Alpes, ms. inćdit (SRA), 1992.

Coquidé, Vermeulen 1995 : COQUIDE (C.), VERMEULEN (C.) Meyzieu-La Chapelle, Chassieu-Brigneux, Contournement sud de Meyzieu. DFS, région Rhône Alpes, ms. inédit (SRA), 1995.

Couturier 1994 : COUTURIER (D.) - Un batiment gallo-romain semi-enterré (Riorges). DFS sous la responsabilité de M.-O. Lavendhomme, région Rhône Alpes, centre archéologique de la Loire, Roanne, 1994.

De Klijn, Motte, Vicherd 1996 : DE KLIJN (H.), MOTTE (S.), VICHERD (S.) - Eléments sur la romanisation des campagnes en Nord Rhône Alpes. in Bayard, Collard, 1996, p. 271-285.

Desbat et alii 1979 : DESBAT (A.), LAROCHE (C.), MERIGOUX (E.) - Note préliminaire sur la céramique commune de la rue des Farges à Lyon. Figlina 4, 1979. pp. 1-17.

Desbat et alii 1989 : DESBAT (A.), GENIN (M.), LAROCHE (C.), THIRION (Ph.) — La chronologie des premières trames urbaines à Lyon. in Aux origines de Lyon, DARA n ${ }^{\circ}$ 2, 1989, pp. 95-118.

Dieudonné-Glad 1993 : DIEUDONNE-GLAD (N.) - Chassieu L'Épine. Activité artisanale : le travail du fer. Rapport d'étude, Rhône Alpes, ms. inédit (SRA), 1993.

Dormoy, Orcel 1992 : DORMOY (C), ORCEL (C) - Détermination d'essences de charbons de bois en provenance du site de L'Épine à Chassieu (69), St Bonnet de (havagne (38), Archćolabs, ms. inćdit (SRA), 1992.

Duby, Wallon 1975 : DUBY (G.), WALLON (A.) - Histoire de la France rurale, des origines à 1340, t. 1, Paris, Ed. du Seuil, 1975 , $714 \mathrm{p}$.

Eyssautier 1993 : EYSSAUTIER (l. d') - Vente de la collection PerNeb chez Christics Londres. in Actualité. Archeologia n 287, février 1993.

Ferdière 1988a : FERDIERE (A.) - Les campagnes en Gaule romaine, t.1: Les hommes et l'environnement en Gaule rurale (52 av. J.-C. - 486 ap. J.-C), Ed. Errance (Hespérides), 1988, 301 p.

Ferdière 1988b: FERDIERE (A.) : Les campagnes en Gaule romaine, 1.2: Les techniques et les productions rurales en Gaule (52 av. J.-C. -486 ap. J.-C), Ed. Errance (Hespérides), 1988, 284 p.

Frascone, Jacquet, Widlak 1993 : FRASCONE (D), JACQUET (P), WIDLACK (W) - Études céramiques des sites de Chassieu L'Épine et Meyzieu Trillet, Rocade Est de Lyon (69). Région Rhône Alpes, ms. inédit (SRA), 1994. 
Frascone, Staniaszek 1992 : FRASCONE (D.), STANIASZEK (L.) : Meyzieu-Décines : Le Trillet, Habitat et nécropole, région Rhône Alpes, ms. inédit (SRA), 1992.

Furger-Gunti, Berger 1980 : FURGER-GUNTI (A.), BERGER (L.) Katalog und Tafeln des Funde aus der spätkeltischen siedlung BaselGasfabrik. Derendingen-Solothurn, Habegger Verlag, 1980.

Genin 1986 : GENIN (M.) - Contribution à l'étude de la céramique augustéenne à Lyon. Mémoire de maîtrise dactylographié, Université Lyon III, 1986.

Godard 1991 : GODARD (C.) — Les ateliers de Vienne, in Recherches sur les ateliers céramiques antiques de la moyenne vallée du Rhône, rapport annuaire du programme $\mathrm{H}$ 13, Lyon, 1991.

Godard 1992 : GODARD (C.) - Une réserve de céramiques de l'époque de Claude à Vienne (Isère). SFECAG, Actes du congrès de Tournai, 1992. pp. 239-264.

Jacquet 1992 : JACQUET (P.) - Etude céramologique des ensembles protobistoriques de Chassieu. I-Hallstatt et II-La Tène. Rapports (2) déposés au SRA Rhône Alpes, 1992.

Jacquet 1995 : JACQUET (P.) - Meyzieu-Les Hermières, Contournement sud de Meyzieu. DFS, région Rhône Alpes, Lyon, ms. inédit (SRA), 1995.

Joly, Bedart 1995 : JOLY (J.L.), BEDART (D.) - St Priest, terrain Illford. Région Rhône Alpes, ms. inédit (SRA), 1995.

Joly, Dawson 1992 : JOLY (J. L.) et DAWSON (T. C.) - Chassieu Sous Trillet, Habitat. Région Rhône Alpes, ms. inédit (SRA), 1992.

Jorda, Provensal, Royer 1990 : JORDA (M), PROVENSAL (M), ROYET (R) - L'Histoire " naturelle " d'un site de l'Age du Fer sur le Piémont méridional des Alpilles. Le Domaine de Servanne (Bouches du Rhône). Gallia, T. 47, Ed. du CNRS, Paris, 1990, p. 57-67.

Kowarli et alii 1991 : KOWATLI (I.), ROYET (R.), SANDOZ (G.), VITAL (J.) - Contournement est de Lyon, voie nouvelle A42/A43, tronçon Meyzieu-St Priest, propositions de sauvetages programmés. Région Rhône Alpes, ms. inédit (SRA), 1991.

Laroche 1987 : LAROCHE (C.) - Aoste (Isère), un centre de production de céramiques. RAN, t. 20, 1987. pp. 281-348.

Lavendhomme 1997 : LAVENDHOMME (M.-O.) - Carte archéologique de la Gaule. La Loire (42). Fondation Maison des Sciences de l'Homme, 1997 p. 159-160 et p. 173-174.

Lavendhomme, Guichard 1998 : LAVENDHOMME (M.-O.), GUICHARD (V.) - Rodumna (Roanne, Loire). Le village gaulois. DAF $\mathrm{n}^{\circ}$ 62, MSH, Paris, 1998, $367 \mathrm{p}$.

Lascoux, Widlak 1994 : LASCOUX (J. P.), WIDLAK (W.) — Un atelier de potier gallo-romain d'époque précoce découvert à Lyon dans le quartier St Vincent. in ZAC St Vincent, Lyon, service archéologique municipal, ms. inédir (SRA), 1994.
Mandier 1988 : MANDIER (P.) - Le relief de la moyenne vallée du Rhône au tertiaire et au quaternaire, essai de synthèse paléogéographique, BRGM n 151,2 t., 1988.

Martin, Blaizot 1994 : MARTIN (S.), BLAIZOT (F.) - Marennes le Pillon, A 46 sud. Rapport de fouilles, région Rhône Alpes, Lyon, ms. inédit (SRA), 1994.

Mérigoux 1985 : MERIGOUX (E.) — La céramique commune sombre d'un dépotoir flavien du site de la rue des Farges. Mémoire de maîtrise, université Lyon III, 1985.

Monnier 1990 : MONNIER (J.) - La Dent, site gallo romain à Meyzieu. CERGR, nlle série nº 8, Lyon, 1990, 186 p.

Motte 1987 : MOTTE (S.) - Létablissement rural gallo-romain de l'Argillier à Château-Gaillard (Ain). Sauvetages archéologiques sur les autoroutes $A 40$ et $A$ 42. Rapport de fouilles. Région Rhône-Alpes, ms. inédit (SRA), 1987.

Motte, Vicherd 1992 : MOTTE (S), VICHERD (G) - Site des Grandes Croix à Beynost (Ain), TGV Contournement Est (Satolas). Région Rhône Alpes, ms. inédit (SRA), 1992.

Paunier 1996 : PAUNIER (D.) - Spécificité du vicus, table ronde $n^{\circ} 4$. in Les agglomérations secondaires - La Gaule Belgique, les Germanies et l'Occident romain. Actes du colloque de Bliesbruck-Reinheim/Bitche. 21/24 oct. 1992. Errance, Paris, 1996.

Perichon, Sanial, Ranchon 1977 : PERICHON (R.), SANIAL (B.), RANCHON (C.) - Céramiques domestiques gauloises et gallo-romaines du nord-est du Massif Central, essai de typologie. Saint Etienne, Centres d'études foreziennes, 1977, $280 \mathrm{p}$.

Perrin 1990 : PERRIN (F.) - Un dépot d'objets gaulois à Larina, Hières sur Amby, Isère. DARA n ${ }^{\circ}$, Lyon, 1990, $174 \mathrm{p}$.

Perrin 1976 : PERRIN (M.) - Essai de claissification typologique préliminaire de la céramiạuede La Tene III découverte à Tournus (Saône-etLoire). Découvertes Archéologiques en Tournugeois n 4, 1976.

Pion 1996 : PION (P.) — Les établissements ruraux dans la vallée de l'Aisne, de la fin du second Age du Fer au débur du Haur-Empire romain (II' siècle av. J.-C./I' siècle ap. J.-C.) bilan provisoire. in Bayard, Collard, 1996, pp. 55-107.

Royet 1996 : ROYET (R.) - Recherches sur le site du Vernai à Saint Romain de Jalionas (Isère). Rapport d'activités pour 1996, région Rhône Alpes, Lyon, ms. inédit (SRA), 1996.

Stcrnini 1991 : STERNINI (M.) - La verrerie romaine du musée archéologique de Nimes, $2^{\circ}$ partie. Cahiers des musées et monuments de Nimes $n^{\circ} 8,1991,207 \mathrm{p}$.

Vaginay 1988 : VAGINAY (M.) et GUICHARD (V.) - L'habitat gaulois de Feurs (Loire', fouilles récentes (1978-1981). D.A.F. $\mathrm{n}^{\circ} 14$, 1988. $199 \mathrm{p}$.

Vicherd 1988 : VICHERD (G.) — Le site de La Terre De Vaux, Grange Rouge, région Rhône Alpes, ms. inédit (SRA), 1988.

Vicherd 1995 : VICHERD (G) - Eléments archéologiques et historiques sur l'évolution de l'habitat rural dans le nord de la région 
Rhône Alpes. in Ländliches Siedlungen zwischen Spätantike und Mittelalter. Archäologie und Museum 33, Liestal, 1995, p. 83-88.

Vicherd, Baudrand, de Klijn 1981 : VICHERD (G.), BAUDRAND (M. N.), de KLIJN (H.) - Le site du Camps De Chanes à Beligneux, région Rhône Alpes, ms. inédit (SRA), 1981.

Vicherd, Motte, Pichon 1985 : VICHERD (G.), MOTTE (S.), PICHON (M.) - Le site du Recourbé à Château Gaillard dars l'Ain, région Rhône Alpes, ms. inédit (SRA), 1985.

Vital 1985 : VITAL (J.) - Le site protohistorique et gallo-romain du Pré de la Cour à Montagnieu (Ain) - CNR. Rapport de fouilles, région Rhône-Alpes, ms. inédit (SRA), 1985.

Vital, Taras, Thieriot 1992 : VITAL (J.), TARAS (M.), THIERIOT (F.) - Le site préhistorique et protohistorique de Genas sous Genas. Rapport de fouilles, région Rhône Alpes, ms. inédit (SRA), 1992.

Wightman 1976 : WIGHTMAN (E.) — Le vicus dans le contexte de l'administration et de la société gallo-romaine, in Le Vicus gallo-romain, Paris E. N. S., 14-15 Juin 1975, Tours, Caesarodunum (Bull. inst. Er. Lat. et centre de Rech. A. Piganiol, $n^{\circ} 11, \mathrm{n}^{\circ}$ spécial), 1976, p. 59-64. 